\title{
Development, power and culture: Volunteer tourism in the Cook Islands
}

\author{
Kylie Enoka
}

2013

A thesis submitted to Victoria University of Wellington in partial fulfillment of requirements for the degree of Master of Development Studies

School of Geography, Environment and Earth Sciences Victoria University of Wellington 


\section{Abstract}

Volunteer tourism is a significant feature of the tourism industry. The phenomenon can be described as a practice where people (typically from 'developed' countries) participate in working holidays, generally to assist areas of need. Specifically focusing on Global Volunteers in Rarotonga in the Cook Islands, this study examined the development implications of volunteer tourism with particular emphasis on the relationship between Global Volunteers and development outcomes, the role of culture and the nature of power within the Global Volunteer programme in Rarotonga.

The study took a qualitative approach to gain an insight into the experiences, stories and understandings of the volunteers, hosts and country managers involved in Global Volunteers in Rarotonga. Semi-structured and unstructured interviews and participant observation were carried out.

The study questioned the notion that volunteer tourism could be linked to development. Despite the positive outcomes and valuable contribution that volunteers made, there was not a strong correlation between the practice and development outcomes. The nature of power was regarded as a significant and complex aspect of volunteer tourism. Power was revealed in both strong and subtle ways and the relationship between those involved was not merely the powerful verses the powerless. Culture was expressed as an authentic and everyday process which led to instances of cultural clashes and opportunities for cultural collaboration. However, deep cultural understanding was not easily obtained through participation in the volunteer programme.

The study argued that volunteer tourism was neither good nor bad. However, the key feature of the volunteer programme involved the agency and ownership possessed by the host organisations to actively work with volunteer tourism organisations to define the type of assistance that the volunteers carried out.

Keywords: volunteer tourism, alternative tourism, development, Cook Islands, host community 


\section{Acknowledgements}

To each of the contributors to this research, thank you for being willing to share your thoughts and experiences with me. It was an honour to meet and talk with each of you. Special thanks to James for your assistance throughout my time in Rarotonga.

To John Overton, it's been a real privilege to have you as my supervisor. Your encouragement and support has been much appreciated. Thank you for always making the time to talk with me and for being willing to answer my endless list of questions.

To my family, I am so grateful for your love, support and encouragement. I love you. Mum and Dad, thank you for believing in me and for telling me, "You can do it". I'm so thankful for both of you. Justin, Luke and Annalise, thank you for your friendship. You are champions.

To my close friends, thank you so much for your support. Your encouraging words always come at the right time. You keep me smiling!

To my office mates and thesis friends, thank you for the good conversations, advice, motivation and fun over the past year. It's been great to have each of you to share the ups and downs of our work.

To Victoria University of Wellington and the New Zealand Aid Programme, thank you for your financial assistance. It would have been extremely difficult to complete this research without your support.

Meitaki Ma'ata. 


\section{Table of contents}

AbStract

ACKNOWLEDGEMENTS

TABLE OF CONTENTS III

$\begin{array}{lll}\text { LIST OF TABLES } & \text { VI }\end{array}$

LIST OF FIGURES VI

GLOSSARY VI

CHAPTER ONE: $\quad$ INTRODUCTION

1.1 The case study: Global Volunteers in Rarotonga .....................................

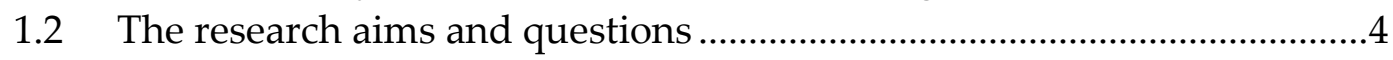

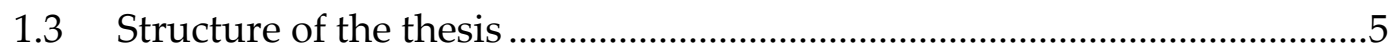

$\begin{array}{lll}\text { CHAPTER TWO: } & \text { LITERATURE REVIEW }\end{array}$

2.1 Volunteering ..............................................................................................

2.1.1 International development volunteering ....................................... 8

2.2 Tourism and development..................................................................

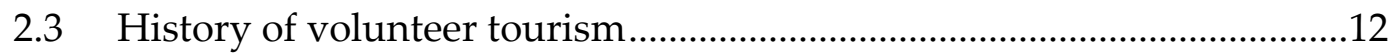

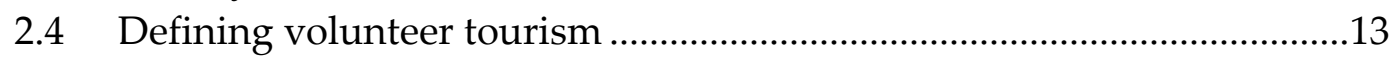

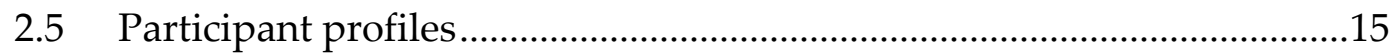

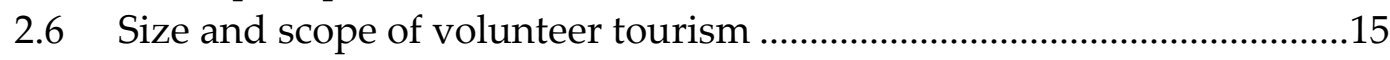

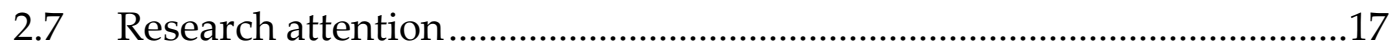

2.8 Volunteer tourism, poverty and development ......................................18

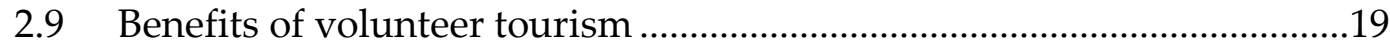

2.10 Limitations of volunteer tourism ........................................................21

2.11 Commodification of volunteer tourism .................................................27

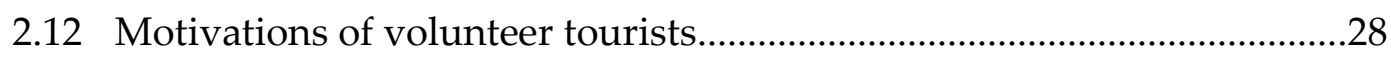

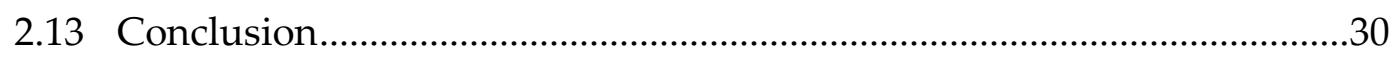

CHAPTER THREE: THE RESEARCH CONTEXT 32

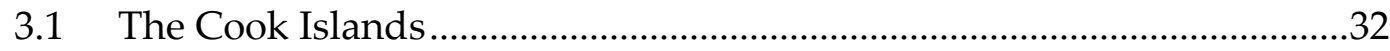

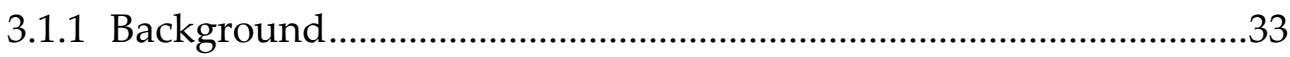

3.1.2 Cook Island development.....................................................................34

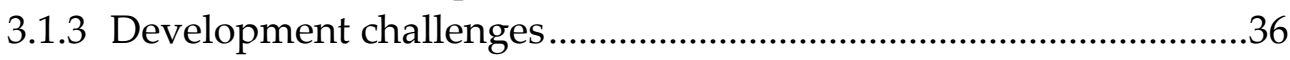

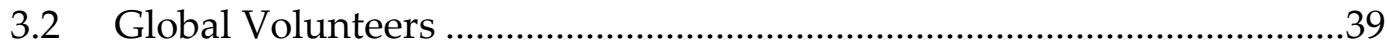

3.2.1 Global Volunteer's vision and philosophy .....................................40

3.2.2 Global Volunteers' programmes .....................................................42

3.3 Global Volunteers in the Cook Islands ................................................43

3.3.1 Volunteer projects and tourist activities.......................................43 


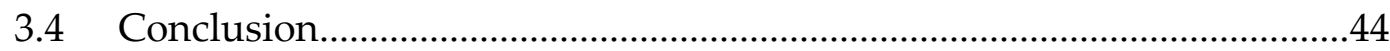

ChAPTER Four: Methodology 45

4.1 Epistemological framework: Social constructivism ....................................45

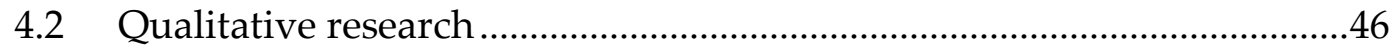

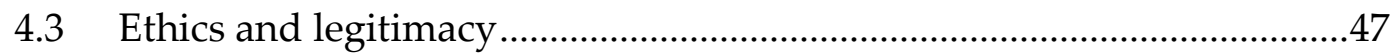

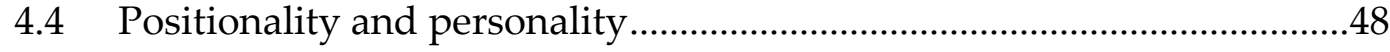

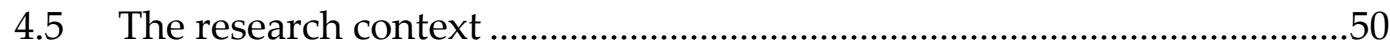

4.6 Cook Island research methods ………………...........................................51

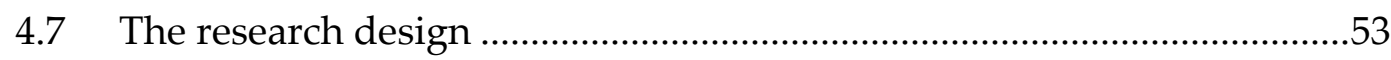

4.7.1 Relationships with contributors …………………….....................54

4.7.2 Research approaches ..................................................................56

4.8 Recordings and attribution .................................................................58

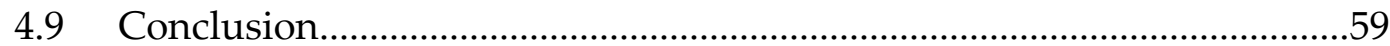

CHAPTER FIVE: $\quad$ RESEARCH FINDINGS

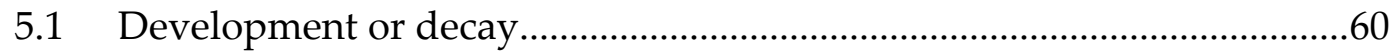

5.1.1 Volunteers' contribution to development ..........................................61

5.1.2 Host organisations and development ................................................64

5.1.3 Country managers' perception of development ...............................67

5.1.4 Influencing factors of positive change .............................................69

5.2 Power to the people ..................................................................................

5.2.1 The power of Global Volunteers........................................................78

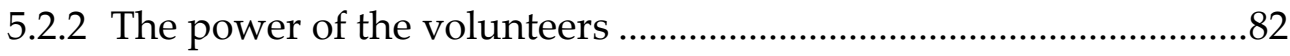

5.2.3 The power of the host organisations ...................................................85

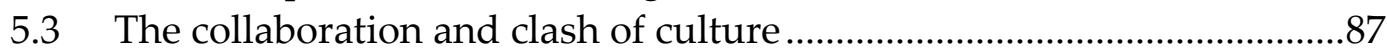

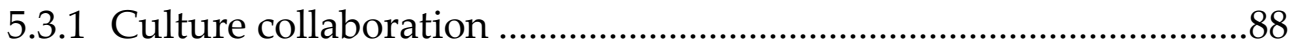

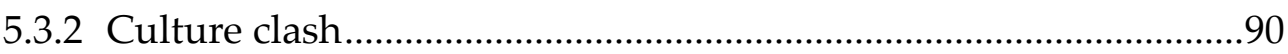

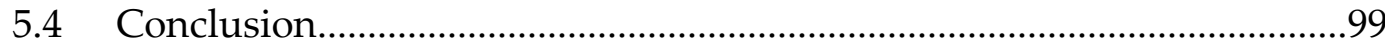

CHAPTER SIX: WIDER REFLECTIONS 100

6.1 The relationship between Global Volunteers and development in Rarotonga ...........................................................................................100

6.1.1 An absence of development language .............................................101

6.1.2 Underlying assumptions of development within volunteer

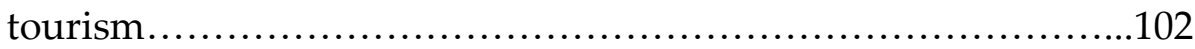

6.1.3 The limitations of development .....................................................103

6.1.4 Positive outcomes of volunteer tourism ..........................................106

6.1.5 Local agency ......................................................................................107

6.2 The nature of power within the Global Volunteer programme

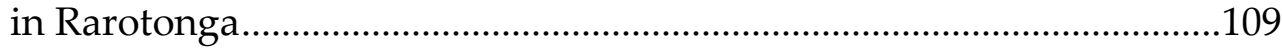

6.2.1 The complexity of power ...............................................................109

6.2.2 The power of volunteers ..............................................................111

6.2.3 The power of host organisations .....................................................113 
6.2.4 The power of Global Volunteers.

6.3 The role of culture within the Global Volunteer programme in Rarotonga.

6.3.1 Distinction between volunteer tourism and mainstream tourism117

6.3.2 Extent of cross-cultural understanding: Culture for experience...118

6.3.3 Relationship building and friendship

6.3.4 Critical engagement....................................................................122

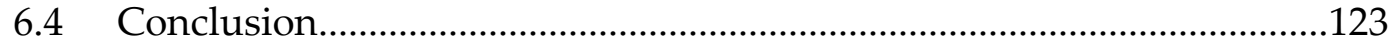

$\begin{array}{ll}\text { ChAPter SeVEN: } \quad \text { CONClusion } & 125\end{array}$

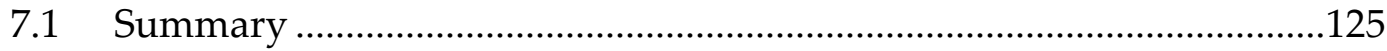

7.1.1 What is the relationship between Global Volunteers and development in Rarotonga? ....................................................125

7.1.2 How has power been revealed through the Global Volunteer programme in Rarotonga?............................................................127

7.1.3 What role has culture played within the Global Volunteer programme in Rarotonga?.............................................................129

7.2 The verdict: Is volunteer tourism good? ............................................130

7.3 The Cook Island context....................................................................131

7.4 Suggestions for future research .........................................................132

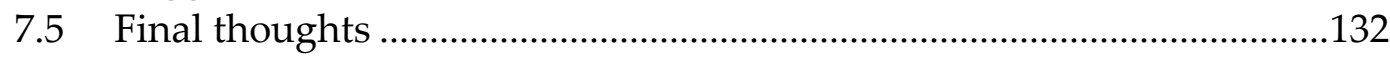

$\begin{array}{lc}\text { REFERENCES } & 134\end{array}$

APPENDIX ONE: LIST OF RESEARCH CONTRIBUTORS ...........................................147

APPENDIX TWO: PARTICIPANT INFORMATION SHEET ............................................148

APPENDIX THREE: ANONYMOUS CONSENT FORM .............................................149

APPENDIX FOUR: NON-ANONYMOUS CONSENT FORM ..........................................150

APPENDIX FIVE: POTENTIAL QUESTIONS FOR SEMI-STRUCTURED INTERVIEWS...151 


\section{List of tables}

Table 1. Cook Island development indicators.................................35

Table 2. Global Volunteers twelve essential services...........................41

Table 3. Volunteers' individual goals......................................63

Table 4. List of research contributors.....................................147

\section{List of figures}

Figure 1. Map of the Cook Islands with insert of Rarotonga.....................33

Figure 2. Enoka family home in Ruatonga, Rarotonga.........................49 


\section{Glossary}

\begin{tabular}{|c|c|}
\hline Akono'anga & "The Maori way" \\
\hline Ei kaki & Flower garland \\
\hline Ei katu & Flower tiara \\
\hline Iwi & $\begin{array}{l}\text { Extended kinship group, tribe, nation, people, nationality, race- } \\
\text { often refers to a large group of people descended from a common } \\
\text { ancestor }\end{array}$ \\
\hline Mana & $\begin{array}{l}\text { Prestige, authority, control, power, influence, status, spiritual } \\
\text { power, charisma }\end{array}$ \\
\hline Marae & $\begin{array}{l}\text { The open area where formal greetings and discussions take place; } \\
\text { often used to include the surrounding complex of buildings }\end{array}$ \\
\hline Papa'a & A person of European decent \\
\hline Papa'anga & Genealogy \\
\hline Talanoa & A Pacific research method involving face-to-face conversation \\
\hline Umu & Earth oven \\
\hline Ura Pa'u & Drum dance \\
\hline
\end{tabular}




\section{Chapter One: Introduction}

The story behind this research began in 2006 when I went on a trip to Cambodia with a group from my church. As a 16 year old, I spent three weeks of my summer holidays teaching English in Cambodian schools and assisting a local church. In addition to these activities, our group visited the typical tourist attractions - Angkor Wat temples, Toul Sleng Genocide Museum and Sihanoukville beach resort town. The type of trip that I participated in was essentially a form of volunteer tourism. The experience was overwhelming. It opened my eyes to the inequality that existed in the world. I developed a greater insight into a different culture and way of life. While I gained a new perspective, I had many questions about the practice that I had participated in. Had our team's assistance been helpful to our hosts? Were we harming the hosts? Would it have been more beneficial to send money? Was it appropriate for me to teach? Was I culturally insensitive? Some of the questions that arose during this trip to Cambodia formed the foundation for this research.

Volunteer tourism can be described as a practice where people (typically from 'developed' countries) participate in working holidays, generally to assist areas of assumed need. The practice can essentially be defined as: 'Those tourists who, for various reasons, volunteer in an organised way to undertake holidays that might involve aiding or alleviating the material poverty of some groups in society, the restoration of certain environments or research into aspects of society or environment' (Wearing, 2001, p. 1).

Volunteer tourism has grown to become a significant feature of the tourism industry. Tourism Research and Marketing (2008) estimated that 1.6 million people participate in volunteer tourism projects each year and they valued the industry at $\$ 1.7$ to $\$ 2.6$ billion USD (Tourism Research and Marketing, 2008). These statistics connote the significance 
of volunteer tourism to both the tourism industry and to the volunteers, host communities and volunteer sending organisations that are involved in the practice.

The body of literature on volunteer tourism has significantly paid more attention to the volunteer tourists rather than the host communities that the volunteers work in. A considerable proportion of the literature is concerned with the motivations of those that participate and whether altruistic or self-interested motivations are more prevalent (e.g. Brown \& Morrison, 2003; Coghlan, 2007; McIntosh \& Zahra, 2007; Tomazos \& Butler, 2009). Other themes have involved volunteer tourist experience expectations (Andereck et al., 2011), the relationship between participation in volunteer tourism and social movement participation (McGehee \& Santos, 2005), volunteer tourist experience and spirituality (Zahra, 2006), volunteer tourist profiling (Stoddard \& Rogerson, 2004) and the sporadic nature of the practice (Cnaan \& Handy, 2005).

Of equal significance, the literature has not been quick to critique the value of volunteer tourism. It has tended to categorise the practice as being a more 'holy' or worthier activity in comparison to its lowlier partner of conventional or mass tourism (e.g. Singh \& Singh, 2001, Gray \& Campbell, 2007). Volunteer tourism has primarily been accepted and promoted as a positive practice for all involved. The practice has overwhelmingly been presented as being inherently virtuous. A range of positive outcomes for the volunteers have been presented, including a more genuine understanding of the host country and culture (Raymond \& Hall, 2008; Guttentag, 2009) and the opportunity for volunteers to contribute to positive social and environmental outcomes (Brown \& Lehto, 2005; McIntosh \& Zahra, 2007), personal development, improved skills and knowledge and increased social networks (Coghlan \& Fennell, 2009; Bailey \& Russell, 2010). In addition, the host communities have been viewed as gaining a combination of tangible and intangible benefits through volunteer tourism, including specific skills (Lough et al., 2011), greater cross-cultural understanding (Raymond \& Hall, 2008), funding (Guttentag, 2009) and the improvement of physical facilities (Sin, 2010). 
Nonetheless, a more critical perspective of volunteer tourism has begun to emerge (Guttentag, 2009). The limitations of the practice have involved the uneven relationship between host communities and the volunteer tourists (e.g. Simpson, 2004; Guttentag, 2009; Sin, 2010; Vodopivec \& Jaffe, 2011), the lack of power possessed by hosts (Guttentag, 2009; Sin, 2010), dependency issues (McGehee \& Andereck, 2008), the burden of volunteers (Raymond, 2008) and potential for volunteers to undermine the 'cultural well-being' of local communities (Coren \& Gray, 2012, p. 222).

The extent to which volunteer tourism has contributed towards development is a fascinating question to pose. The relationship between poverty, development and volunteer tourism has been discussed within the literature (Simpson, 2001; Sin, 2009; Vodopivec \& Jaffe, 2011). Poverty has been viewed as being 'romanticised' and trivialised through volunteer tourism (Simpson, 2004, p. 688). According to Sin (2009), volunteer tourism has created a superficial understanding of poverty and development. Furthermore, Vodopivec and Jaffe (2011) found a disconnection between volunteer tourism and development work. This research seeks to build on these themes and to address some of the critical questions that have been raised, with specific consideration of whether volunteer tourism is an effective and appropriate means of development.

\subsection{The case study: Global Volunteers in Rarotonga}

This research focuses on a specific case study of a volunteer tourism organisation in a single location. More specifically, it considers Global Volunteers in Rarotonga, Cook Islands. Global Volunteers is a private, non-sectarian, non-profit, United States-based volunteer sending organisation that coordinates short-term teams of volunteers in a range of countries across the world (Global Volunteers, 2012). ${ }^{1}$ The majority of volunteers that participate on programmes are from the US and span a variety of ages

\footnotetext{
${ }^{1}$ When Global Volunteers (2012) is referenced throughout this thesis, the information has come
} from the Global Volunteers website (www.globalvolunteers.org) unless otherwise stated. 
(Global Volunteers, 2012). Although this research views Global Volunteers as a volunteer tourism organisation, they self-identify as a development organisation (Global Volunteers, 2012). Thus, the issue of the development benefits of volunteer tourism has particular relevance in this case.

Global Volunteers has been in Rarotonga since 1998, with 127 volunteer teams assisting on the island since its establishment (Global Volunteers, 2012). The volunteers have been involved in a range of activities over the years but their current primary project involves supporting schools with their literacy programme. Secondary projects include assistance with a range of organisations across Rarotonga, including, disability and mental health groups, environmental projects, labour projects, administration, elderly care, a research centre and a selection of non-government organisations (Global Volunteers, 2012).

\subsection{The research aims and questions}

The aim of this thesis is to develop a greater understanding of the development implications of volunteer tourism in the Cook Islands. Rather than trying to understand all development implications, the study specifically aims to gain an insight into how power and culture are reformed through volunteer tourism. This will be carried out through a consideration of the voices, experiences and views of volunteers, host organisations and the volunteer-sending organisation. By reflecting on each of these groups, the study seeks to reveal a more detailed picture of volunteer tourism than what has previously been presented.

The central research question that is considered within this research is:

What are the development implications of volunteer tourism in the Cook Islands? 
In order to engage with this central research question, this research is broken down into the following three key research questions that are specific to the Global Volunteers case study in the Cook Islands:

1. What is the relationship between Global Volunteers and development in Rarotonga?

2. What is the nature of power within the Global Volunteer programme in Rarotonga?

3. What role has culture played within the Global Volunteer programme in Rarotonga?

It is important to note that these questions are not independent of each other. Each of the key themes within these questions interacts and coordinates with one another. Culture and power can be viewed as a spin-off from development, the starting point and centre of this research.

\subsection{Structure of the thesis}

This thesis has been structured around seven chapters (including this introductory chapter). An outline of each of the subsequent chapters is presented below.

Chapter Two frames the research around the existing literature on volunteer tourism. This literature is presented with the intent of identifying gaps, grounding the study within the existing literature and building on what has already been established. The

starting point of the chapter involves an examination of volunteering more broadly, then focuses more specifically on volunteer tourism. The review then considers the size and scope of the volunteer tourism industry, the main areas of research attention and the relationship between development, poverty and volunteer tourism. Subsequently, the benefits, limitations, commodification and the motivations of volunteer tourism are considered. 
Chapter Three contextualises the study through an examination of the location and volunteer tourism organisation that this study considers. This chapter includes a discussion of the Cook Island's development indicators and the country's challenges to development. Following this, it examines Global Volunteers as a volunteer tourism organisation and then narrows in scope to consider the Global Volunteer programme in Rarotonga.

Chapter Four sets out the methods used in this research. It explains how the research was carried out with reference to the key processes used. Social constructivism is established as the epistemological framework for the study and qualitative research is recognised as the chosen research method. Subsequently, a consideration of the ethics and legitimacy of the research, positionality, the research context, Cook Island research methods and the design of the research is made.

Chapter Five presents the voices, experiences and views of the contributors in addition to the observations made during fieldwork in Rarotonga. These research findings are separated into the key themes of the study: development, power and culture.

Chapter Six reflects on the research findings and links the central themes into the wider literature. This chapter is framed around each of the key questions of the research.

Chapter Seven summarises each of the three key questions that this study has examined. Based on these concluding remarks, the section reveals whether volunteer tourism is good and reflects on suggestions for future research. This is followed by some final thoughts for this research. 


\section{Chapter Two: Literature review}

This chapter analyses the key areas of literature surrounding volunteer tourism. It situates the research in two fields - volunteering and tourism but pays primarily attention to the volunteering literature. Firstly, the chapter provides a background of volunteering and examines the relationship between tourism and development. Subsequently, it examines how volunteer tourism has been defined in the literature followed by the formation of a definition which is specific to this research. The review then focuses on the size and scope of the volunteer tourism industry, the main areas of research attention, the relationship between development, poverty and volunteer tourism and the benefits and limitations of the practice with reference to postdevelopment. Following this, a discussion of the commodification of the practice and the motivations of volunteer tourists is made. The volunteer tourism literature will be presented with the intent of identifying gaps, grounding this study within the existing literature and building on from what has already been established.

\section{$2.1 \quad$ Volunteering}

A western understanding of volunteering can be shown through the New Zealand government's 2002 Volunteering Policy Project. This project defined volunteers as, 'Those who, of their own free will, undertake unpaid work outside their immediate household, to benefit the common good' (Tamasese et al., 2010, p. 8). The above definition provides an easily identifiable description of volunteers. However, in practice, volunteering has not been perceived as being so clearly defined. For instance, Lyons (2003) suggested that in practice, selfish motives, coercion of participants to volunteer and monetary incentives often clashed with this strict volunteering notion of freely working without pay (Lyons, 2003). As a result, Cnaan et al. (1996) suggested that each of these aspects of volunteering could be placed along a continuum. For example, 
rather than volunteering without pay, Cnaan et al. (1996) proposed that the volunteer could be placed on a continuum between 'no pay' to 'stipend or low pay'.

It is important that the concept of volunteering is localised to this research's Cook Island context. The term, 'volunteer' is a foreign concept in the Pacific. According to Tamasese et al. (2010, p. 9), 'Pacific peoples do not ... necessarily associate the unpaid work they undertake to contribute to the community, or to fulfil cultural obligations, as 'volunteering'. However, Pacific people do participate in activities which are similar to volunteering (Tamasese et al., 2010). Tamasese et al. (2010, p. 9) considered these activities to be closely associated with traditional Pacific concepts: 'to serve', 'duty to care', 'a requirement in order to sustain the community', 'a cultural obligation or expectation' and 'a form of love and reciprocity relating to kinship and protocol'. Although these activities are not necessarily labelled as volunteering, much of the voluntary activities within the Cook Islands are centred on the extended family and the church. In his book, 'Voluntary Service and Development in the Cook Islands', Crocombe (1990) outlined the extensive array of volunteer organisations in the Cook Islands. He conveyed that the majority of Cook Islanders belong to and participate in a volunteer organisation, especially within the church (Crocombe, 1990).

\subsubsection{International development volunteering}

International development volunteering is a form of volunteering. Georgeou and Engel (2011) viewed the term as being difficult to define due to the words, 'volunteer' and 'development' being problematic in their own right. However, academics have attempted to define the term. According to Georgeou and Engel (2011), 'To be development volunteering, civic service or development in the recipient community must be a core objective'. Devereux (2008) suggested that there were six traits that effective long-term volunteering for development was characterised by: ‘humanitarian motivation; reciprocal benefit; living and working under local conditions; long-term commitment; local accountability and North-South partnership; and linkages to tackle 
causes rather than symptoms' (Devereux, 2008, p. 359-360). These features of international development volunteering connote a comprehensive practice.

A range of positive outcomes of international volunteering have been outlined within the literature. According to Lewis (2006), international volunteering was beneficial because it built a bridge between professional development workers and the general public who are interested in development. Scheyvens (2002a, p. 113) proposed that some of the development work had, 'Risen in response to a direct need for assistance in a Third World Country'. The listed benefits within the literature included: tangible assistance; such as skills and resources, cross-cultural understanding, engagement with unequal power relations and the underlying causes of poverty (Lewis, 2006; Devereux, 2008; Georgeou \& Engel, 2011).

Despite the positive connotations of international development volunteering, the literature has also highlighted a number of negative aspects. Devereux (2008) suggested that, 'At its worst, international volunteering can be imperialist, paternalistic charity, volunteer tourism, or a self-serving quest for career and personal development on the part of well-off Westerners (Devereux, 2008, p. 357). Georgeou and Engel (2011, p. 301) also noted that international development volunteering was informed by a 'Western development discourse'. Through a speech given to a group of US students that were going to volunteer in Mexico, Illich (1968) presented his disgust of North American 'dogooders' in Latin America. He found that the volunteers created disorder and challenged the volunteers to, 'Recognize your inability, your powerlessness and your incapacity to do the 'good' which you intended to do' (Illich, 1968). Although each of these beneficial and negative aspects were specific to international volunteering, many of them also correlate with volunteer tourism. 


\subsection{Tourism and development}

The connection between tourism and development has been widely discussed within the literature. According to Scheyvens and Momsen (2008, p. 22), tourism 'has been an integral component of economic development strategies in developing nations for over half a century'. Furthermore, Sharpley and Telfer (2002) argued that development was the very reason why tourism was established. Sharpley and Telfer $(2002$, p. 1) proposed that 'it is this potential contribution to development that is the fundamental justification for establishing tourism in the first instance'.

It is generally agreed that the type of development that tourism has promoted has largely been economic (Sharpley \& Telfer, 2002; Archer et al., 2004; Singh 2012). Tourism has been viewed as being instrumental in producing a number of economic outcomes. According to Archer et al. (2004), tourism is 'more effective than other industries in generating employment and income particularly in peripheral regions'. With specific reference to the 'third world', Singh (2012, p. 1) proposed that tourism 'promises to create employment opportunities because it is labour-intensive; it also earns foreign currency, direly needed for infrastructure development'. However, not all of the economic outcomes have been viewed positively. For instance, Scheyvens and Momsen (2008) highlighted how the tourism industry could negatively impact other industries. This was illustrated through an example of primary production which, 'may suffer as a result of land, labour and capital being invested in tourism, significantly threatening the livelihoods of some groups of people' (Scheyvens and Momsen, 2008, p. 28). Furthermore, Scheyvens \& Momsen (2008, p. 29) argued that while economic gains could be made through tourism, the benefits were often skewed towards outsiders.

Despite these economic links, it is important to note that when academics consider development as a broader concept, the outcomes of tourism are not so optimistic. This perspective can be shown by Sharpley and Telfer $(2002$, p. 2) who proposed that when 
development included elements such as 'education', 'freedom' and 'self-reliance', the contribution of tourism to development was lowered. To illustrate, Macnaught (1982) found that work in the tourism industry was often 'dehumanising'. In addition, other academics have viewed tourism as a 'new form of colonialism' (Turner \& Ash, 1975; Britton, 1982; Brohman, 1996).

In terms of culture, tourism has produced a number of adverse outcomes. In addition to tourists' promotion of culturally inappropriate behaviour, Macnaught (1982) argued that tourists made expectations on the type of culture which they wished to experience from their hosts. Macnaught (1982, p. 372) found that this was particularly the case within song and dance performances for tourists in the Pacific. This phenomenon was described by MacCannell (1976) as 'staged authenticity'. In support of MacCannell's (1976) notion of 'staged authenticity', Croall (1995) argued that tourism played a role in trivialising culture. On the other hand, the changes that tourism brings to host cultures have not always been perceived negatively. Liu (2003, p. 467) for instance suggested that 'sociocultural changes brought about by tourism development are beneficial'. He argued that tourism's promotion of 'modern values, social progress and cultural evolution should be greatly appreciated'.

Alternative forms of tourism arose as a response to some of these critiques to mass tourism (Scheyvens 2002a). Gursoy et al. (2010, p. 381-382) defined alternative tourism as being, 'less commercialised and consistent with the natural, social, and community values of a host community'. Scheyvens (2002a, p. 11) described alternative tourism as supporting 'forms of tourism which are small scale, minimise environmental and cultural interference, and which prioritise community needs, community involvement and community interests'. Wearing and Neil (1999) suggested that alternative tourism was attractive as it increased the likelihood of the tourists and locals forming meaningful and genuine relationships. Sustainable tourism also developed out of a critique of mass tourism. Like alternative tourism, sustainable tourism is concerned 
with, 'Respecting natural, social and cultural values in host country and communities' (Vodopivec \& Jaffe, 2011, p. 114).

Volunteer tourism is perceived as a form of alternative tourism (e.g. Wearing, 2001; Brown \& Morrison, 2003; Stoddart \& Rogerson, 2004; Callanan \& Thomas, 2005; Lyons \& Wearing. 2008; McIntosh \& Zahra, 2008; Conran, 2011). It has also been associated with the 'sustainable tourism' movement (McIntosh \& Zahra, 2007; Raymond \& Hall, 2008; Vodopivec \& Jaffe, 2011). Due to this connection between alternative tourism, sustainable tourism and volunteer tourism; the literature tends to categorise volunteer tourism as being a more 'holy' or worthier practice in comparison to its lowlier partner of mass tourism (e.g. Singh \& Singh, 2001; Gray \& Campbell, 2007). Although a shift towards a more critical response to the practice has started to emerge (e.g. Guttentag 2009), these 'alternative' and 'sustainable' labels associated with volunteer tourism has led to the practice being viewed in a positive light.

\subsection{History of volunteer tourism}

Although volunteer tourism in its current form is relatively new, the practice has arguably existed for many years (Andereck et al., 2011). Andereck et al. (2011) traced early forms of volunteer tourism back to missionary movements. Tomazos and Cooper (2012) traced the origins of volunteer tourism to the aftermath of the First World War when peace was a priority among the people and the emergence of the pacifist movement had gained momentum. In 1919, Pierre Ceresole presented at an international conference in the Netherlands (Tomazos \& Cooper, 2012). Ceresole proposed that international teams of volunteers were needed to work together to repair war damages, in the form of work camps (Tomazos \& Cooper 2012). In turn, Ceresole suggested that this approach would create a sense of unity among the people and would help to build peace (Tomazos \& Cooper, 2012). The International Red Cross was founded in 1861 with similar motivations and intentions of peace (Tomazos \& Cooper, 
2012). In 1961, the United States Peace Corps was formed. The Peace Corps developed into a large scale volunteer organisation which sent volunteers from the US across the world (Tomazos \& Cooper, 2012). The Peace Corps approach has influenced the current model of volunteer tourism (Tomazos \& Cooper, 2012). In addition to these organisations, the growth of volunteer tourism has roots in the alternative and sustainable tourism movements of the 1970s and early 1980s (Crossley, 2012). By the 1990s, consumers were challenging traditional ways of travelling and had become more interested in alternative travel (Coghlan \& Fennell, 2006). These 'conscious consumers' also helped spur the growth of volunteer tourism (Coghlan \& Fennell, 2006).

\subsection{Defining volunteer tourism}

Within the literature, debate has surfaced around where the boundaries of volunteer tourism begin and end (Lyons 2003; Blackman \& Benson 2010). However, key features of volunteer tourism have been identified and agreed upon, often with reference to Wearing (2001). Wearing's (2001) definition of volunteer tourism has been consistently used and prioritised among the literature; with authors commonly citing his definition to describe the phenomenon (e.g. Tomazos \& Butler, 2005; McIntosh \& Zahra, 2007; Guttentag, 2009; Vodopivec \& Jaffe, 2011; Tomazos \& Butler, 2011; Coghlan \& Gooch, 2011; Tomazos \& Cooper, 2012; Coren \& Gray, 2012). Wearing (2001, p. 1) defined volunteer tourism as, 'Those tourists who, for various reasons, volunteer in an organised way to undertake holidays that might involve aiding or alleviating the material poverty of some groups in society, the restoration of certain environments or research into aspects of society or environment'.

Definitions by other academics have prioritised varying elements of volunteer tourism. Uriely et al. (2003) defined volunteer tourism as a form of postmodern tourism. McGehee and Santos (2005, p. 760) prioritised the importance of 'discretionary time and income' within their definition by describing volunteer tourism as, 'Utilizing 
discretionary time and income to travel out of the sphere of regular activity to assist others in need'. Other elements such as the sporadic and episodic nature (Cnaan \& Handy, 2005), the limited length of time which people are involved (Novelli, 2005; Tomazos \& Butler, 2009), the importance of people paying to volunteer (Conran, 2011; Tomazos \& Butler, 2012), volunteer tourism being a form of 'justice tourism' (Scheyvens 2002b, p. 102) and the potential for peace through the practice (Brown \& Morrison, 2003) have been identified and prioritised in the literature. Additionally, volunteer tourism has been separated out into broad categories (Brown \& Morrison, 2003; McMillon et al., 2006). Examples of these categories have included administration, economic development, professional/technical assistance, social justice and education (McMillon et al., 2006). Within these categories, a distinction between volunteer tourism involving conservation or development work has been made (Scheyvens, 2002b).

Volunteer tourism has been recognised by a number of different names within the literature. Tomazos and Butler (2012, p. 177-178) cited examples of the various names used, including: 'volunteer vacation', 'mini mission', 'mission-lite', 'pro-poor tourism', 'vacation volunteering', 'altruistic tourism', 'service based vacation', 'participatory environmental research' and 'voluntourism'. Each of these names depicts volunteer tourism as 'A tourist experience with the benefit of helping others' (Tomazos \& Cooper, 2012, p. 407). These names connote a practice which is distinct from mass tourism.

It is important to note that scholarly work has largely ignored the host communities within their definitions of volunteer tourism. Definitions are centred on the volunteer: what the volunteer does, where the volunteer goes and the length of time that the volunteer participates. Definitions are generally silent about the communities that host the volunteers. This indicates the attitude that host communities are perceived as being less important than the volunteers within the practice. As a central objective of this study is to gain a greater understanding of the host communities, it is imperative that the host communities are incorporated into the definition of volunteer tourism. 
Therefore, this research expands Wearing's (2001, p. 1) definition of volunteer tourism to explain the term as, 'Those tourists who, for various reasons, volunteer in an organised way to undertake holidays that might involve aiding or alleviating the material poverty of some groups in society, the restoration of certain environments or research into aspects of society or environment', generally in collaboration or cooperation with a host community.

\subsection{Participant profiles}

The literature has provided profiles of the type of people who participate in volunteer tourism. These descriptions offer an indication of the average volunteer tourist demographic (Andereck et al., 2011). Brown and Lehto (2005) recognised that there are

more women than men who participate in volunteer tourism. Although there is a diverse age bracket of those involved in volunteer tourism, Andereck et al. (2011) identified that a large proportion of volunteer tourists are aged between 35 and 44 . According to Stoddart and Rogerson (2004), the educational background and employment of volunteer tourists varies between individuals. Within their Habitat for Humanity case study, they found that a large amount of the volunteers were students, professionals, general managers and those that worked in office environments. Although the literature has presented volunteer tourists as a diverse group, the type of people that volunteer tourism attracts is limited by the level of disposable income, time and health required for people to participate in the practice.

\subsection{Size and scope of volunteer tourism}

The breadth of volunteer tourism projects and organisations around the world has been portrayed within the literature (Novelli, 2005; Wearing, 2001). These are a combination of not-for-profit and for-profit organisations (Brown \& Lehto 2005). Some examples of 
volunteer tourism case studies within the literature have included volunteers assisting on a Habitat for Humanity project in South Africa (Stoddard \& Rogerson, 2004), 'gap year' projects (Simpson, 2004), volunteers working with sea turtles in Costa Rica (Campbell \& Smith 2006), Australian volunteers working on a Marae in New Zealand (McIntosh \& Zahra, 2007) and a group of Singaporean university students working in a hospitality course in Vietnam (Sin, 2009). Other examples of volunteer tourism operators which Brown and Lehto (2005, p. 479-480) presented included: 'CrossCultural Solutions' (www.crossculturalsolutions.org), 'The American Hiking Society' (www.americanhiking.org), and 'Earthwatch' (www.earthwatch.org). According to Brown and Lehto (2005, p. 480), there are an extensive range of volunteer tourism projects, including, 'Agriculture, archaeology, community development, conservation, construction, education and teaching, environmental protection and research, technical assistance, historic preservation, medical and dental, work camps'. Although volunteer tourism is usually located in countries containing extreme poverty, volunteer tourism is not limited to 'poor' locations. Lyons (2003) for example, discussed Australian participants working in a summer camp in the US.

Despite the difficulty of estimating the size of the practice, it is widely agreed that volunteer tourism has increasingly risen in significance (Young, 2008; Raymond \& Hall, 2008; Blackman \& Benson, 2010; Bailey \& Russell, 2010; Andereck et al., 2011; Lyons \& Wearing, 2012; Tomazos \& Cooper, 2012). Coghlan and Fennell (2009) give evidence of the growing popularity of the practice, particularly during the last 15 years, by noting the increase in both volunteer tourism research studies and travel opportunities. Tourism Research and Marketing (2008) estimated that 1.6 million people participate in volunteer tourism projects every year and that the industry has an estimated value of \$1.7 to \$2.6 billion USD. Lough et al. (2011, p. 121) estimated that one million individuals from the US volunteer abroad every year with $70-80$ percent of these volunteers serving for eight weeks or less. Tomazos and Cooper (2012) presented a more modest estimate of volunteer tourist numbers. They suggested that 600,000 
people participated in volunteer tourism each year (Tomazos \& Cooper, 2012). According to Tourism Research and Marketing (2008), there were 300 listed volunteer tourism organisations in 2008. Regardless of these varying estimates, the literature has shown that volunteer tourism has become increasingly popular. Thus, the research area is both relevant and contemporary.

\subsection{Research attention}

Although volunteer tourism research that focuses on the host communities has begun to emerge (e.g. McGehee \& Andereck, 2008; Conran, 2011), it is interesting to note that the bulk of existing research is centred on the volunteers rather than the host communities. Much of the volunteer tourism research has been undertaken based on the motivations of volunteer tourists (Brown \& Lehto, 2005; Campbell \& Smith, 2006; Coghlan \& Fennell, 2009). Other themes in the literature have included volunteer tourist experience expectations (Andereck et al., 2011), the relationship between participation in volunteer tourism and social movement participation (McGehee \& Santos, 2005), volunteer tourist experience and spirituality (Zahra, 2006), a profiling of volunteer tourists (Stoddard \& Rogerson, 2004), volunteer tourist subjectivities (Crossley, 2012, p. 237) and the transformative learning of volunteer tourists (Coghlan \& Gooch, 2011). Studies have also been carried out on specific volunteer tourism organisations (e.g. Coghlan, 2007; Tomazos \& Cooper, 2012).

Yet, as Gray and Campbell (2007) acknowledge, volunteers are only one side of the coin of volunteer tourism. The other side of the coin are the host communities. Although the host communities are equally important, the literature has ignored them from discussions on volunteer tourism (Sin, 2010; Holmes et al., 2010; Lough et al., 2011; Woosnam \& Lee, 2011; Conran, 2011). Lough et al. (2011, p. 121) exemplified this by suggesting that, 'We know relatively little about their [volunteer tourists] actual effects on host communities and organizations- particularly from the perspectives of host- 
organization staff'. This gives us the opportunity to gain a deeper insight into the host organisations' perspectives of volunteer tourists.

\subsection{Volunteer tourism, poverty and development}

The relationship between poverty, development and volunteer tourism has been discussed in the literature (Simpson, 2004; Sin, 2009; Vodopivec \& Jaffe 2011). It is important to shed light on what the literature articulates about this relationship. Specifically focusing on gap year volunteer projects, Simpson (2004, p. 688) discussed how poverty was 'romanticised' and trivialised through volunteer tourism advertising material. She suggested that volunteer tourists developed the belief, 'That somehow people do not really mind living in poverty'. Sin (2009) agreed with Simpson (2004) that volunteer tourism created a superficial understanding of poverty and development. She conveyed that there was a lack of critical thinking by volunteer tourists about the conditions in host communities. Sin (2009) found that volunteer tourists had the perspective that 'Aid-recipients were naturally poor, and failed to understand prevailing circumstances that impede aid-recipients' efforts to break out of the povertycycle' (Sin, 2009, p. 496). As a result, the wider issues surrounding poverty are only 'passively' considered by volunteer tourists (Simpson, 2004, p. 688).

Simpson (2004) suggested that 'development language' was rarely used in marketing and discussion. She found that there were limited references to international development (Simpson, 2004). Instead, a language of 'making a difference' and 'doing something worthwhile' existed (Simpson, 2004, p. 683). This implied that the volunteer

tourism industry does not consider the practice to be development work. Similarly, Vodopivec and Jaffe (2011) found a disconnection between volunteer tourism and development work. Vodopivec and Jaffe (2011) expressed the problems of viewing volunteer tourism as development work. They found that volunteer tourism was a leisure activity which suggests that, 'Engaging with the world's problems and 
inequalities can be a time-out, and that the volunteers' experience is disconnected from their own lifestyles and behaviour, in the field and at home' (Vodopivec \& Jaffe, 2011, p. 120). This is exemplified by Simpson (2004, p. 682) who argued that gap year volunteering, 'Perpetuates a simplistic ideal of development' which 'Legitimizes the validity of young unskilled international labour as a development 'solution".

\subsection{Benefits of volunteer tourism}

Volunteer tourism has been described as, 'The antithesis of mass tourism and all the problems frequently associated with it (Guttentag, 2012). Participants of the practice have been portrayed as being 'the quintessential 'new moral tourists" (Gray \& Campbell, 2007, p. 465). These tourists are depicted as being, 'part of a new 'elite' of ethically driven and morally conscious tourists' (Tomazos \& Cooper, 2012, p. 405). As an outcome, volunteer tourism is viewed as being a noble way to travel (Mustonen, 2005). In effect, the literature has overwhelmingly accepted and promoted volunteer tourism as a positive practise (Guttentag, 2009). Wearing (2001) in particular, is positive of volunteer tourism, suggesting that volunteer tourism can be viewed as a development strategy where both the locals and visitors benefit from the activity. He suggested that volunteer tourism has the potential to bring 'value change and changed consciousness' (Wearing, 2003, p. 4).

The benefits for volunteer tourists have been widely examined within the literature. The positive experiences that volunteers gain though participating in volunteer tourism have been examined (Bailey \& Russell, 2010; Raymond \& Hall, 2008; Guttentag, 2009). Examples of these positive experiences include gaining a more genuine understanding of the host country and culture than would be possible through conventional tourism (Raymond \& Hall, 2008; Guttentag, 2009) and the opportunity to contribute to positive social and environmental outcomes (Brown \& Lehto, 2005; McIntosh \& Zahra, 2007).

Both Coghlan and Fennell (2009) and Bailey and Russell (2010) agree that through 
volunteer tourism, participants gain a combination of personal development, improved skills and knowledge and increased social networks.

Host communities gain a combination of tangible and intangible benefits through volunteer tourism. Sin's (2010, p. 986) research in Cambodia outlines examples of direct tangible benefits to the host communities, including; 'improvement of physical facilities, such as having groups of volunteer tourists build new or extend existing school buildings ... or refurbish weaving factories ...'. Other tangible benefits include the funding that can come as a result of volunteer tourism (Guttentag, 2009; Lough et al., 2011). Intangible benefits include the opportunity for volunteer tourists to introduce new ideas and pass on specific skills to host communities and the prospect for volunteer tourists to address worker shortages (Lough et al., 2011). Both Raymond and Hall (2008) and Lough et al. (2011) discussed the opportunity for greater cross-cultural understanding through volunteer tourism. Moreover, Palacios (2010) portrayed that the short length of stay and the often prolonged time between projects meant that it was less likely that host communities would become dependent on volunteers and as a result there was less of a chance that the practice would create labour displacement issues in the host communities.

The mutual benefits of both the host communities and the volunteers have been discussed in the literature. Guttentag (2012, p. 156) suggested that volunteer tourism, 'Can create an environment in which power is equally shared between tourists and hosts'. McIntosh and Zahra (2007) highlighted the mutual benefits through their study of volunteer tourists on a Marae in New Zealand. They observed the formation of meaningful relationships between the hosts and the volunteers (McIntosh \& Zahra, 2007). The hosts gained willing workers who were positive role models for their children while the volunteers had a chance to gain a more authentic cultural experience (McIntosh \& Zahra, 2007). Conran (2011, p. 1466) described the creation of mutual understanding between cultures. Furthermore, Higgins-Desboilles (2003) discussed the 
relational properties by suggesting that the practice has the potential to be used as a form of reconciliation between Aboriginal Australians and Australians of European descent.

\subsection{Limitations of volunteer tourism}

Although it is important to recognise the benefits of volunteer tourism, it is equally important that the limitations of the practice are not ignored so that a balanced account of the practice is presented. The volunteer tourism literature has only recently started to analyse the possible negative impacts of volunteer tourism (Guttentag, 2009). The limitations of the practice discussed in the literature can be split into two main categories: uneven power relations and cultural misunderstanding.

Despite the literature's portrayal of a mutual and reciprocal relationship between the host communities and the volunteer tourists (Wearing, 2001; McIntosh \& Zahra, 2007; Lyons \& Wearing, 2012); the depiction of an uneven relationship between host communities and the volunteer tourists has also emerged within the literature (e.g. Simpson, 2004; McGehee \& Andereck, 2008; Guttentag, 2009; Sin, 2010; Vodopivec \& Jaffe, 2011). Sin (2010) portrayed that this unequal relationship reinforces existing power structures and hierarchies between 'developed' and the 'developing'. McGhee (2011, p. 93) suggested that, 'The volunteer tourism industry itself establishes power/knowledge relations between the economically and socially powerful volunteer tourists ... and the less powerful host communities (who are, by nature, being exploited or dominated by forces that place them in the position of being 'voluntoured')'. Simpson (2004), Raymond and Hall (2008) and Conran (2011) found that this type of relationship creates a dichotomy of 'them and us'. This dichotomy has been described in relation to Said's (1978) notion of orientalism throughout the scholarly articles (e.g. Simpson, 2004; Conran, 2011). Orientalism refers to this creation of a 'binary opposition' where different groups are set off against each other (Conran, 2011, p. 1464). 
Additionally, Sin (2010) found that uneven relationships were heightened within host communities when a particular group within the host community benefited more than another group. Sin's (2010) case study in Cambodia described how host communities sometimes felt that they had to appear needy in order to receive volunteer tourists by describing the, "Very real threat of becoming or appearing "too rich" for volunteer tourism'. This similarly has enforced uneven power relations between the volunteers and the host communities.

The literature has expressed that the control and authority of the volunteer tourists over the host communities is off balance. Both Guttentag (2009) and Sin (2010) emphasised this lack of power possessed by host communities with regard to their decision making capabilities. They found that host communities were often forced to propose volunteer projects which were in line with the volunteers' needs and what they considered to be suitable rather than projects which met the needs of the host communities (Guttentag, 2009; Sin, 2010). Sin (2010) found that host communities had to appear needy in order to attract volunteer tourists to their projects. Furthermore, Guttentag (2009) conveyed that in some instances, host communities were not consulted at all. Sin (2009, p. 495-496) noted that, 'The paradox herein is that volunteer tourism will almost always involve the 'richer' and 'better off' providing aid to the 'poor' and 'worse off'.

The lack of power that host communities hold in volunteer tourism can be illustrated through volunteer project planning. Sin (2010) discussed the complexity of writing proposals for host communities to gain volunteer tourists for their projects. Moreover, Sin (2010, p. 989) suggested that volunteer projects had to be deemed "suitable" for the volunteers which often led to superficial projects. As a result, hosts had limited power over the types of projects that the volunteers were working on in their communities (Sin, 2010). 
This imbalance of power between host communities and volunteer tourism organisations has led to dependency issues. McGehee and Andereck (2008), Guttentag (2009) and Sin (2010) discussed the notion of dependency in host communities. In addition to locals losing employment opportunities when volunteers are available to carry out jobs without pay, a situation is created where host communities rely on volunteers to get work completed (Guttentag, 2009). Sin (2010, p. 990) conveyed the varying degrees of dependency by suggesting that, 'This issue of dependency can possibly range from seemingly trivial instances of children asking volunteer tourists for pens or sweets, to larger societal problems with entire communities expecting handouts'.

These issues of power are often a consequence of the inadequacy of volunteer tourism organisations. McGehee (2011, p. 86) argued that, 'Volunteer tourism organizations have the potential to act either as catalysts for positive sociocultural change or facilitators of neo-colonialism and dependency'. The poor organisation and implementation of volunteer tourist organisations impacts on both the volunteer tourists and the host communities (Bailey \& Russell, 2010; Coren \& Gray, 2012). This can be portrayed through the ability (or inability) of volunteer tourism organisations to select suitable participants. Guttentag (2009) found that due to the limited participant requirements of volunteer tourism organisations, participants did not always have the necessary skills to be effective in their host communities. The literature conveyed that volunteer tourism organisations often provide volunteers who lacked language and professional skills (McGehee \& Andereck, 2008; Lough et al., 2011). Academics found that it is essential that the volunteer tourists have the proper skills to make a positive contribution (Raymond \& Hall, 2008, p. 538).

Volunteer tourism literature has portrayed the potential for volunteer tourists to be a burden on host communities (Raymond, 2008; Sin, 2011). This is particularly due to the insufficient skills of the volunteers which cannot be put to good use (Raymond, 2008). 
Sin (2011) suggested that there were instances in which volunteer tourists were a distraction and drained staff time in the host community. Part of this burden is a consequence of the volunteers' limited time in the host communities. Lough et al. (2011, p. 133) conveyed that, 'Volunteers serving for longer durations would be able to integrate more fully in the organization, would consume less staff time for orientation and training relative to their total time volunteering, and could be trained to perform more complex tasks and 'sustainable projects". The amount of time that volunteers spent in the host community impacted on the host communities and influenced the type of experience that the volunteer tourists received.

The negative relationship between cross-cultural understanding and volunteer tourism has been discussed in the literature. Simpson (2004); Raymond and Hall (2008) and Sin (2010) argued that volunteer tourism does not always result in increased cross-cultural understanding. In reality, volunteer tourism may 'undermine' the 'cultural well-being' of local communities (Coren \& Gray, 2012, p. 222). Simpson (2004) highlighted this view within gap year programmes where existing stereotypes and generalisations were often reinforced in volunteer programmes. Examples of volunteer tourists being insensitive to the host's culture and having little regard for the interests of the local people and communities have been examined (Scheyvens, 2002; Sin, 2010). Raymond and Hall (2008) suggested that in order for cross-cultural understanding to be developed, it was important that volunteers and host communities were provided with opportunities for interaction and exchange.

Palacios (2010) and McGehee (2011) discussed how the type of language that volunteer tourism organisations used contributed to neo-colonial attitudes within volunteer tourism. This language was prevalent in both promotional material and within the projects themselves. In a study of an Australian university volunteer tourism programme, Palacios (2010) found that Eurocentric attitudes were reinforced by volunteer tourism. Both the volunteer tourists and the hosts commonly held 
perceptions that western knowledge was superior (Palacios, 2010, p. 869). In addition, volunteers' comments such as the locals being 'poor-but-happy' sometimes led to poverty being excused or justified by the volunteers (Simpson, 2004, p. 688). Case studies have shown that volunteer tourists were not always encouraged to critically reflect on poverty (Simpson, 2004; Palacios, 2010).

The limitations of volunteer tourism can be viewed through a post-development lens. Sidaway (2008, p. 16-17) summarised post-development as, 'A critique of the standard assumption about progress, who possesses the keys to it and how it may be implemented'. Nederveen Pieterse (2000) exemplified this assumption by rejecting development because it was a western and homogenising concept. He defined postdevelopment as, 'A radical reaction to the dilemmas of development. Perplexity and extreme dissatisfaction with business-as-usual and standard development rhetoric and practice, and disillusionment with alternative development' (2000, p. 175). Esteva (1992), a key post-development writer argued that development in its current state had failed. Fundamentally, post-development writers criticise development as being part of the problem rather than the solution (Kiely 1999). They are concerned with uneven power relations, western dominance and how knowledge is constructed (Kiely 1999).

A post-development lens would critique volunteer tourism by rejecting the 'businessas-usual' attitude that is often prevalent in discussions of volunteer tourism. It would demote the practice as another method of assuming western control. A postdevelopment perspective would question the qualification and the authority that the volunteers have in participating in volunteer tourism. Both Palacios (2010) and Vodopivec and Jaffe's (2011) perspective of volunteer tourism is aligned with postdevelopment thinking. Vodopivec and Jaffe (2011, p. 124) proposed that, 'Despite the promotion of participatory approaches within new development discourse, volunteer tourism is reinforced by the idea that the development will come from outside, and is located in the hands and wallets of enlightened, wealthy volunteer consumers'. Palacios 
(2010, p. 864) conveyed that the 'North' retained a dominant position of control through volunteer tourism. He gave an example of this dominant position of control within his case study where a volunteer was asked to give feedback in a field which they had no knowledge of or experience in because the host staff perceived her as an expert (Palacios, 2010, p. 869). This case study links to Illich's (1968) critique of volunteering. This highlights evidence of Eurocentric attitudes and the perceived superiority of Western knowledge (Palacios, 2010). McGehee (2011, p. 96) additionally illustrated this dominant position of volunteers through a portrayal of images on volunteer tourism operator websites, such as pictures of volunteers reading to children and pictures of volunteers with 'protective posses with children'. McGehee (2011, p. 96) conveyed that, 'Rarely are members of the host community shown in positions of power or dominance over the volunteers'. Rather, these images show the volunteers in control of the hosts.

Nonetheless, it is important that the inadequacies of post-development are not overlooked (Kiely, 1999). Post-development has been criticised for dividing the world into an 'evil West' and a 'noble south' (Kiely, 1999). This division oversimplifies the world and makes it difficult to see the diversity within the categories. Both Kiely (1999) and Curry (2003) agree that post-development can be criticised for portraying that the whole world will experience development in a singular way. Kiely (1999, p. 38) argued that, 'Only the most blindly Eurocentric analyst could argue that Tanzania, South Korea, India and Brazil have become increasingly similar'. Evidently, each of these countries have different experiences of development.

In the context of volunteer tourism, post-development has been useful for dismissing the claim that the practice is a neutral process (Kiely, 1999). The theory has been worthwhile for generating a deeper and more critical understanding of volunteer tourism. However, a post-development outlook has been perceived as being overly negative. According to Kiely (1999), post-development ignores the role of agency. Within volunteer tourism, each of the groups involved hold a degree of agency. 
Additionally, a post-development lens would unfairly paint all volunteer tourists in a negative light while praising the host communities. This is not a reflection of reality. There are actors on both sides who positively and negatively interact with volunteer tourism. Furthermore, by completely rejecting development, Curry (2003, p. 406) argued that, 'Possibilities for improvements, for example, in health, education, and material well-being' would be denied. If a post-development theorist was to outright reject volunteer tourism, it would deny the positive changes which have come as a result of the practice.

\subsection{Commodification of volunteer tourism}

A contradiction of commodification has been described within the volunteer tourism literature (Conran, 2011). On one hand, volunteer tourism is portrayed as a form of alternative tourism which is regarded as a protest against the commodification of tourism (Wearing, 2001). This is shown by Conran (2011, p. 1455) who suggested that volunteer tourism, 'Emerge[ed] as a rebellious acquiescence to the status quo of neoliberal global capitalism'. On the other hand, volunteer tourism has been depicted as a fundamental element of commodification (Vodopivec \& Jaffe, 2011; Tomazos \& Cooper, 2012; Coren \& Gray, 2012). The practice has taken, 'The form of commodified products and services' (Conran, 2011, p. 1455). This process of commodification is in line with capitalist ideologies and dominant neoliberal understandings. It follows the trends of development privatisation (Vodopivec \& Jaffe, 2011).

The commodification of volunteer tourism has resulted in the growth of organisations which are working for profit. Tomazos and Cooper (2012, p. 421) described this process where, 'Volunteer tourism organisations ... evolved into hybrids of monetary gain and service blending business acumen with a social mission'. The commodification of volunteer tourism is not entirely bad as it has brought economic benefits to host communities (Gray \& Campbell, 2007; Clifton \& Benson, 2006). However, the literature 
has shown that host communities have also been negatively impacted by the commodification (Vodopivec \& Jaffe, 2011). This change has resulted in the capabilities of local communities being undermined (Vodopivec \& Jaffe, 2011). It has prevented organisations from supporting host communities and has led to instances where operators have exploited host communities in order to increase their revenue (Lyons \& Wearing, 2008; Cousins et al., 2009). As a result, host communities have grown their dependence on outside assistance (Vodopivec \& Jaffe, 2011; Sin, 2011). In addition, the economic benefits from volunteer tourists have been portrayed as being skewed towards the local elites rather than those who are in need (Clifton \& Benson, 2006). These various perspectives connote the complex issues surrounding the commodification of volunteer tourism.

\subsection{Motivations of volunteer tourists}

Much of the literature on volunteer tourism is focused on the motivations and perceptions surrounding why people participate in volunteer tourism. The major debate about the motivation of volunteer tourists within the literature is centred on whether these volunteers hold altruistic or selfish motivations. Through a study of volunteer tourists in Guatemala, Vodopivec and Jaffe (2011, p. 116) found that the overall motivation of the practice was primarily based on 'doing good'. Zahra and McIntosh (2007) also agreed that the most important motivation of volunteer tourists was altruism.

Authors, such as Coghlan (2007), McIntosh and Zahra (2007) and Tomazos and Butler (2009) consider the motivations more broadly. Along with altruistic motives such as the desire to work with communities in developing countries, Coghlan (2007) examines more self-centred motives such as the enhancement of self-image, cultural awareness, independence and the development of personal knowledge. Tomazos and Butler (2009, p. 2) also suggest that altruistic motives exist alongside more selfish 'material' and 
'social' motivations. Similarly, in their Thai and Vietnamese case studies, Coren and Gray (2012) conveyed that the most important motivating factor for volunteer tourists was the challenge of participating in the project offered. Brown and Lehto (2005) found that cultural immersion, giving back and making a difference, seeking camaraderie with fellow volunteers, family bonding and education were the key motivators for volunteer tourists. Brown and Morrison (2003) suggested that altruism may not be the primary motivation for volunteer tourists, since the volunteers are also tourists. They conveyed that there were two competing mindsets of the volunteer tourists, those that were 'volunteer-minded' and those that were 'vacation-minded' (Brown \& Morrison, 2003).

Tomazos and Butler (2012) proposed that unlike more conventional volunteers or tourists, the motivations of volunteer tourists uniquely existed on a 'motivational see-

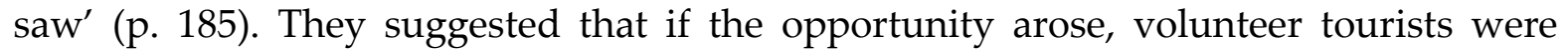
likely to be self-centred- even if their initial motivations were altruistic (Tomazos \& Butler, 2012). Coghlan and Fennell (2009) had a more cynical view of participant motivations in comparison to the other authors mentioned. They found that 'Volunteer tourism represents a form of social egoism, engaging participants to help others through instrumental means but for the purpose of achieving the ultimate goal of benefiting oneself' (Coghlan \& Fennell, 2009, p. 393). Guttentag (2009) took the debate of motives a step further to suggest that the existence of selfish motives for volunteer tourism was irrelevant. He proposed that the important element of volunteer tourism was about ensuring that the practice was beneficial overall (Guttentag 2009). It is interesting to note that some of these motivating factors contradict the western definition of volunteering that was outlined in section 2.1 of this chapter (Tamasese et al., 2010, p. 8; Coghlan \& Gooch, 2011). 


\subsection{Conclusion}

This literature review has been presented with the purpose of grounding the study and engaging with the key themes within the existing literature on volunteer tourism. Volunteer tourism was recognised as both a significant and relevant research topic due to the increasing popularity and size of the industry. The review acknowledged Wearing's (2001) commonly cited definition of volunteer tourism as the most substantial definition within the literature but recognised that host communities needed to be included. As an outcome, the definition of volunteer tourism for this research expands on Wearing's (2001, p. 1) definition to define the practice as, 'Those tourists who, for various reasons, volunteer in an organised way to undertake holidays that might involve aiding or alleviating the material poverty of some groups in society, the restoration of certain environments or research into aspects of society or environment', generally with the collaboration or cooperation of a host community.

The volunteer tourism literature presented a limited insight into the perspectives held by the host communities. Although this study seeks to engage with the viewpoints of both the volunteers and the hosts, a central objective of the research is to develop a deeper understanding of the host community's perspectives of volunteer tourism. As an outcome, it is hoped that in addition to the volunteers' views, the host communities' views will be prioritised and valued too.

Based on this literature review, it was interesting to note that although the benefits of volunteer tourism have been prioritised within the literature, there were also many limitations of the practice too. As an outcome, this study seeks to present a more balanced picture of volunteer tourism with consideration of both the benefits and limitations. The benefits and limitations of volunteer tourism were framed around elements of culture and power with the development implications of the practice woven throughout these discussions. Culturally, the practice was viewed as an 
opportunity for both cross-cultural understanding and misunderstanding (Raymond \& Hall, 2008). In terms of power, volunteer tourism was understood as a practice which created an environment of equal power sharing between hosts and tourists but was also seen to reinforce existing power structures (Sin, 2010; Guttentag, 2012). While the literature presented many positive outcomes of volunteer tourism, it questioned whether these could be viewed as development, particularly due to the lack of engagement with deeper issues (Simpson, 2004; Vodopivec \& Jaffe, 2011).

This research is interested in expanding the knowledge surrounding the development implications of volunteer tourism, with a particular focus on the three central themes that emerged from the literature: development, power and culture. These themes link to each of the research's key questions:

1. What is the relationship between Global Volunteers and development in Rarotonga?

2. What is the nature of power within the Global Volunteer programme in Rarotonga?

3. What role has culture played within the Global Volunteer programme in Rarotonga?

The study seeks to engage with these key questions through an analysis of Global Volunteers in Rarotonga, with the aim of developing a broader understanding of volunteer tourism. 


\section{Chapter Three: The research context}

This chapter will contextualise the research. Firstly, the Cook Islands will be presented as the location of the study. A presentation of the Cook Island's background, development situation and development challenges will be made. Following this, the chapter will examine the Global Volunteers overall programme and then will specifically focus on the Global Volunteer programme within Rarotonga.

\subsection{The Cook Islands}

This research is situated in Rarotonga, the largest of the Cook Islands. The Cook Islands are located in the South Pacific Ocean, roughly half way between Hawai'i and New Zealand. There are 15 major islands which constitute the Cook Islands. These are scattered across 2 million square kilometres of the Pacific Ocean. The total land area of the country is 240 square kilometres (Cook Islands Government, 2012a). The islands are clustered into two distinct groups, the Northern Group and the Southern Group. The Northern Group is made up of Manihiki, Nassau, Penrhyn, Pukapuka, Rakahanga and Suwarrow. This group of islands are mainly low coral atolls (CIA, 2012). The Southern Group includes: Rarotonga, Aitutaki, Atiu, Mangaia, Manuae, Mauke, Mitiaro, Palmerston and Takute. These islands are typically volcanic and hilly (CIA, 2012). The Cook Islands excluding Rarotonga are known as the Outer Islands. A map of the Cook Islands with an insert of Rarotonga is illustrated in Figure 1 below.

The estimated population of the Cook Islands in 2011 was 17,791 people (Cook Islands Statistics Office, 2012b). Rarotonga is the most populated with 13,097 people living on the island (Cook Islands Statistics Office, 2012b). Rarotonga is the commercial and government centre of the Cook Islands (Central Policy and Planning Office, 2011). 
Figure 2. Map of the Cook Islands with insert of Rarotonga

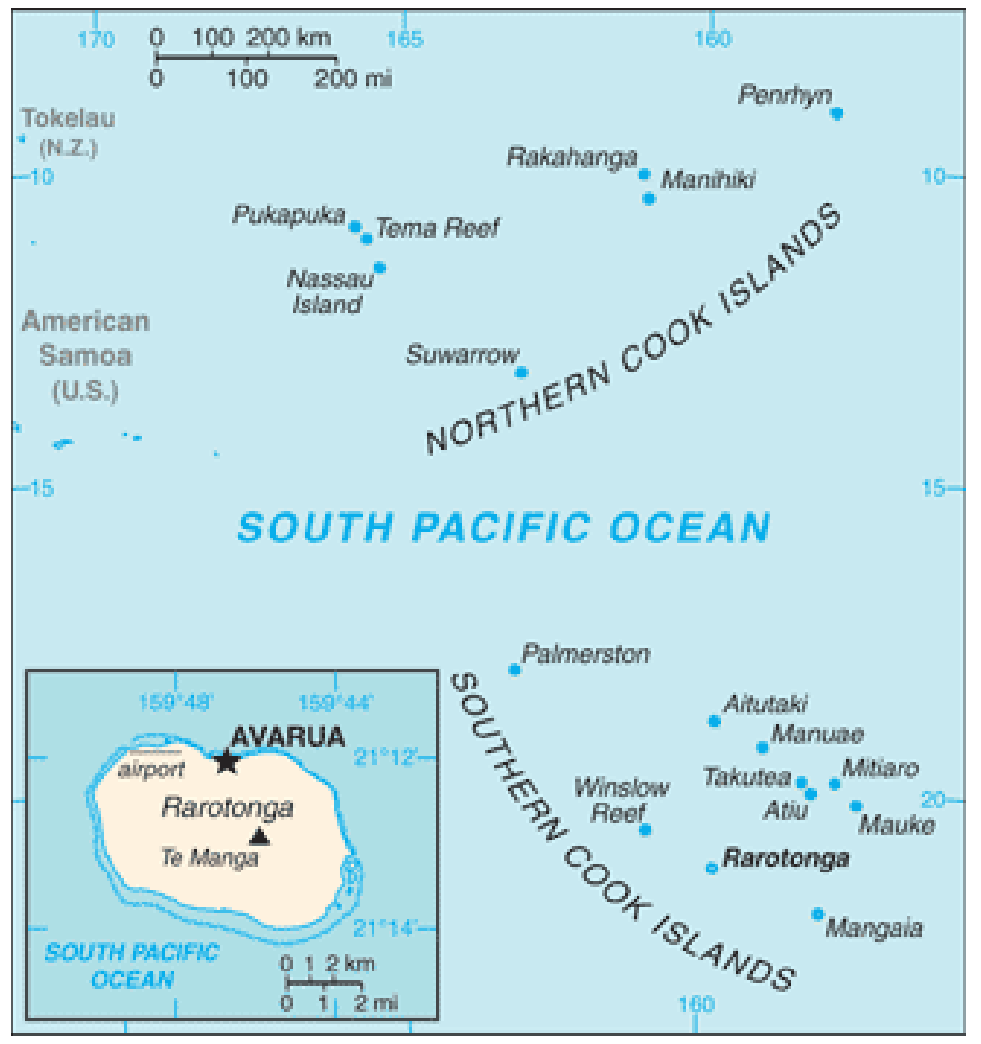

Source: CIA, 2012

\subsubsection{Background}

The Cook Islands have had a long history of experience and interaction with the outside world. According to the New Zealand Ministry of Foreign Affairs and Trade (2012b), the Cook Islands were first settled in the $13^{\text {th }}$ century by people from nearby islands. Missionaries from the London Missionary society first brought Christianity to the Cook Islands in 1821 (Cook Islands Government, 2012b). In 1881, a British Consul was appointed for the Southern Group (Cook Islands Government, 2012b). In 1888, the Cook Islands were colonised by the British and became a British protectorate (Central Policy and Planning Office, 2011).

The Cook Islands have an extensive and unique relationship with New Zealand. Administrative control of the Islands was transferred to New Zealand in 1900 (Central 
Policy and Planning Office, 2011). In 1965, the Cook Islands became self-governing in free association with New Zealand. This allows Cook Islanders to have New Zealand citizenship which gives them open access to work and live in New Zealand and Australia. It also means that the Cook Islands 'administers its own affairs' (MFAT, 2012b).

\subsubsection{Cook Island development}

In comparison to other Pacific nations, the Cook Islands are relatively prosperous. They have been viewed as having some of the strongest development indicators in the region (European Commission, 2007). When examined on a surface level, poverty is not viewed as a major issue. Food and shelter, for instance, is widely accessible by most people (Fieldwork Journal, 17 March, 2012). The development indicators presented in Table 1 show the Cook Islands in a favourable light. However, when poverty is considered on a deeper level, it becomes clear that Cook Islanders face a poverty of opportunity. According to the UNDP (2008, p. 4), a poverty of opportunity within the Cook Islands can be seen as, 'Hardship of opportunity to access resources needed (including cash) to meet the basic needs of the household, obligations to the wider kin network, community and the church'.

While a poverty of opportunity does exist in Rarotonga, it is particularly notable within the Outer Islands. The UNDP (2008) highlighted the higher vulnerability of the Outer Islands to the poverty of opportunity by arguing that the Outer Islands have, 'Limited access to employment and income generating opportunities, suffer inferior health and education facilities (in comparison to Rarotonga), which are compounded by high exposure to natural disasters' (UNDP, 2008, p. 4). The European Commission (2007) also agreed that the Outer Islanders received a smaller income and less adequate services to those in Rarotonga. 
Table 1. Cook Island development indicators

\begin{tabular}{|l|l|}
\hline Development Indicator & Figure \\
\hline $\begin{array}{l}\text { Percentage of population in extreme } \\
\text { poverty }\end{array}$ & $0 \%$ \\
\hline $\begin{array}{l}\text { Percentage of population that struggled } \\
\text { to meet the basic food poverty line }\end{array}$ & $2 \%$ \\
\hline $\begin{array}{l}\text { Percentage of population that struggled } \\
\text { to meet the basic needs poverty line }\end{array}$ & $24.4 \%$ \\
\hline $\begin{array}{l}\text { Average life expectancy } \\
\text { Access to safe drinking water }\end{array}$ & $\begin{array}{l}72.8 \text { years } \\
99.25 \% \text { of Rarotonga }\end{array}$ \\
\hline $\begin{array}{l}\text { Coverage of essential supplies and } \\
\text { medicines to all health clinics and } \\
\text { hospitals }\end{array}$ & $100 \%$ \\
\hline $\begin{array}{l}\text { Instances of maternal mortality (between } \\
\text { 2001 and 2006) }\end{array}$ & $0 \%$ \\
\hline $\begin{array}{l}\text { Literacy rate } \\
\text { wroportion of the resident population }\end{array}$ & $38 \%$ of males \\
\hline
\end{tabular}

Source: Central Policy and Office, 2010.

The Cook Island economy has been described as one of the strongest in the Pacific (Central Policy and Planning Office, 2010; Asian Development Bank, 2011). The leading income producers include tourism, fishing, agriculture and financial services. Pearls are the leading export (Cook Islands Government, 2012a). In 2011, Gross Domestic Product (GDP) was \$334,825 NZD (Cook Islands Statistics Office, 2012a). According to the Central Policy and Planning Office (2010), the average income in Rarotonga was \$15,700 NZD, the average income in the Southern Group was $\$ 7,200$ NZD and the average income in the Northern Group was \$7,800 NZD. These income statistics further 
highlight the differences between Rarotonga and the Outer Islands. About 70 percent of all households in the Cook Islands are engaged in some form of agricultural activity for subsistence, commercial gain or both (Cook Island Government, 2012).

\subsubsection{Development challenges}

Despite the relatively positive indicators of Cook Island development, the country faces a number of challenges which prevent it from moving forward.

\section{Official development assistance}

With 14 percent of the Cook Island's GDP made up of development assistance in 2010/11, the Cook Islands can be viewed as being reliant on development assistance. New Zealand and Australia are the biggest donors to the Cook Islands. Both countries have a harmonised aid programme in the Cook Islands which gives New Zealand responsibility for the administration of Australia's Official Development Assistance (ODA) in addition to its own. In 2011/12, \$19 million NZD in New Zealand ODA and \$4.4 million AUD in Australian ODA was allocated to the Cook Islands (MFAT, 2012a; DFAT, 2012). Other significant donors to the Cook Islands include Japan, India, the European Union, China and international organisations such as the Asian Development Bank (Central Policy and Planning Office, 2010).

\section{Tourism}

Tourism is a major industry of the Cook Islands with the industry providing approximately 65 percent of the country's GDP (MFAT, 2012a). A quick drive around Rarotonga demonstrates the importance of this industry to the islands. Tourism is concentrated around Rarotonga with Aitutaki as a secondary location (Cook Islands Government, 2012). In 2011, 83,646 of the 112,643 people that visited the Cook Islands said the primary purpose of their visit was for a vacation (Cook Island Statistics Office, 2012). Although the tourism industry has been beneficial to the Cook Island economy, the economy is very reliant on the industry. As an outcome, any changes that take place 
within the global tourism industry greatly impact on the Cook Islands. For instance, the 9/11 terrorist attacks led to a reduction in the numbers of tourists from North America (NSCP, 2011; Cook Islands Government, 2012a). This affected the livelihoods of many people who work in the tourism industry. Furthermore, tourism has played a role in the out-migration of the Outer Islands as people have moved to Rarotonga in search of more work opportunities (Levinson \& Milne, 2004).

Although this overreliance on tourism has been viewed as a negative part of the Cook Island economy, it has alternatively been perceived as a defining factor which has set the Cook Islands economy apart from other Pacific nations. In 1985, Bertram and Watters formulated a model of migration, remittances, aid and bureaucracy (MIRAB) in five Pacific Islands, including the Cook Islands (Bertram \& Watters, 1985). Bertram and Watters (1985) suggested that the economy and society of the selected Pacific Island states relied heavily on MIRAB. Although many aspects of the MIRAB model do have some validity in the Cook Islands, the point of difference between the Cook Islands and some of the other Pacific Islands is that tourism plays a significant role in the Cook Islands' economic development (Levinson \& Milne, 2004; Marsters et al., 2006).

\section{Depopulation}

Since Cook Islanders are New Zealand citizens, they can freely live and work in New Zealand or Australia. As a result, these countries are fairly accessible to Cook Islanders. The majority of Cook Islanders have spent time living outside of the Islands. According to MFAT (2012a), there are approximately 78,000 Cook Islanders living in New Zealand, Australia and the US. With a current population of 17,791 people, there are four times the amount of Cook Islanders living away from the Islands than those currently living in the Cook Islands (Cook Islands Statistics Office, 2012b). However, it is important to note that many of the Cook Islanders that are living outside of the Cook Islands remain in close connection through family connections, remittances and regular holidays. 
It has been proposed that people were leaving the Cook Islands because they were dissatisfied with the local conditions (Central Policy and Planning Office, 2010). The National Millennium Development Report suggested that the, 'Cook Islands has to compete with higher wages, lower prices and the better quality of many goods and services offered in New Zealand, which is one of the major reasons people leave the islands' (Central Policy and Planning Office, 2010). The outward migration of Cook Islanders has serious implications for the Cook Islands, leading to a labour shortage for the tourism industry in Rarotonga and less demand for goods and services on the island (Central Policy and Planning Office, 2010). This becomes particularly significant when many of the people who leave the Cook Islands are well educated (UNDP 2008). With a declining population, particularly in the Outer Islands, the sustainability of the Cook Islands has been questioned (Asian Development Bank, 2011).

\section{Island vulnerability and 'smallness'}

The vulnerability of the Cook Islands to natural disasters and the 'smallness' of the Cook Islands has had a detrimental impact on the Cook Islands' development. The most recent natural disaster that caused extensive damage was Cyclone Pat which hit Aitutaki in 2010 (Central Policy and Planning Office, 2010). Cyclone Pat caused damage to both housing and public infrastructure (MFAT 2012b). The damages that natural disasters such as Cyclone Pat bring to agriculture, housing and tourism infrastructure increase pressure on the Cook Island economy (Asian Development Bank, 2011).

The 'smallness' of some states has been perceived as being a constraint on economic development (Connell, 2010). 'Smallness' in the Cook Islands relates to the 'remoteness and isolation (resulting in high transport costs to markets, and costly tourism), diseconomies of scale (with small domestic markets), limited natural resources and narrow production bases, substantial trade deficits, few local skills, vulnerability to external shocks and natural disasters (principally cyclones), as well as disproportionately high expenditure on administration' (Connell, 2010, p. 115). Each of 
these factors relating to the 'smallness' of the Cook Islands has been seen as bringing about negative consequences to the islands.

However, perceiving the Cook Islands as being small is only one way of understanding the islands. In response to the 'smallness' of the Cook Islands identified by Connell (2010), Hau'ofa (1993, p. 6) would argue that this perception is an 'Economistic and geographic deterministic view of a very narrow kind, that overlooks culture, history, and the contemporary process of what may be called world enlargement'. Hau'ofa (1993, p. 7) suggested that the Pacific Islands should be viewed as 'Sea of islands, rather than 'islands in the sea'. By viewing the Pacific islands as a 'Sea of Islands', Hau' ofa (1993, p. 7) argues that it represents a 'more holistic perspective in which things are then in the totality of their relationship'. Despite these varying perspectives, the Cook Islands faces issues related to its size and classification as a group of islands.

\section{Cook Islands summary}

This section has established the Cook Islands as a country which has had long term contact with people from outside the Islands, relatively low levels of poverty and a successful tourism industry. However, it was noted that although the Cook Islands were in comparatively good shape, a poverty of opportunity existed in conjunction with a number of other development challenges which prevented the islands from moving forward. Furthermore, there was evidence of a disparity between Rarotonga and the Outer Islands. Each of these elements are of particular relevance to Global Volunteers' work in Rarotonga. The remainder of this chapter will present Global Volunteers.

\subsection{Global Volunteers}

This research is centred on the work of Global Volunteers. Global Volunteers is a private, non-sectarian, non-profit, US based organisation which was founded in 1984 
(Global Volunteers, 2012). The organisation coordinates short-term teams of volunteers in a range of countries across the world. Although most of Global Volunteers' programmes are focused on assisting areas of high need, the locations are not limited to developing countries (Global Volunteers, 2012). To quantify the scope of the organisation, 300 teams serve on Global Volunteers' programmes each year and 28,000 volunteers have participated on a programme since its establishment (Global Volunteers, 2012). Global Volunteers was granted Special Consultative Status with the United Nations (UN) in 1999 (Global Volunteers, 2012).

\subsubsection{Global Volunteer's vision and philosophy}

Global Volunteers essentially classifies itself as a development organisation. The organisation's vision is to, 'Wage peace and promote justice worldwide through comprehensive community development partnerships' (Global Volunteers, 2012). Global Volunteers suggests that they take a participatory approach through their 'philosophy of service':

A development strategy, which is based upon outside government agencies, religious organizations, or NGOs doing the job for, or attempting to impose solutions on, local people is doomed to failure. It is only when local people decide to act that positive change will occur. It is only when local people decide to implement development plans, that those plans have any currency. And it is only when local people take a leadership role in the creation of those plans, that they have any chance of success (Global Volunteers, 2012).

Global Volunteers (2012) underlying principles include: work at the direction of local leaders and at the invitation of 'community partners' on comprehensive communitybased development projects, hand-in-hand with local people, with sustained, long-term goals and impacts. ${ }^{2}$ Their focus areas are centred on an 'Essential Services Model' which was based on the work of several key agencies within the UN. This model highlights hunger, health and IQ as interlinking essential services within the Global

2 Although Global Volunteers (2012) uses the term 'community partner', this thesis uses the term 'host' as it is less emotive. 
Volunteer programmes (Global Volunteers, 2012). The focus areas which branch out from these essential services are outlined in the following table.

Table 2. Global Volunteers twelve essential services

\begin{tabular}{|l|l|}
\hline Essential Services & Focus \\
\hline Hunger & $\begin{array}{l}\text { - School and Household Gardens } \\
\text { - Child Nutrition } \\
\text { - Micronutrient Supplementation } \\
\text { - Improved Stoves }\end{array}$ \\
\hline Health & $\begin{array}{l}\text { - Health, Nutrition and Hygiene Education } \\
\text { - Malaria and Dengue Fever Prevention } \\
\text { - Deworming } \\
\text { - HIV/AIDS Education }\end{array}$ \\
\hline QQ & $\begin{array}{l}\text { - General Education } \\
\text { - Promoting Girls' Education } \\
\text { - Psychosocial Support }\end{array}$ \\
\hline
\end{tabular}

Source: Global Volunteers, 2012

According to Global Volunteers (2012), most of the volunteers work on three of the services, including: school and household gardens using EarthBox technology, hygiene education focusing on hand washing with soap and water and general education tutoring math, science and computer literacy and teaching conversational English. The organisation suggests that they only provide services which a community requests but advises communities of what has been requested by other communities so that they know what is available to them (Global Volunteers, 2012).

Global Volunteers recognises that the volunteers are also tourists to the communities that they are working in (Global Volunteers, 2012). As an outcome, volunteers have time and opportunities to explore the wider communities and participate in tourist 
activities. However, since the programme is categorised as a 501C-3 tax exempt programme, Global Volunteers does not organise any commercial tourist activities for the volunteers (Global Volunteers, 2012).

Despite their self-identification as a development organisation, this research fundamentally recognises Global Volunteers as a volunteer tourism organisation. Global Volunteers has a number of central features which connect their organisation to the volunteer tourism industry rather than development work. These features of volunteer tourism have been outlined within chapter two. Although the organisation's 'philosophy of service' prioritises the local people's ownership over their own development, Global Volunteers' 'essential services' suggest that they have already predetermined the programmes' priority areas.

\section{Global Volunteers' programmes}

Global Volunteers' programmes are typically two to three weeks in length (Global Volunteers, 2012). The programme commences with an orientation and training on day one. By day two, volunteers are usually involved with their work projects. The volunteers typically work eight hours a day, five days a week. They are initially led by an American team leader when a new project is first set up and then passed on to a local Country Manager who is usually part of the host community (Global Volunteers, 2012).

Volunteers pay a programme fee to participate on the programme which covers the cost of food, accommodation, transport, administration, project materials and the services of the team leader or Country Manager (Global Volunteers, 2012). This programme fee excludes the cost of travel to the host community and free time activities (Global Volunteers, 2012). The standard programme fee for the Cook Islands was $\$ 2,695$ for the two week programme and \$2,895 for the three week programme (Global Volunteers, 2012). Although the suitability of each programme varies between countries, Global 
Volunteers markets its programmes to a range of categories, including: couples, groups, students, seniors and families (Global Volunteers, 2012). Since the organisation is based in the US, 97 percent of the volunteers are from the US or Canada (Global Volunteers, 2012). There are no age restrictions and accompanied children can participate on selected programmes (Global Volunteers, 2012). There are limited restrictions around who can participate.

\subsection{Global Volunteers in the Cook Islands}

Global Volunteers has been operating in Rarotonga since 1998 (Global Volunteers, 2012). Although the number of volunteers has varied over the years, the programme is well established with 127 volunteer teams assisting on the island since its commencement (Manager 1, April 15, 2012). In 2012, seven Global Volunteers teams

were scheduled to volunteer in Rarotonga. There are typically between five and twenty people on each volunteer team. When Global Volunteers was first established, a team leader from the US was responsible for the programme (Manager 3, March 29 2012). In 2004, the programme was taken over by the first Cook Island Country Manager (Manager 3, March 29 2012). There have been four local Country Managers since then. When Global Volunteers first sent volunteer teams to Rarotonga, they were hosted by the Ministry of Health, with work primarily located at Rarotonga hospital (Manager 3, March 29 2012). Today, Global Volunteers is hosted by the Cook Island's Civil Society Organisation (CICSO), with a focus on literacy activities within the schools (Manager 1, April 15, 2012).

\subsubsection{Volunteer projects and tourist activities}

The Cook Island programme is unique to other Global Volunteers country programmes in that there are multiple hosts across the island (Manager 1, April 15, 2012). The work projects that the volunteers assist with vary, depending on the needs at the time of the programme and the type of skills and experience that the volunteers have (Global 
Volunteers, 2012). The primary project involves supporting the schools with their literacy programme. Literacy in this sense is taken broadly to mean reading, mathematics, English and teacher-aid help with special needs students (Manager 1, April 15, 2012). There are also a number of secondary projects with a range of organisations across Rarotonga. These work projects are often part time and undertaken in conjunction with the full time projects in the schools. The organisations that Global Volunteers has worked with have varied but the list includes disability and mental health groups, environmental projects, labour projects, administration, elderly care, a research centre and a variety of Non-Government Organisations (NGOS) (Global Volunteers, 2012).

The volunteers in Rarotonga typically work up to eight hours per day, five days a week. Weekends and afternoons are free for the volunteers to participate in tourist activities. As a team, volunteers have a few meals a week at local restaurants, experience an island dinner and cultural performance at a local hotel and occasionally participate in presentations of history and culture by local people (Fieldwork Journal, 19 March 2012).

\subsection{Conclusion}

By focusing on the Cook Islands and Global Volunteers, this chapter has contextualised the research. There are two key ideas which should be taken from this chapter. Firstly, even though the Cook Islands face some development challenges, with evidence of a disparity between Rarotonga and the Outer Islands, for the most part, the Cook Islands were identified as having some good indicators of development, being a wellestablished tourism destination and having a history of contact with people from outside the islands. Secondly, although Global Volunteers was predicated on 'comprehensive community development', this study regards Global Volunteers as a volunteer tourism organisation. This can be demonstrated through Global Volunteer programme in the Cook Islands. 


\section{Chapter Four: Methodology}

This chapter sets out the research methodology. It examines the 'recipe' used to carry out the study with a discussion of the key 'ingredients' and processes which took place. Firstly, I establish social constructivism as the epistemological framework for the research and discuss qualitative research and the reasoning behind choosing this approach. Following on from this, I discuss the ethics and legitimacy of the research, my positionality, the research context, Cook Island research methods and the design of the research.

\subsection{Epistemological framework: Social constructivism}

An epistemology is concerned with knowledge, understanding and the nature of thinking. It involves 'The theory of how we come to have knowledge, or how we know that we know something' (Wilson, 2008, p. 33). This research takes a social constructivist epistemological approach which asserts that, 'knowledge is always relative to its social setting' (Barnes, 2000, p. 748). Multiple realities are brought about by shared cultures and environments. Under social constructivism, the researcher and the contributors come together to create a mutual reality (Wilson, 2008, p. 37). The purpose of the research is to interact with contributors to develop a common meaning and to come to an understanding of a construction that is better informed than it was before (Wilson, 2008, p. 37). Taking the social constructivist perspective a step further, this research concedes that I am only an interpreter of knowledge rather than a creator of knowledge (Wilson, 2008). As the researcher, I interpret and present the knowledge that has been revealed by each of the contributors. 
With regard to Global Volunteers in the Cook Islands, this research seeks to engage with each of the contributors about their realities so that we can better understand the development implications of volunteer tourism.

\subsection{Qualitative research}

As an outcome of the social constructivist epistemological framework for this research, the methodology is purely qualitative in nature. Qualitative research is more interested in making sense of peoples' worlds and perceptions rather than searching for the absolute truth or hard facts (Brockington \& Sullivan, 2003). It enables the researcher to recognise the existence of multiple realities. Qualitative research focuses on attitudes and views and has the aim, 'To understand differing and often competing 'subjectivities' in terms of very different accounts of 'facts', different meanings and different perceptions' (Gray, 2004, p. 116).

Qualitative research was used in this study because I was primarily interested in hearing about the experiences and perspectives of the contributors rather than trying to quantify or calculate the development implications of Global Volunteers in Rarotonga. One of the central objectives of this research was to give a voice to those that host the volunteers. It is my view that the hosts' voices would have sank under the numbers and figures had I used quantitative approaches in this research. By gaining a sense of the varying perspectives and attitudes of the contributors in a qualitative manner, I had a better opportunity to obtain a holistic view of the operation of Global Volunteers in Rarotonga (Mayoux, 2006). 


\subsection{Ethics and legitimacy}

The ethics and legitimacy of carrying out this research involved four different levels of authority: Victoria University of Wellington, the Cook Island government, Global Volunteers and the personal level. Ethics approval for the research was gained from the Victoria University Human Ethics Committee on 27 March 2012. Country approval to undertake research in the Cook Islands was granted by the Cook Island Research Committee on 22 March 2012. Permission to situate the study on the Global Volunteers Cook Island programme was given by the Cook Island Country Manager prior to arriving in Rarotonga.

Although each of these formal levels of consent are an obligatory part of research and represent an agreed upon standard of practice, the personal ethics that are held by the researcher are equally important. Throughout the research (fieldwork and writing), I had the attitude of 'doing no harm' and minimising any potential consequences for each of the contributors involved in the study. I sought to be guided by Linda Tuhiwai Smith's (1999, p. 120) list of research principles:

1. Aroha ki te tangata (a respect for people);

2. Kanohi kitea (the seen face, that is present yourself to people face to face);

3. Titiro, whakarongo ... kōrero (look, listen ... speak);

4. Manaaki ki te tangata (share and host people, be generous);

5. Kia tupato (be cautious);

6. Kaua e takahia te mana o te tangata (do not trample over the Mana of people);

7. Kaua e mahaki (don't flaunt your knowledge).

Smith's (1999) principles relate strongly to both the Cook Island context of the research and my personal background. The expression of these principles will be discussed throughout the remainder of the chapter. 


\subsection{Positionality and personality}

My positionality has fundamentally influenced this research. Chacko (2004, p. 52) defined positionality as, 'Aspects of identity in terms of race, class, gender, caste, sexuality and other attributes that are markers of relational positions in society, rather than intrinsic qualities'. She argued that positionality 'sets the tone of the research, affecting its course and its outcomes' (Chacko, 2004, p. 52). Another layer of positionality was identified by Cook Island researcher Jean Mitaera who considered the researcher as the 'first paradigm' (Koloto, 2003). Mitaera recognised that the researcher's, 'values, genealogies, social location, beliefs, languages, worldview' are of foremost importance as they interact with the research (Mila-Schaaf, 2009). When the researcher is viewed as the 'first paradigm', the neutrality of the researcher is challenged (Mila-Schaaf, 2009). As the first paradigm in this research, I am not neutral to the study. The existing knowledge that I carry shapes the way that the research looks. Being aware of positionality encourages the researcher to be mindful of their biases and vigilant about ensuring that the contributors' views are accurately presented. This relates to Smith's (1999) fifth research principle, 'Kia tupato (be cautious)'.

\section{The local}

I am Cook Island Māori, New Zealand Māori and European. I was born and grew up in Wellington, New Zealand. My dad, Teupokoina Enoka was born in the Cook Islands of a Cook Island father, Tutere Enoka and a Papa'a mother, Mercia Enoka. Dad moved to Wellington, New Zealand with his family when he was a young boy. My mum, Loretta Enoka (nee Potaka) was born and grew up in the Rangitikei district of New Zealand to her Father, Tumihau Potaka and mother, Hilda Potaka (now Neil). Mum's family moved down to Wellington during her teens. Both of mum's parents are a mix of Māori and European background. The Iwi that I affiliate with are Ngāti Hauiti and Ngāti Tama. 
Figure 2. Enoka family home in Ruatonga, Rarotonga

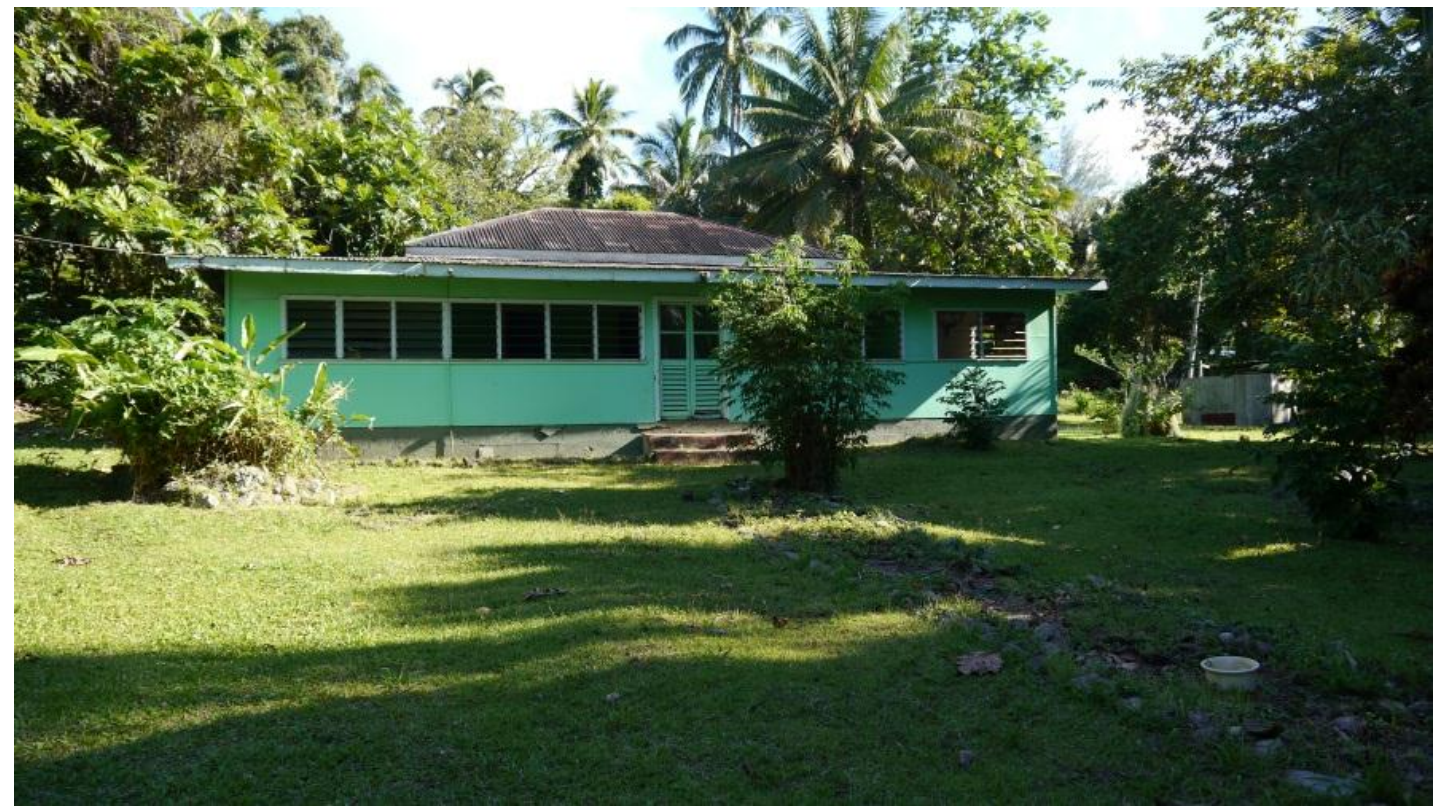

Source: Enoka, 2012

Although I did not initially 'feel' like a local in the Cook Islands, this label was given to me from the time the wheels of the plane hit the tarmac in Rarotonga. My aunty greeted me at the airport by saying, "welcome home" and placed an Ei kaki around my neck and an Ei katu on my head. I was welcomed 'home' to an island that I have never lived in. At first, I struggled with the 'local' label. This was partly due to not being able to speak Māori, having a limited understanding of the Cook Island culture and having fair skin. Yet, the longer I stayed on the Island, the more I started to identify with being a Cook Islander. I formed relationships with family members, I learnt some of our family history, I visited significant sites and participated in island life. I found myself talking about the tourists and the foreigners as 'others' rather than placing myself into those categories.

Chacko (2004, p. 53) proposed that the categories researchers identify with, such as 'local/foreigner' or 'insider/outsider' impact on how we position ourselves both socially and theoretically. These categories have a flow on effect to the way that we look at our research. However, being the 'insider' or the 'outsider' are not strict categories - they 
exist along a continuum (Scheyvens et al., 2003). The ability to move along either direction of the continuum was important in this study. Despite being called a local, there was a differentiation between me as a local who grew up in New Zealand and a local who grew up on the Islands. As a New Zealand born Cook Islander, I could be identified as an 'outsider' which meant that contributors would not automatically assume that I knew what they were talking about and would elaborate on their explanations. This helped me to side step any cultural faux pas. Additionally, Smith (1999) explained that even if you consider yourself to be an 'insider', as a researcher, you are automatically made an 'outsider'. It was important to be aware of each these categories.

\subsection{The research context}

The research context of Global Volunteers in the Cook Islands forms the basis of a case study on the phenomenon of volunteer tourism. Robson (2011) suggested that an important part of qualitative research is the need to understand the setting or context in which the topic is being researched. Yin (1994, p. 1) defined a case study as 'An empirical inquiry that investigates a contemporary phenomenon within its real-life context especially when the boundaries between phenomenon and context are not clearly evident'.

This case study approach has the advantage of narrowing the topic of volunteer tourism into a smaller, more manageable size and gives a specific example of the phenomenon in action. Geering (2007, p. 1) asserted that, 'Sometimes, in-depth knowledge of an individual example is more helpful than fleeting knowledge about a larger number of examples. We gain a better understanding of the whole by focusing on a key part'. Following on from this logic, it is anticipated that by focusing on the development implications of Global Volunteers in the Cook Islands, a deeper understanding of the development implications of volunteer tourism more broadly will 
be made. Conversely, case studies have been described as being problematic because of the difficulty of generalising from a specific case (Gray, 2004). Even so, it is my hope that this study will add to the multiple case studies on volunteer tourism, enabling a greater explanation of the various opportunities and issues surrounding the practice (Yin, 1994).

The location of this study was primarily chosen due to my family links to the Cook Islands. Being able to spend time with family, seeing where I came from and experiencing island life were strong motivating factors for situating this study in Rarotonga. Practical concerns were also taken into account with a good support network already on the island, the location of Rarotonga being easily accessible from New Zealand and being able to communicate straightforwardly with the contributors. Issues of time, money and the scope of a master's research project having to be completed within a year restricted the research to the single location.

It is important to note that this research is positioned within a specific organisation, location and time - Global Volunteers in Rarotonga, 2012. The research is placed within the boundaries of each of these elements. If any of these variables were to change, the research observations would alter.

\subsection{Cook Island research methods}

It was not possible for this research to be carried out in a completely 'Māori way' since I am not totally literate in Akono'anga. Nevertheless, the Cook Island context of the research influenced the way that the study was conducted. Ultimately, I aimed to respect and value each of the contributors and the knowledge that they held throughout the research. This objective corresponds to principles one and six of Smith's (1999) research principles. I sought to retain 'Aroha ki te tangata' (a respect for people) 
and did not want to trample over the Mana of the people, 'Kaua e takahia te mana o te tangata' (Smith, 1999, p. 120).

Throughout the study, I endeavoured to use research methods which were relevant to the Cook Island context. A research tool which has been widely discussed and used in Pacific contexts is Talanoa. Halapua (2000, p. 1) described Talanoa as, 'frank expression without concealment in face-to-face dialogue'. Talanoa is about talking honestly with each other or sharing stories without covering up our inner thoughts and agendas (Halapua, 2000). It involves reciprocity and is driven by common interests (Mila-Schaaf, 2009). It would be narrow-minded to say that Talanoa in its entirety was incorporated into the study but aspects of the approach were definitely integrated into this methodology. These are discussed below.

Face to face communication is essential in the Cook Island context. I know that my dad can say a hundred words through the way that he moves his eyes. Communication that takes place through the eyes or through body language is equally important to what comes out through the mouth. This relates to Smith's (1999, p. 120) principle two, 'Kanohi kitea (the seen face, that is, present yourself to people face to face)'. Prioritising face to face communication was crucial for both me and the contributors to engage with each other. Seeing the contributors' facial expressions during interviews was an important way of attaching emotion or feeling to what was said verbally. A 'faceless' interview over email or telephone or a paper survey without face to face communication could have had the potential to isolate contributors and make them feel apprehensive about being involved in the study. This would have made it difficult to gain an in-depth insight into the contributors' perspectives and attitudes which would have been counterproductive to the research.

The oral tradition of the Cook Islands made interviews an important part of the research methodology. During interviews, stories were often shared by contributors. 
These stories were a way that each of the contributors could explain their experiences of Global Volunteers at a personal level.

As the researcher, receptive learning and my ability to be foremost a listener was very important in the Cook Island context. Smith (1999, p. 120) used principle three to describe this research attribute, 'Titiro, whakarongo ... kōrero (look, listen ... speak)'. This approach relates well to my personality and has been ingrained into me through my family upbringing. Looking, listening and then finally speaking gave space for the contributors to present their views. It also gave me an opportunity to process information and enabled me to be sensitive toward Cook Island culture. By looking and listening, I was able to follow the example of others during interactions. For instance, if the contributors took their shoes off at the front door, I also took my shoes off at the front door. If the contributors ate with their hands, I also ate with my hands.

The practice of eating and sharing food is an important part of Cook Island culture. There is a saying that goes that you cannot eat food at the same table as your enemy. In other words, the sharing of food creates a sense of unity and agreement. Food was commonly shared with contributors, usually at the conclusion of interviews. The sharing of food turned the interviews into more informal and social gatherings.

\subsection{The research design}

The field research was carried out in Rarotonga over a period of seven weeks in 2012. It coincided with a Global Volunteer programme which hosted volunteers for three weeks. The contributors that were involved in the research included the volunteers, former and current Global Volunteers' Country Managers and former and current hosts. The hosts were typically heads of Non-Government Organisations (NGOs), school principals and school teachers. Each of these hosts had currently or previously hosted Global Volunteers' participants at their organisations. 
The current Cook Island Global Volunteers' Country Manager acted as my gatekeeper in the study. Through the Country Manager, I was given right of entry into the 'research site' (Willis, 2006, p. 147). The Country Manager aided my access to Global Volunteers and introduced me to most of the hosts. My association with the Country Manager assured the volunteers and hosts that the research was legitimate and made the practicalities of finding contributors easier. The view that gatekeepers can potentially sway (even if it is unintentional) the researcher towards ignoring certain groups has been examined in the literature (Valentine, 1997; Willis, 2006). By introducing me to some of the contributors, the Country Manager had the power to regulate who was involved in the study. To counter this regulation, I ensured that I involved additional contributors.

This attachment to the country manager and the resulting connection to Global Volunteers had the potential to mislead contributors about who I was representing. I was careful to ensure that each of the contributors knew that I was from Victoria University of Wellington rather than Global Volunteers. Overall, the country manager's support was very useful. It would have been extremely difficult to carry out the research without their support and assistance.

\subsubsection{Relationships with contributors}

Chacko (2004) argued that building and maintaining relationships are the most significant aspect of fieldwork. She suggested that, 'Interpersonal relationships and research can be enhanced by learning from those whose expertise are derived from experiencing life in an area where the researcher, at best, be a sojourner' (Chacko, 2004, p. 61). Bearing in mind that the duration of the fieldwork in Rarotonga was fairly short, relationships were crucial for me to make the most of the experience. 


\section{Hosts}

I was introduced to most of the hosts by the current Global Volunteers' Country Manager. This initial 'meet and greet' with the hosts took place a few days before an interview was arranged and broke down the 'stranger barrier' between myself and the contributors. Prior to the start of an interview, the hosts usually asked me my family name and the area where my family came from. From this information, most of the hosts worked out who my family was and in some cases could link their own Papa'anga back to mine. This exchange gave me a sense of belonging and further built up my own identity as a local. It also gave meaning and legitimacy to the relationship formed between me and the hosts.

Through Papa'anga, contributors were able to link who I was into their reality which helped them feel comfortable about talking with me. This created a sense of rapport where mutual trust and respect was formed between me and the contributors (Gray, 2004). In some instances, the respect that particular family members had on the island was extended to me through my family name. Merriam et al. (2001, p. 406) made the assumption that, 'The more one is like the contributors in terms of culture, gender, race, socio-economic class and so on, the more it is assumed that access will be granted, meanings shared, and validity of findings assured'. My Cook Island heritage assisted with this access.

\section{Global Volunteers}

I met the volunteers at the Global Volunteer programme orientation. My relationships with the volunteers initially stayed within the constraints of the research. However, as time went on, friendships were formed beyond the confines of the study. The importance of maintaining a balance between researcher and friend has been described by Scheyvens et al. (2003). Scheyvens et al. (2003) discussed the potential for deception when research contributors are also friends. I tried to prevent deception by remaining open with contributors and having a set space for 'research time'. The relationships that 
I had with the volunteers added value to the research, making interactions and interviews feel more natural and unconstrained.

\subsubsection{Research approaches}

\section{Participant observation}

Participant observation is a research method which comprises of generating data through, 'Observing and listening to people in their natural setting ... to discover their social meanings and interpretations of their own activities' (Gray, 2004, p. 241). This approach originated from anthropological research and usually involves intensive study carried out over a long period of time (Gray, 2004). Although making the participant observation long term would have improved the research - in my case, the time period of participant observation was relatively short. Participant observation was used throughout the Global Volunteer's three week programme.

Participant observation involved attending the Global Volunteers orientation and subsequent meetings, observing volunteers and hosts working, volunteering at a school, sharing meals, going to social events and 'hanging out' with the volunteers. Participant observation helped me to identify with the research contributors and to understand the varying perspectives that arose during interviews (Brockington \& Sullivan, 2003). Through this process, I experienced the situation of both the hosts and the volunteers. This helped me to see the wider picture (Gray, 2004). The approach was really useful for considering dynamics, interactions and the relationships between volunteers and the hosts. It also gave me an opportunity to build relationships with the contributors. Sometimes I received light hearted taunts from the volunteers about my status as the researcher within the group- for example, during dinner one night, someone in the group exclaimed to the table that I was going home to write up some notes about our dinner (Fieldwork Journal, 23 March, 2012). Overall though, I felt accepted and very welcomed into the group. 


\section{Fieldwork journal}

I kept a fieldwork journal which recorded aspects of both the ordinary and unusual interactions and happenings which took place throughout my time in Rarotonga. The journal was used as a way of keeping a record of what I did each day and included notes of things that needed to be followed up. The journal was useful for engaging and reflecting on my research experiences. It was very helpful for identifying reoccurring themes in the study. This corresponds to McGregor's (2006) belief that journal writing enables the researcher to think through the issues that they record.

\section{Interviews}

Interviews were used as a means of engaging with contributors during my field research. In total, 22 interviews were carried out. Before the interview commenced, a research information sheet was given to the contributors and discussed (Appendix Two). Interviews were either semi- structured or unstructured. The type of interview approach used was fluid and depended on how contributors responded at the beginning of the interview. My attitude towards interviews was to 'go with the flow' and to react to how the contributor wanted the conversation to go. In most cases, interviews loosely followed the interview schedule with room to veer beyond the set questions (Appendix Five). This approach enabled interviews to stay focused while still allowing opportunities for contributors to communicate the ideas which they thought were important (Willis, 2006). This method relates to the previously discussed Talanoa approach where 'frank expression' (Halapua 2000, p. 1) was prioritised.

In some instances, the first question was a strong enough prompting for the contributor to share their story- almost completely undisrupted. This led to a more unstructured, conversational style interview (Willis, 2006). Gray (2004, p. 213) argued that 'Despite the challenges involved, the well-conducted interview is a powerful tool for eliciting rich data on people's views, attitudes and the meanings that underpin their lives and behaviours'. These interviews helped me to gain a sense of the varying and comparable 
perspectives that contributors held about Global Volunteers. They were useful for gaining in-depth information from contributors and gave me the opportunity to fill in the gaps and answer questions that had arisen during participant observation. Although contributors were very willing to share, these conversations sometimes carried on for long periods of time. I was very aware that the contributors were busy people and that their time was valuable.

The 'data' obtained from these interviews were transcribed verbatim. Interview transcripts were analysed and grouped thematically. The themes and quotes from these interviews form the basis of the findings that follow.

\section{Location}

The majority of the hosts' interviews were carried out in their work places. In addition to making the hosts feel at ease, the location of these interviews enabled me to locate experiences and perspectives to a particular setting and gave me the opportunity to see where the volunteers worked. The interview location often gave me the chance to experience a glimpse into the working life of the hosts. However, the interview location meant that I had to make allowances for disruptions. It was not uncommon to experience loud background noises, ringing telephones, chickens running under the table and people interrupting the interview. I had to be flexible to the surroundings. The volunteers' interviews were undertaken in the meeting room in their accommodation. This was a comfortable and relatively quiet area where the volunteers could talk. The Country Mangers' interviews took place in their homes. This enabled the interview to be more of a natural situation.

\subsection{Recordings and attribution}

Recordings of the interviews were either handwritten or electronically recorded. The contributors' consent was always given before recordings were made. Permission to use 
the information provided by the contributors was given verbally or through a signed consent form, depending on what was more appropriate. The volunteers and hosts agreed to confidentiality. In order to retain this confidentiality, the identities of some of the contributors have been deliberately confused and code names are used. The current and previous Country Managers accepted that their views could be identified. Examples of the consent forms used are situated in Appendix Three and Appendix Four. Each of the contributors' code names and the dates of the interviews are tabled in Appendix One.

\subsection{Conclusion}

To conclude, this chapter has presented the methodology of the research. It has framed the research around a social constructivist epistemology and presented qualitative research as the central approach. In addition to a discussion of ethics and legitimacy and positionality, the chapter gave attention to the Cook Island context and Cook Island research methods. Finally, the design of the research was examined. This research methodology has set the foundation for the research findings. 


\section{Chapter Five: Research findings - "Less than a drop in}

\section{the bucket?"}

This chapter presents the voices, experiences and views of the contributors and the observations made during fieldwork in Rarotonga. In order to make sense of the findings, they have been separated into the three central themes of the research's key questions: development, culture and power. Although these themes have been presented separately, they should not be viewed in isolation. Each of these themes has overlapped and interacted with one another.

\subsection{Development or decay}

Development, then, is a complex, multidimensional concept which not only embraces economic growth and 'traditional' social indicators, such as healthcare, education and housing, but also seeks to confirm the political and cultural integrity and freedom of all individuals in society. It is, in effect, the continuous and positive change in the economic, social, political and cultural dimensions of the human condition, guided by the principle of freedom of choice and limited by the capacity of the environment to sustain such change (Sharpley, 2002, p. 27).

Development is a challenging concept to define. However, for the purpose of this study it will be understood by Sharpley's (2002) definition above. Sharpley's (2002) definition is useful for understanding development because it recognises the many layers that make up the concept. When considered more loosely, development can be defined as 'positive change' (Chambers, 1997, p. xiv). ${ }^{3}$ Accordingly, when issues of development are discussed, this research is referring to the contribution that Global Volunteers has had in bringing about positive change. Therefore, the terms, 'development' and

${ }^{3}$ Chambers (1997, p. xiv) uses the phrase, 'good change' to describe development. In this thesis, 'good' was replaced with 'positive'. 
'positive change' are used interchangeably. Within this research, this notion of 'positive change' has the potential to be perceived as being subjective and overly encompassing. However, I suggest that it captures the core of development.

This section assesses the first key question of the research: What is the relationship between the Global Volunteer programme and development in Rarotonga? While there were positive outcomes of the volunteer programme, this findings section argues that the relationship between Global Volunteers and development is inconclusive. This argument will be made through an analysis of the volunteers' contribution to development, the hosts' perspective of development, capacity development, specialist skills and the Country Managers' views of development. Following this, the determining factors of positive change will be reflected on.

\subsubsection{Volunteers' contribution to development}

As an outcome of Global Volunteers' self-identified status as a development organisation (identified in chapter three), there is an expectation that those involved in the volunteer programme would carry out development work. However, the volunteers who contributed to this study were hesitant about correlating their assistance with development. Several of the volunteers struggled to give a confident response when they were asked if they thought that they had contributed to positive change. Volunteer 1 (April 3, 2012) exemplified this ambiguity and uncertainty surrounding whether their assistance in Rarotonga had contributed to positive change:

Ummmm. Maybe. I'm not really. It's not my. I don't know if it has something to do with me but umm maybe yes. Maybe yes. I am unsure about that (Volunteer 1, April 3, 2012).

When the volunteer was asked about whether they had made a positive impact on the people that they were assisting, they were not convinced. However, the volunteer suggested that the people were not negatively impacted through their assistance: 
I hope so. I do not really feel that, but I hope so. I have not a bad feeling about it. But I don't feel like this particular person learnt a lot because of me. I think it's. I think I haven't had a bad impact (Volunteer 1, April 3, 2012).

A different volunteer suggested that the defining feature of positive change involved the creation of genuine connections between the volunteers and the locals. They implied that since these genuine connections were not made, they had not contributed to positive change:

I think someone ... who has been doing this a half a dozen times or more is making real connections with people and that's when you start to make some progress probably. Isn't it? I think it's just a wee tip of the iceberg really. I think making contact with some of the kids was quite good but I don't know if we have made any real positive change (Volunteer 4, April 5, 2012).

Another volunteer completely rejected positive change as an objective of the volunteer programme. The volunteer disputed the notion that development was part of the volunteer programme due to the small contribution that it made to Rarotonga:

I don't know that that's my goal [positive change]. I don't think that should be your goal. Like I said, you're a volunteer, you're here, it's less than a drop in the bucket on the island so how can you affect a lot of change. That's not what you are here for (Volunteer 2, April 5, 2012).

\section{Volunteers' individual and team goals}

The negative correlation between the volunteer programme and development identified above by volunteers raised the question of what the volunteers' goals of the programme were, if positive change was not a key outcome. The volunteers set individual and team goals during the programme's orientation. Each of these goals gave an indication of the volunteers' motivations for volunteering. The individual goals can be categorised into two groups: inward focused goals which were centred on the volunteers, and outward focused goals which considered the hosts. Examples of these individual goals are outlined in the table below. 
Table 3. Volunteers' individual goals

\begin{tabular}{|l|l|}
\hline Inward Focused Goals & Outward Focused Goals \\
\hline 'Start new phase in my life' & 'Give and receive skills' \\
\hline 'To make friends' & 'Engage, seek and learn with local people' \\
\hline 'Relax and be in sync with island time' & 'Laugh and play with children as we learn' \\
\hline 'To have a good time' & 'Be immersed in Cook Island culture' \\
\hline 'Challenged with new activities' & $\begin{array}{l}\text { 'Know and understand how Cook } \\
\text { Islanders live' }\end{array}$ \\
\hline 'To meet new friends' \\
\hline 'To learn (mutually) with more & \\
\hline
\end{tabular}

Source: Fieldwork Journal, 19 March, 2012.

When the volunteers conversed about their team objectives, they discussed whether 'making a difference' should be a goal. While one of the volunteers was adamant that 'making a difference' should be a team objective, two of the other volunteers discarded the proposed goal entirely (Fieldwork Journal 19 March, 2012). These volunteers advocated that being of service to the Cook Island people should be the team's priority. Both of the volunteers conveyed that volunteering was about giving without receiving rather than 'making a difference' (Fieldwork Journal, 19 March 2012). As a group, the volunteers decided to word the goal as 'to be of service' instead of 'making a difference'. The other team goals included: 'to grow in our knowledge and understanding of Cook Island people and culture' and 'to have fun'. While 'making a difference' portrayed notions of development, the other individual and team goals did not explicitly aspire towards development. 
The majority of the host organisations agreed that Global Volunteers had contributed to positive change in Rarotonga. They found that the volunteers had made a decent contribution which often had long term significance to their organisations:

I think so. Because when they don't come, the children that they help in the schools are not getting that even though it's only for a short time I think the positive impact is so much that it does make a difference. ... So if they weren't there then that work won't get done or maybe later or not so immediate ... we still have the draws or bookshelves that they did and you can see that the clinic in town is really nice done by them and at one time they were doing ramps in houses for disabled people. That's an impact for long term. So there are a lot of things that they do there's a positive impact and quite long term in people's lives (Host 13, April 2, 2012).

I think so. They have been coming for a while, so yeah. It's been great for the school kids, but it helps a lot (Host 1, April 3, 2012).

Furthermore, a few of the hosts conveyed that they hoped to reciprocate the impact that the volunteers had on their organisations:

I would like to also think that we have that impact on them as well. While we are looking at ourselves, "does that have a positive impact on us?" I think always for me that it would be nice for us to have an impact on their lives. And we must do because people write letters back or we receive a little note or card to say they enjoyed their stay. I think it has got to be a two way thing. I think it's really important that it works both ways (Host 13, April 2, 2012).

In some instances however, due to the type of people and the kind of work that the volunteers were participating in, the hosts found that the volunteers were not always contributing to positive change:

It's all about motivation and enthusiasm. Some would come and not work very hard and leave early to go snorkelling. It depends. For me, half and half. Some have been fabulous and some have been. It's really hard (Host 12, March 30, 2012).

I don't know if I would say change. No for us, maybe for some of the other projects. They have contributed to the up keep and our desire to maintain our particular area. But no major changes that they have contributed to (Host 11, April 26, 2012). 


\section{Capacity development}

The assistance that the volunteers carried out within the host organisations could usually be viewed as a means of developing capacity and maintaining the day-to-day running of the organisations rather than a substantial contribution towards development. The areas where volunteers assisted have varied between organisations but have included assistance with reading programmes and teacher aide support in the schools, accounting and finance, policy, strategic planning, legal advice and secretarial duties. Other volunteer assistance has involved more practical outcomes. In most of the organisations that I visited, the hosts pointed out different areas that Global Volunteers had played a role in implementing (Fieldwork Journal, 2 April 2012). Smaller items such as bookshelves, curtains and painted walls to bigger features such as extensive shelving and buildings were identified by the host organisations as positive outcomes of the volunteers' assistance (Fieldwork Journal, 2 April 2012).

One of the hosts agreed with this concept of capacity development by suggesting that the volunteers were useful for filling gaps in their organisation:

There are jobs like in any organisation, even if it's just menial stuff like answering the phones, helps us a lot. Sometimes we are so busy that we don't have anyone to answer our phones. Sometimes we get people and we are like right now we just need someone to answer our phone and they are so willing. Because really, they are just willing to help wherever they can, which is great (Host 2, April 2, 2012).

For the most part, the host organisations decided what type of assistance they would like from the volunteers. Even though these tasks might not be perceived as being substantial by the volunteers, the hosts found the assistance to be valuable:

Before the school year even began, I had two volunteers help wipe the books. Things get very mouldy and dusty here on the island. Their work was invaluable. It wasn't a particularly hard job to do. It didn't require extra expertise. The work could have been done without them but it would have taken heaps of time to do (Host 7, March 26, 2012). 
The 'extra hands' of the volunteers have increased the capability of the organisations. Host 9 (April 4, 2012) exemplified this capacity development role of the volunteers by conveying that, 'We embrace all our volunteers. We need the hands. So if it's not the expertise, it's the extra hands'. Although this role that the volunteers have played in developing the capacity of host organisations has not been explicitly linked with development outcomes, the hosts have valued the volunteers' assistance and benefited from the extra assistance in this area.

\section{Specialist skills}

In addition to capacity development, some volunteers contributed their specialised skills to the host organisations. Host organisations emphasised the significant contribution of these particular volunteers. Through interacting with the hosts, I gained a sense that the volunteers with specialised skills were the most valuable volunteers for the host organisations (Fieldwork Journal, 31 March, 2012). The organisations were able to freely utilise the volunteers' skills which would often be costly and in some instances inaccessible if they were to try and get them through another route (Host 12, March 30, 2012). These specialised volunteers were sought after by the hosts. Volunteer assistance gave organisations the opportunity to complete tasks which they had not previously had the resources to undertake (Host 2, April 2, 2012; Host 12, March 30, 2012).

Through the exchange of skills, volunteers were able to generate positive outcomes which had the prospect of affecting long term change. This can be illustrated by the following example of an NGO that gained core funding through a proposal which two volunteers assisted with:

You know we had a big proposal and I hadn't had much experience with doing that and we had two ladies available - one whose line of work was writing proposals and sending them out to funders and the other was on the other end who were actually part of the funding agency who accepts proposals. So it was perfect (Host 2, April 2, 2012). 
This funding proposal was not completed entirely by the volunteers. The volunteers started the proposal and further trained the host. Once the volunteers left, the organisation was able to finish the proposal themselves (Host 2, April 2, 2012). The funding gained through this proposal gave the organisation substantial finances to expand their programme (Host 3, May 1, 2012).

As a general trend, the organisations that I spoke with referred to the high need for specialist assistance. This was characterised by the following volunteer who described the lack of specialists on Rarotonga and the ensuing role of Global Volunteers in meeting this need:

When we look at the Ministry of Health as a whole, they have one physiotherapist up at the hospital. And she's got her work cut out. And there is no way that she can come down here and do any physiotherapy to our people ... We certainly don't have any speech therapists on the island. We do have an occupational therapist on the island but when we look at the clients they are expected to work with, it would take them years to get through the whole lot. And so any Global Volunteers with a specific training- we embrace it. We have got to, because they don't come around often. Because of the lack of specific skills, we need them and Global Volunteers provides. It's a huge benefit (Host 9, April 4, 2012).

When the volunteers contributed their specialised skills to the host organisations, they had the prospect of making a positive contribution to their host organisations.

\subsubsection{Country managers' perception of development}

As ambassadors of Global Volunteers, the Country Managers were enthusiastic of the positive outcomes that had occurred as a result of the Global Volunteer programme in Rarotonga. One of the Country Managers reflected on some of these below:

There has been lots of positive outcomes for the organisations, lots of positive outcomes for the children's literacy and reading and maths, science and music. It's helped the capacity of some of our NGOs in terms of things like financial book keeping, financial note keeping, and record keeping, proposal writing and actually giving them the capacity so that they can actually move forward with 
proposals and funding. So there has been lots of positive spin offs for Global Volunteers in the Cook Islands (Manager 1, April 15, 2012).

Country Managers held a holistic perspective and appreciated growth in areas such as relationship building and cultural understanding (Manager 2, March 29 2012). One of the Country Managers identified that even if the changes were not visible, it did not mean that positive change was not taking place:

Even if the actual physical project wasn't growing, the relationship building and understanding between cultures was always building and expanding. And for Global Volunteers, I think that is a number one priority. So, it's good, definitely a positive overall (Manager 2, March 29 2012).

Country Managers could see the changes which took place over a longer period. Throughout the volunteer programme, the current Country Manager consistently reminded volunteers that they were part of a longer chain of volunteers that had served on Rarotonga (Fieldwork Journal, 18 March 2012). As a result, the Country Manager perceived the programme as, 'A sustainable effort of service to Cook Island people and children' (Manager 1, April 15, 2012). This perspective was reiterated by a previous Country Manager:

I always tell them [volunteers] that you might not see the difference but you are helping to put a little drop in a bucket and eventually the bucket is going to overflow and change is going to happen and people's lives will be improved (Manager 3, March 29 2012).

According to another previous Country Manager, although big changes were not always made, the outcomes of the projects were always positive and moving forward:

As Country Managers, you might get disheartened because there might not be big changes from year to year. The projects would be ticking over and almost the same and not really growing at a rate that we might have had the vision for but it was always something positive. I don't believe there was anything backwards (Manager 2, March 29 2012).

While the Country Managers had a broader outlook of the volunteer programme and could acknowledge and appreciate the positive outcomes that had taken place over a 
longer period of time, these outcomes were not substantial to the point that they could be regarded as development outcomes.

\subsubsection{Influencing factors of positive change}

The contributors to this research highlighted a number of factors which influenced the potential for Global Volunteers to contribute towards positive change. These influencing factors included: the duration of the volunteer programme, the substance of the programme, the responsibility and capacity of host organisations and Global Volunteers, the extent to which the volunteers were seen as being burdensome and the need for volunteers.

\section{Duration of volunteer programme}

The short timeframe of the Global Volunteer programme in Rarotonga infringed on Global Volunteers' contribution towards positive change. The consensus among the volunteers was that the two or three week timeframe of the volunteer programme was far too short for positive changes to be made. Volunteers conveyed that development could only take place if the duration of the programme was much longer, which would enable volunteers to be more 'embedded' in the local context:

You can't really be effective in three weeks, and if you want to do that perhaps you need to go somewhere for a few years and get embedded in the thing. That is the challenge for me now (Volunteer 4, April 5, 2012).

Another volunteer agreed that a longer volunteer programme would be desirable but it would be difficult to attract the volunteers:

Definitely better longer but I don't think many volunteers would be able to spend that much time - there is the expense, timeframe ... I think it would be hard to make it longer (Volunteer 5, April 11, 2012).

The views of the volunteers paralleled the perspectives of the host organisations. The timeframe of the volunteer programme infringed on the opportunity for the organisation to make good use of the volunteers: 
I think the only thing that I would be able to take advantage of Global Volunteers is that they are here for a little bit longer, whether it be up to four weeks or longer. Then we could definitely use them. With some of our projects, it doesn't really give them enough time to really do something and be here long enough to see it work and be here when it is being implemented.... If they are here a little bit longer, then we would be more willing to do more in-depth work with things that need to be done (Host 2, April 2, 2012).

The host organisations agreed that if the volunteers were assisting for a longer period, they would have the opportunity to make a more useful contribution (Host 2, April 2, 2012; Host 11, April 26, 2012; Host 12, March 30, 2012; Host 14, April 24, 2012). This view was expressed by a host who stated that despite having a lot of pressing projects; volunteers were often given alternative tasks because they were not with the organisation for a long enough period for the work to be worthwhile (Host 14, April 24, 2012). Other hosts reinforced this perspective:

There is some work that I can't give them because by the time we have taught them it's time for them to go back so it's not beneficial to us (Host 11, April 26, 2012).

By the time I train someone to do something, and if they don't learn it right away and I've trained them it's taken up my whole day and then they go home so it's not worth it (Host 12, March 30, 2012).

\section{Substance: "I've been training, I'm an apprentice volunteer"}

The intensity and type of work that the volunteers participated in influenced their assessment of whether they thought that they had contributed to development in Rarotonga. Volunteers alluded to the lack of substance within the Global Volunteer programme, with one volunteer describing the programme as 'work experience' rather than actual volunteer work (Volunteer 4, April 5, 2012). When reflecting on her time at the hospital, another volunteer conveyed that while she was able to experience what it is like to be a nurse in Rarotonga, she did not participate in any 'real' work (Fieldwork Journal, 27 March, 2012). These remarks give the impression that the volunteers did not consider their assistance to be substantial. The volunteer quoted below stressed this concept of work experience: 
I guess I do see that we are really only doing work experience - well that's how I felt. I guess if I had been on one work project for two to three weeks you might take two to three days to familiar yourself and make progress but I sort of bounced around from one project to another so you only really seem to get a sense of what's being done in a little inkling ... I've been training, I'm an apprentice volunteer (Volunteer 4, April 5, 2012).

This notion of work experience was connected to the fragmented style of volunteering and tasks that were given to this particular volunteer. While this was not necessarily the experience of all volunteers, this particular style of volunteering denied the possibility of the programme's contribution to development.

\section{The responsibility of host organisations}

The responsibility to utilise volunteers rested with the host organisations. The host organisations were responsible for ensuring that volunteers were effectively informed, resourced and managed. The attitude that host organisations had towards the time and effort that they were willing to contribute towards the volunteers influenced the usefulness of the volunteers' work. A previous Country Manager emphasised the significance of the responsibility that the hosts had towards the volunteers:

It's actually a bit of work on their part. Because they have to give up some of their time to do a bit of training and explain exactly what they want done. You can't just necessarily go; "OK, I want you to do this". Well how do I do it? (Manager 3, March 29 2012).

In some instances, it was recognised by the Country Managers that the responsibility of the volunteers was not adequately carried out by host organisations. This was attributed to the hosts' lack of enthusiasm in using the volunteers:

I wish that the local people were more enthusiastic about making good use of the volunteers. Because we had some really good community partners who made really good use of the volunteers and were helpful, there were other ones who had just quite large needs and could take advantage of the volunteers and use them but just getting them to have the enthusiasm to do it. It does take time to welcome the volunteers in and orientate them and they are only there for three or four weeks, so for community partners it's actually a difficult thing (Manager 2, March 29 2012). 
According to the Country Managers, positive changes were more likely to occur when the host organisations put effort into the volunteers. When the hosts took responsibility for the volunteers, they were able to reap the benefits of the assistance:

For me, I always thought it would be really good if the community partners could see the advantage that they are gaining by taking that time to train the volunteers and use them well. Because the schools and organisations that did take them in and train them and use them well, they got the benefit from it (Manager 2, March 29 2012).

The capacity of host organisations to maintain responsibility of volunteers influenced the extent to which the volunteers were utilised. The organisations that had a deep need for volunteers did not always know how to effectively make good use of the volunteers. This was particularly true when volunteer projects were still being established (Manager 3, March 29 2012). In contrast, organisations that did not necessarily have a high need for volunteers often had the capacity to make good use of them (Fieldwork Journal, 29 March, 2012).

The impact of the host organisation's capacity on the volunteers' work can be exemplified through the following example. On arrival at the host organisation, a volunteer was given a box of resources without any instruction of what they ought to do with the resources (Volunteer 2, April 5, 2012). Limited information was given to the volunteer about what they needed to carry out:

I don't think you can give any educator a box with children's notes about their behaviour, their educational issues and then walk away. I mean that just floored me that that was what was expected, that I would know what to do from then forward. I had no idea what curriculum they used, what reading books they used. I didn't even know if I was to develop a new programme or what. I was told here it is and then you are going to work in the library ... I was definitely told by the administrator that everything was in the box. Well everything was not in the box. And so I needed more guidance (Volunteer 2, April 5, 2012).

This lack of management was particularly significant as the organisation was lacking in the specific area that the volunteer had knowledge and experience in (Volunteer 2, 
April 5, 2012). Another volunteer expressed their concern with the lack of organisation by both the host organisation and Global Volunteers:

There really needs to be a close link between what the teacher is doing and what we are doing and we need to discuss that and then we've got a framework to be working in. And I'm not a teacher myself so I don't really know how they would do it but it just seems logical that they are supporting the other teaching programme rather than just working on stuff that you think is interesting ... It was almost left to the last moment virtually until we knew what we were doing next (Volunteer 4, April 5, 2012).

This situation contrasted with the experiences of a different organisation that Global Volunteers gave assistance to. When volunteers arrived, they were given a full brief of the work before they started their tasks (Fieldwork Journal, 20 March, 2012). The volunteers knew exactly what to expect, the resources that were available and the background of the students that they were working with (Fieldwork Journal, 20 March, 2012). As an outcome, the volunteers were able to be effectively utilised. This connoted the importance of the host organisations taking responsibility for the volunteers.

\section{Responsibility of Global Volunteers}

Much of the responsibility of the volunteers is held by Global Volunteers. During the fieldwork, I gained a sense that the management of the Global Volunteer programme, by both the head office and the Country Managers had weakened. The general feeling that I received from the volunteers was that there was a deep lack of organisation by Global Volunteers. This lack of organisation ranged in scope, but involved the volunteers not having enough food to prepare their lunches, the Country Manager providing insufficient information about the volunteers' schedule, inadequate transport to projects and limited information about the type of projects that the volunteers were working on (Fieldwork Journal, 31 March, 2012).

Based on the observations, there was not a good connection between what took place at the local level with the information that the head office provided to the volunteers. In 
some instances, out-of-date information was given by the head office which led volunteers to arrive on the island with expectations which did not match reality:

You are expected to be flexible. However, everybody has a responsibility. No one knew when the schools were going to open in January. So in January when the first team arrived, the schools weren't opened. So no schools, no people back on the island, they were still away on holiday. People were fitting here, there and everywhere. So already its putting people at a disadvantage when you come to volunteer and your first week is spent washing, cleaning- what you weren't expecting to do (Volunteer 5, April 11, 2012).

From the volunteers' perspective, the programme orientation and subsequent instruction by the Country Manager was insufficient. As a result, many of the volunteers felt like they were not supported nor adequately prepared to volunteer on their work projects (Volunteer 1, April 3, 2012; Volunteer 2, April 5, 2012; Volunteer 4, April 5, 2012; Volunteer 5, April 11, 2012).

\section{The burden of volunteers}

Although volunteers were inherently viewed as a valuable asset, the host organisations sometimes referred to the volunteers as being burdensome. This was due to the time that it took to explain tasks, to build relationships and to make resources available for the volunteers. One of the hosts indicated that there were instances when it was not necessarily a convenient time to host volunteers. This led to the volunteers being viewed as a burden:

Sometimes it can be a bit of a pain for us sometimes, especially when we are busy. We are like, "oh damn the volunteers are coming oh". You know, sometimes you've just got to force yourself to make time. Sometimes it's great timing, other times it's not so great timing. You try and make the most of them anyway (Host 2, April 2, 2012).

As previously outlined in chapter three, the Global Volunteer programme requires the hosts to work 'hand in hand' with the local people (Global Volunteers 2012). This means that for every volunteer assisting in a project, a local person is obligated to work alongside the volunteer. While this approach is useful, the hosts suggested that the 
policy puts pressure on their organisations. This was particularly significant for some of the smaller organisations where staff numbers were often low and the organisations were reliant on local volunteers who were only available after regular work hours (Host 1, April 3, 2012).

\section{The need for volunteers}

Host organisations did not express dependence on Global Volunteers. The common theme among the hosts was that they could function fine without the volunteers and that the quality of their services would not suffer if volunteers did not assist (Host 4, March 22, 2012; Host 5, March 23, 2012; Host 8, March 26, 2012; Host 9, April 4, 2012; Host 13, April 2, 2012). However, the hosts suggested that if volunteers were available, it made sense to use them (Host 5, March 23, 2012):

The work is going to get done if the volunteer is not there but maybe slower, not now. Maybe a couple of weeks from now it will eventually get done when they get around to doing it. But having it done when they are here is a better option of course to get it done now. [We are] Not dependant but appreciative of what they do (Host 13, April 2, 2012).

We do, we have to [function without volunteers]. But when we get them it's a sigh of relief. It's great that we can learn from this person. It's helpful ... it's a sigh of relief to get them to come and help out (Host 1, April 3, 2012).

If they are available, it is an advantage to the schools to use them. We may as well use them. The volunteers release the pressure from the teachers who are already under a lot of pressure and have a big workload. It is a great thing that the volunteers are involved (Host 6, March 26, 2012).

Country Managers viewed the locals' attitude towards volunteering as a hindrance towards the Global Volunteer programme no longer being needed in Rarotonga. They suggested that it was highly unlikely that Rarotonga would get to a position where volunteers were not needed:

I think there is so much need here. There's always need for volunteers ... It would be good if they would work themselves out of a job to the point where the community don't need anybody else to come in. It would be wonderful if local people learnt here to volunteer more but it's so expensive to live here that if 
people realise that they have time to volunteer then they've got time to get a job and make money ... then after hours everyone has got their cultural things, church things or family ... So I don't think that here in the Cook Islands at least that there would never be a need for volunteers. I think there is always going to be (Manager 3, March 29 2012).

While another Country Manager was hesitant about the whole island getting to the stage where Global Volunteers were no longer needed, their goal was for the individual projects to be self-sufficient:

The aim I suppose for me was to have projects that would continue on with locals only, but that enabled the next lot of volunteers to go on into new projects ... there is always different projects to do and if we can teach locals to continue a project and allow volunteers to go to a new one that was always a good thing. I'm not sure about working completely volunteer free. That would be quite a big thing (Manager 2, March 29 2012).

The views of the hosts and the Country Managers regarding the need for volunteers was particularly significant due to the reduced size and scope of the Global Volunteer programme in Rarotonga since the global financial crisis. Host organisations recognised the decline in volunteer numbers, with one host suggesting that the Global Volunteer programme in Rarotonga was dying out (Host 10, March 29, 2012). Although the focus in Rarotonga was to rebuild the programme (Manager 1, April 15, 2012), it was important that the impact of having fewer volunteers on the Rarotongan programme was considered.

This section has assessed the relationship between development and the Global Volunteer programme in Rarotonga. There were a range of positive outcomes of the Global Volunteer programme, particularly involving capacity development and specialised skills which volunteers brought to host organisations. However, the extent to which Global Volunteer's work could be considered development was unconvincing. There were a number of factors which limited the programme's assistance from making a contribution towards development in Rarotonga. 


\subsection{Power to the people}

Somewhere in the world, a child needs your help. Who needs something you know how to do. Who needs a week or two of your time, and their life's arc will be forever changed.

As a Global Volunteer, you'll become significant in ways you could not imagine. You'll travel. You'll engage a foreign culture. You'll put your personal skills to work nurturing, teaching, feeding, planting, building, shaping and often saving children.

You will leave your mark on the world. And the world, in turn will leave its mark on you (Global Volunteers, 2012).

The above quote was taken from the homepage of the Global Volunteers website. There are clear assumptions embedded throughout these words which challenge the equal balance of power between the people involved in the Global Volunteer programme. Power can be defined as, 'The ability to achieve certain ends' (Johnston, 2000). Allen (1997) identified three conceptions of power: power as an inscribed capacity, power as a resource and power as strategies, practices and techniques. Each of these conceptions of power are useful for understanding the different dimensions of power within the Global Volunteer programme in Rarotonga.

This section will address the findings which relate to the second key question of the research: What is the nature of power within the Global Volunteer programme in Rarotonga? These findings will be framed around the power of each of the groups involved with Global Volunteers in Rarotonga, including; Global Volunteers as a sending organisation, the volunteers and the hosts. This section presents Global Volunteers as the most powerful group within this relationship but recognises that each of the other groups hold varying degrees of power at different times. Throughout this section, the complexity of power within volunteer tourism is exposed. 
As the sending organisation, Global Volunteers has the strongest level of influential power over the volunteer programme in Rarotonga. The organisation has the power to determine who can participate, to define the focus and to control the standards of the programme. As a result, the organisation possesses the largest potential to bring positive outcomes or to cause detrimental consequences for each of the groups involved.

\section{Choice of participants}

Global Volunteers has the power to choose who can participant on the volunteer programme in Rarotonga. This has significant implications for the host organisations. The requirements (or lack of requirements) which Global Volunteers adheres to when deciding if volunteers are suitable for the Cook Island programme plays a big part in determining the value of the volunteer assistance to their hosts. Global Volunteers holds the power and responsibility to ensure that participants have the necessary background, skills and health requirements to be involved in the programme.

The application process is described by Global Volunteers as being 'fast and easy' (Global Volunteers, 2012). Once the volunteers have selected the programme that they wish to participate in, they are asked by email about their physical condition, why they wish to volunteer and about their background. The volunteers are required to provide three references to Global Volunteers who are emailed a set of questions to answer. From this information, Global Volunteers decides whether the volunteers are suitable participants (Global Volunteers, Personal Communication, 5 September, 2012).

Apart from the personal emailed references, there are no formal background or health checks carried out by Global Volunteers before participants have been selected to volunteer; despite the central focus of the Cook Island programme being situated 
around work with children in the local schools. One of the contributors to this research discussed Global Volunteers lack of selection criteria in this area:

It's almost like you want to volunteer. It doesn't matter who you are, what your skills are, you could be a child molester back home because there is no background [check] - and you are thrown into a school. Whether you speak English well, whether you are a farmer back home or whatever - you are thrown into a school ... and the principals and teachers are expected to give you something that will fulfil your desire to volunteer (Volunteer 5, April 11, 2012).

The following two situations emphasised the lack of standards required by Global Volunteers before volunteers were accepted to participate on the volunteer programme. In these situations, the English level and the age of the volunteers were not adequately considered by Global Volunteers:

How could she [volunteer] have been accepted to teach in the schools? It's not right. Just because they're people in the Cook Islands, it doesn't mean that anybody that doesn't speak English can teach them. That to me is offensive. Like her, we have people over eighty and then they are in all of the newspapers back in the States, "Oh look at this wonderful lady"- they don't know what an inconvenience that lady, wonderful old lady was to the rest of the group. When she got lost, nobody had a clue where she was. When she can't make it on the bus- that the bus driver switches off the bus, comes down, helps her up. ... It is wonderful that she wants to volunteer. But she should walk for five minutes around the corner from where she is living, I'm sorry ... It's just not fair. It's not right. It's just not right (Volunteer 5, April 11, 2012).

The significance of accepting suitable participants was recognised by the following host who shared her view about the preferential age of the volunteers:

I like it if the volunteers are not too old. I want them to be a good age. When they are too old, it is hard for them to cope with the children and have the energy to keep up with the children. They need to be able to walk. ... When they are too old, the volunteers cannot fit with our school programme. The younger ones are more energised (Host 8, March 26, 2012).

One of the volunteers identified that they lacked qualifications for the programme but detached the responsibility from themselves and onto Global Volunteers:

I do not speak English very well. I do not have an educational studies or nothing like that. I even don't have children. I have no idea how to educate children or 
how to behave. I mean I was really like a green horn, I was a very very beginner. So, but I was sure that the people who invited me to come or the people that decided that I could come knew about the skills that I did not have. Therefore I was not so afraid. I mean, I was so nervous. I was unsure if I can handle it but at the very end I had to say, I mean, they should know it and this is not my problem (Volunteer 1, April 3, 2012).

This particular volunteer recognised that the power ultimately lay with Global Volunteers to determine their adequacy for the volunteer programme in Rarotonga. Global Volunteers had the responsibility to determine suitability.

\section{Focus of the programme}

The focus of the Global Volunteer programme in Rarotonga connoted the comparative power of the organisation over the host organisations. Although Global Volunteers suggested that they worked, 'At the invitation and under the direction of local community partners', Global Volunteers had the power to determine the focus area and to set the agenda of the organisation (Global Volunteers 2012).

Despite the assertion that they are working under the direction of the local people, Global Volunteers have promoted technology, such as 'Earthbox planters' and 'Tippy taps' in Rarotonga. Although this technology has not yet been implemented in Rarotonga, the CEO of Global Volunteers discussed the possibility of incorporating the technology into its activities with the hosts on his last visit to Rarotonga (Host 5, March 23, 2012). The possible implementation of this technology revealed the comparative power differences between Global Volunteers and the local organisations in Rarotonga. Some hosts did not agree with this change in focus, suggesting that it moved away from what they valued about Global Volunteers (Host 5, March 23, 2012). The following contributor discussed the friction between the locals needs and Global Volunteers focus:

I see Global Volunteers focusing on agriculture and water but there is no need for it here. So basically it is very OK to do in Africa in certain areas but you do not need food and water here ... So I don't see there is that need here for 
showing people how to grow their back garden, for getting people to use less fresh water. They have taps all over the schools- so why would you have a carton to wash your hands when you can open up a tap? They are concentrating on things that do not apply to here. So that's why I see there is a little bit of friction between the needs of the people here (Volunteer 5, April 11, 2012).

The approach that Global Volunteers has taken at all levels of its operation has given an indication of the organisation's attitude towards power. Global Volunteers use of power from a leadership perspective can be conveyed through an outlook of the CEO's recent visit to the Cook Islands:

As head of a volunteer organisation, he did not even take the time to visit where the volunteers spend their time. I mean, how can you be the head of an organisation and not know how many have come on the island? Not know what they are working in? I don't want to hear how busy you are, I don't want to hear how many countries you are working in. ... What are you going to be doing for the Cook Islands? Where are your volunteers? Where do you place them? What are they working at? How can you not thank the local people? How can you not visit with them? ... And when you approach him, he had no idea about the volunteers - when they were coming here, what they were doing, what kind of programmes they were involved in ... And that to me was shocking (Volunteer 5, April 11, 2012).

Global Volunteers holds the power to decide how its programmes are monitored and evaluated. There have been no formal evaluations of the Global Volunteer programme in Rarotonga. This lack of evaluation is discussed by the following contributor:

OK I mean, 127 teams coming here to the Cook Islands is wonderful. However, you look at how many people have gone through and you say how many people have been empowered by it? And is it all really work for the people of the Cook Islands? Was it work done with the local people? You see, nobody does their homework, there is no research done, there is nobody that has ever said OK, out of all of the volunteers that went here, what has been accomplished? After all these years, somebody needs to have done it and that's what I thought why the $\mathrm{CEO}$ was coming here. To kind of figure out, OK what can we move onto next? (Volunteer 5, April 11, 2012). 


\subsubsection{The power of the volunteers}

The power which is held and expressed by the volunteers is a significant element of the Global Volunteer programme in Rarotonga. The individuals that participate on the programme inherently hold power right from the beginning. The volunteers are distinguished from mainstream tourists and have the ability to engage in spaces which are usually inaccessible to visitors to the island. Power is not evenly distributed among the volunteers. There are some individuals who exude their power more openly than others. As an outcome of the power differences between the volunteers and their hosts, this has resulted in some hosts being intimidated by the volunteers.

\section{Inherent power}

By being in a position to volunteer and making the choice to volunteer, those that participate on the Global Volunteer programme are presented with a mantle of respect by the locals. This can be linked to Allen's conception of power as an 'inscribed capacity'. One of the Country Managers expressed this view:

I'm just always amazed that people have paid money and also paid for air flights to come here and give two weeks of work. I think that speaks volumes about the type of person that comes here and volunteers (Manager 1, April 15, 2012).

Before the volunteers have even carried out any work or met their hosts, they are identified as reputable people. Although this is not necessarily an incorrect acknowledgement, it enables the volunteers to hold a degree of power based on the assumption that all people who use their time and money to volunteer are inevitably respectable people. As an outcome, the hosts sometimes view themselves as being inferior to the volunteers. This can cause the local people to put the volunteers' needs above their own:

They [local people] will never say that they are not happy. Because even when they are insulted, they always feel that the foreigner is right. They have that feeling that people are better than them. These people that come, they respect the fact that the people that have come from so far have given up their time, spent their own money so they will never say, "these volunteers are useless" or 
"I cannot work with these volunteers" or "I have nothing to give them to do" (Volunteer 5, April 11, 2012).

While those that participated on the Global Volunteer programme identified themselves as both volunteers and tourists, the host organisations predominantly recognised them as volunteers. This identification influenced the level of power held by the volunteers. By being a volunteer, participants were able to engage with locals in spaces which were largely inaccessible by mainstream tourists. One of my fieldwork journal entries expressed this thought:

As I was driving past the school this morning, there were a few kids from my class that recognised me and waved to me. They had big grins on their faces. I can see why the volunteers would want to have this experience. I feel like I am more than a visitor. There is no way that I would have been able to have this experience as a regular tourist (Fieldwork Journal, 21 March, 2012).

Country Managers recognised participants of the Global Volunteer programme as volunteers rather than tourists. One of the Country Managers strongly disagreed with the volunteer tourism label of the programme and insisted that the volunteers were on the island to work (Manager 1, April 15, 2012). Another Country Manager suggested that it was important that each participant did not feel like a tourist:

I really wanted them to not feel like a tourist. I only had one volunteer who told me that she didn't felt like she really got to know anybody. Most people that come are immersed into the culture; get to know people quite well - even if it's having a cuppa tea in the break room at the school or wherever they are working. And they go to the market place and they recognise a whole bunch of people there on a Saturday morning, so they actually feel like part of the family or part of the community (Manager 3, March 29 2012).

By enabling a volunteer experience rather than a 'regular' tourist experience, the hosts gave participants access to their personal space. As a result, there is the prospect of volunteers using their access to this space to push their own agenda. However, host organisations and Country Managers found that this rarely occurred:

Every now and then you would get a volunteer come in big and brash, "I'm a big American who can come in and do anything and go anywhere", and you 
would have to tone them down. Most of the time they were OK, they were good volunteers (Manager 2, March 29 2012).

\section{Individual agency}

The demonstration of the volunteers' power often depended on the nature of individual volunteers. Some individuals were more open than others in promoting their influence which affected how the volunteers' assistance was carried out. The following contributor discussed this idea by portraying that some volunteers were more proactive than others within their work projects:

There are the ones that will always find a way, they have it in them, you know nobody approaches them, and they will go around, talk to people, trying to find something to do in a school. Then there are the ones that sit there in a dirty library fixing the books day in day out, day in day out. Then of course they are going to be disappointed. Of course they are upset (Volunteer 5, April 11, 2012).

The power held by the volunteers and hosts was not always evenly balanced, often due to the comparative education of each group. This imbalance of power between volunteers and their hosts can be exemplified by one of the previous Country Managers who contested that in some cases, the volunteers caused the locals to feel intimidated. This influenced the type of relationship that locals had with the volunteers:

Sometimes the locals would feel like they were less skilled or maybe feel intimidated by some volunteers. Or even just due to the fact that some of the volunteers were often very well educated. And so it would take a while for them to warm to the volunteers and vice versa to the point where they can work alongside each other. In orientation, we always tell the volunteers to not expect too much and to not come in and tell the locals what to do. You need to be working under their direction and beside them and that's fine but then from the other side the locals also need to recognise that the volunteers are there to work with them and that was another thing that we had to continually do is remind the locals that they are here to work beside you and they are not going to tell you what to do. They are not lorded over you, well hopefully not (Manager 2, March 29 2012). 


\subsubsection{The power of the host organisations}

The hosts and the volunteers work closely with each other throughout the programme. Since the volunteers are situated in the hosts' workplaces, the hosts are in the position to hold control over the volunteers. The hosts retain control over the volunteers through an initiation process and through determining acceptable practice within their organisations. Although the hosts are not necessarily aware of the power that this responsibility entails, it has significant implications for the Global Volunteer programme in Rarotonga.

\section{An initiation process}

The previous Country Managers portrayed that the hosts sometimes took the volunteers through an 'initiation process' where they would wait for volunteers to prove themselves before the volunteers were properly welcomed into the hosts' organisations. This initiation process promotes the assertion of the hosts' power:

They will often sit back and wait to see the volunteers prove themselves before they show appreciation. That's what I kind of felt. And it seemed to be repeated all over to the different groups that the locals would invite them and welcome them on the first day like Islanders would but in terms of working alongside of them they won't necessarily make the volunteers feel welcome until the volunteers have sort of proved themselves (Manager 2, March 29 2012).

Yeah I kind of got that too. And I think it's to do with the shyness. Even though they are used to having volunteers they are not used to having these particular volunteers (Manager 3, March 29 2012).

The outcome of the host organisations' initiation process can be expressed through the experience of the following volunteer who did not initially feel comfortable about asking their host organisation for assistance:

Literally it took me until Thursday of that week before I had a clue what I was doing because I finally could ask the teachers which I didn't feel that I could do (Volunteer 2, April 5, 2012). 


\section{Acceptable practice}

The hosts determined acceptable practice during the volunteers' time with their organisations. This gave the hosts power over the volunteers. This can be demonstrated through the following illustration where one of the volunteers felt unsafe assisting a patient with Tuberculosis at the hospital with an inadequate mask but did not do anything about the situation because they did not want to step out of line with the host:

At the hospital ... there was a person who had active Tuberculosis. I was trained about how infectious it is, but the way they dealt with it at the hospital was substandard so it was kind of scary. The little masks that they used to wear to go into the patient were insufficient and they had a small supply of more adequate masks that they weren't using. The nurse that I was working with said that her supervisor had to say that it was OK to use those masks and they were just sitting in the office. I did go into the room with the little mask and it was uncomfortable. I didn't feel OK about being in there for very long. So I didn't ask if I could use them because it wasn't offered to me so it seemed like it was in this. I was just working with the nurse that I was assigned to work with and going with what she said, I didn't want to step out of her realm (Volunteer 3, March 28, 2012).

In addition to the power differences between the volunteer and the assigned nurse, the above example indicated that the volunteer had to work within the hospital's larger power structure that the local staff were working under. It was up to the supervisor to give the nurse permission to use the adequate masks. This situation connoted the complexity of power between the volunteers and their hosts.

This section has given attention to the differences in power between Global Volunteers, the volunteers and the hosts. Although it has been recognised that Global Volunteers has absolute power over the volunteer programme, it has acknowledged that the other groups involved are not entirely powerless. Each of these groups had the capacity to hold a degree of responsibility and authority over certain areas of the programme. These findings have shown that the assertion of power is not straightforward. Power has been presented as being complex within volunteer tourism. 


\subsection{The collaboration and clash of culture}

It's lunch time. We are sitting in the school staff room, about to share a lunch of corned beef, cabbage and noodle stew with bread rolls. The teachers start digging into the food with their hands. One of the volunteers asks me in a hushed tone, "Where are the knives and forks?" I shrug my shoulders and with the lead of the teachers, eat a stew for the first time with my hands (Fieldwork Journal, 22 March, 2012).

The above fieldwork journal entry illustrates an example of a typical situation that volunteers experience in Rarotonga. Despite the seeming normality of eating lunch, this practice is embedded in culture. Notions of sharing food, the ways in which the eating takes place and the types of food that are shared are elements of cultural identity. Since the volunteers are situated in the locals' workplaces, they have many opportunities to interact and engage with a culture that is different to their own. Each volunteer and local person brings their own culture to the 'table' within these interactions.

Culture is an intrinsic part of our being. It is in our values, our beliefs and our identity. It is in the way that we express ourselves and in the language that we speak. Jonassen (2003, p. 127) defined culture as, 'The total way of life of the people: a living, dynamic and ever-growing entity. It incorporates notable interpretations of human actions including both expressive arts and ceremonial activities'. Wichman (2003, p. 143) suggested that 'Culture is the way we live, look, interact and communicate. It is how we want to portray ourselves as individuals, as groups, or as a nation, locally and internationally'. Our culture follows us everywhere. We cannot detach it from who we are.

This final part of the chapter situates the research on the third key question: What role has culture played within the Global Volunteer programme in Rarotonga? By focusing on the collaboration and clash of culture within the Global Volunteer programme in Rarotonga, it is argued that volunteer tourism is both useful and detrimental for 
promoting cultural understanding. This can be observed through instances of cultural collaboration which demonstrate cultural exchange and attitude change. Additionally, it can be shown through instances of cultural clashes where negative expectations and comparisons, a learning process, outsider policies, and language and translation issues have revealed cultural conflict. The importance of the Country Manager's role as active cultural translators is viewed as a priority.

\subsubsection{Culture collaboration}

The collaboration of culture can be described as a process where people from more than one culture come together to work towards a shared outcome and draw on elements of each other's culture as part of that interaction. In the case of Global Volunteers in Rarotonga, the volunteers and the hosts collaborated culturally as they worked with one another on the various work projects.

\section{Cultural exchange}

Most of the volunteers and hosts who contributed to this research suggested that the hosts' culture was more explicitly shared than the volunteers' culture. However, this was not portrayed as being a negative part of the volunteer programme. For the most part, the volunteers recognised that the sharing of their own culture was not a major aim or goal of the volunteer programme or their time in the Cook Islands. Nevertheless, the volunteers and hosts naturally shared their culture as they work with each other. This notion of cultural exchange can be demonstrated through the words of the following contributors who conveyed that culture naturally flowed throughout their relationships and conversations with each other:

When we are working together I talk about culture, I talk about history ... One group that was with me for pretty much three weeks, we put an Umu down together. The conversation is not always one way from me. I'm interested in what they are doing. Yes, I do have genuine interest in who they are and where they come from. It's two way (Host 11, April 26, 2012). 
The exchange of cultures is always there and that's a good thing. And we learn from that too, you know all the experiences that they [volunteers] bring here (Host 2, April 2, 2012).

There is a good exchange between volunteers and students. Students and staff share their culture with the volunteers. The volunteers enjoy the local food in the staff room. They try to participate and adapt. They want to know more ... Volunteers share their own culture. They tell the students and staff where they come from and what the country is like. They bring photos and letters and they have a chance to explain what it is like where they come from (Host 8, March 26, 2012).

The perspectives of the above contributors connoted an exchange of culture which occurred naturally. While the Global Volunteer programme set the platform and initiated the interaction between the volunteers and the hosts, each of the groups involved used the opportunity to culturally collaborate with one another.

\section{Attitude change}

The building of relationships between the volunteers and their hosts has positively altered the existing attitudes of both groups. As volunteers and hosts work closely with each other, they were able to contextualise their thoughts and had the opportunity to gain a deeper understanding of each other's cultures and backgrounds. In some instances, pre-existing attitudes were challenged through this collaboration. One of the volunteers demonstrated this argument through an "oops" experience that tested her earlier views of Cook Island parents' attitudes towards education:

What surprised me a lot was that I thought that other parents or adults should be a little more concerned about education. So, I was really surprised when the school had parent teacher meetings and the next day they were happy because nearly every parent joined this meeting at school. And that was a kind of a oops. Children's education must be one of the first priorities for parents or for the ones that have to look after the children. So that was a little bit surprising for me (Volunteer 1, April 3, 2012).

In addition, the collaboration between hosts and volunteers gave opportunities for the hosts pre-existing views of the volunteers to be challenged. This opportunity was 
illustrated through a host who worried about how the volunteers might react to the conditions of the Islands, suggesting that, 'Sometimes you feel that they [volunteers] might be a bit stuck up, but they are not you know. Volunteers are giving people so it just makes sense that you don't have to worry about things like that' (Host 2, April 2, 2012).

Alternatively, in some situations, pre-existing ideas were so embedded within the volunteers' worldview that it was difficult for their prevailing mindsets to be altered through their new experiences. To illustrate this, one volunteer presented their views of education:

I don't think most of them feel that education is important, maybe it isn't for most of them, if you are going to stay here. Education is really critical if you want to make a difference, if you want to go outside in the world and if you're ambitious and want to make a change. ... The seeking of education doesn't seem to be strong here. You can lead a horse to water but you can't make them drink. And maybe it isn't, you know. Maybe you need to assess what you mean by education. ... I think there is a lot of people here who feel that they are very successful and learn very little. They probably didn't go very far in school and they are very happy so who's to say that they are not successful. So again you need to assess where you put your emphasis. Because I'm not sure there is a lot of training programmes here if you want to go on to university you have to go off the island so that takes you away from the island and how many come back? (Volunteer 2, April 5, 2012).

The attitude change occurred when the volunteers and hosts worked alongside each other. It came about when individuals of each group had experiences which challenged their pre-existing understanding of one another. These experiences usually arose naturally during day-to-day interactions. They were not manufactured by Global Volunteers.

\subsubsection{Culture clash}

As a general trend, both the hosts and volunteers widely agreed that there were no major areas of cultural conflict between each group. Even so, the differences in culture 
have played a role in creating diverse experiences. These differences have brought about instances of culture clash.

\section{Volunteer expectations}

Cultural clashes arose when volunteers arrived in Rarotonga with individual expectations that did not match reality. A previous Country Manager of the volunteer programme exemplified the significance of volunteer expectations by suggesting that the attitude that volunteers came with on arrival to Rarotonga influenced whether they would be disappointed or not, 'If they come with the right attitude to give and not necessarily expect anything back or come with an open mind and no expectations then they wouldn't be disappointed' (Manager 3, March 29 2012). The Country Manager was not afraid to have the following conversation with the volunteers during the initial orientation:

If you are expecting this to be just like it is at home back in the States where you have got all these things at your fingertips, you know you should have stayed home, don't bother travelling because it's going to be completely different. We don't have the same resources and things aren't as easy here so you just have to make the most of what you have and learn to utilise what you have' (Manager 3, March 29 2012).

Unfulfilled expectations caused some volunteers to be apathetic towards their surroundings and to miss the existence of the 'silver lining' during the volunteer programme (Manager 3, March 29 2012). This point was illustrated through the story of a volunteer who quit the programme after the first couple of days because he did not feel appreciated by his hosts:

I'm like but you've only just got here, what were you expecting? Because we don't really say thank you until the end so you are kind of missing out because you have not given them an opportunity to thank you. But some people expect that they are going to be making friends after the first day, or going to be invited to someone's house for a meal and they might not have that experience (Manager 3, March 29 2012) 


\section{Volunteer comparisons}

The differences between the Cook Islands and the home countries of the volunteers caused volunteers to make comparisons. This could be partially attributed to the expectations that volunteers held when they first arrived in the Cook Islands. Conversations between volunteers consistently revolved around discussions of relating and associating what they were experiencing in Rarotonga to their home countries (Fieldwork Journal, 29 March, 2012). Comparisons were drawn on trivial aspects such as food, the weather and modes of transport to more significant differences such as the priorities of parents, the education level of children, family values and the types of resources that were available (Fieldwork Journal, 29 March, 2012).

According to the Country Manager, these regular comparisons could be understood as a process where volunteers were seeking to make sense of their foreign surroundings (Manager 1, April 15, 2012). They could be viewed as a method which enabled volunteers to consider their place within the new environment. This process was helpful as it allowed each volunteer to individually clarify their role as a volunteer.

However, this process of comparing had the potential to develop down a dangerous route when volunteers went beyond comparing and as a consequence could not accept the differences between environments. This became particularly significant when discussions on these comparisons were not critically examined in a safe environment. The Country Manager played an important part in building this safe environment and providing opportunities for discussion.

Comments made by the volunteers, as an outcome of comparing the Cook Islands to their homes, have the potential of insulting the locals. Derogatory remarks, such as, "I can't wait to eat real food”, "I can't wait to be back where I can pick my phone up and it will always work" and "Why do you have computers if no one knows how to use them?", were made by previous volunteers (Volunteer 5, April 11, 2012). If these 
discussions were not appropriately engaged with and undertaken in a safe environment, they led to the emergence of prejudiced attitudes where volunteers place superiority on their ideals over alternative understandings.

The hosts in Rarotonga reacted negatively to the comparisons made by volunteers. This can be exemplified through the perspective of the following contributor who experienced instances where volunteers openly compared the educational level of Cook Island students with the students in their own countries:

I would like them to not compare our children with theirs, for example, comparing the learning level of Cook Island children to the learning level of American children or New Zealand children. I would like them to just take what is in front of them. I don't want them to compare (Host 5, March 23, 2012).

Although the volunteers usually had good intentions, comparisons were viewed as being unhelpful when they were said in the wrong environment. It was important that volunteers had space to work through and reflect on the different situations that they were confronted with.

\section{A learning process and missed opportunities}

Volunteers missed opportunities to take part in cultural experiences when aspects of culture went beyond their own understanding. While there are a range of learning models which are suited to each individual, a kinaesthetic learning approach is culturally relevant in the Cook Island context. ${ }^{4}$ As a collective, Cook Islanders generally learn by doing. Although it may be customary to learn through this kinaesthetic approach in the Cook Islands, this style is not necessarily used in the volunteers' own places of learning.

\footnotetext{
4 'Kinesthetic learning is a learning style involving experiential learning. This takes place through students, 'total physical involvement with a learning situation' (Reid, 1987, p. 89).
} 
This kinaesthetic form of learning was demonstrated through the local dance lessons which the volunteers attended as an extracurricular activity. Before entering the dance lesson, volunteers were excited about learning the Ura $P a^{\prime} u$. However, they did not participate in the lesson when they arrived at the auditorium. The dance lesson was a continuous flow of learning where each of the 'specialist' dancers demonstrated moves to the beat of a drum while the other dances imitated the moves. The movements were not explained verbally. With their own cultural lens, volunteers did not initially see that the teaching was taking place. The volunteers were waiting for the dance teachers to instruct in a way which was culturally appropriate to them. As a result, they missed the opportunity to learn the Ura $\mathrm{Pa}^{\prime} u$. However, despite missing this opportunity, the dance lesson enabled volunteers to gain insight into a different learning approach. This dance lesson illustration echoed the need for effective cultural translators who could explain the day to day cultural practices to volunteers as they arose.

When discussing the dance lessons, one of the volunteers suggested that there was always a learning process that had to take place when you are in an unfamiliar situation:

I think there is a learning curve though. Like at the dance lessons where we should have just gotten into it and started dancing but I didn't realise. I thought there was going to be some like pause ... but there is that learning curve of how the culture works (Volunteer 3, March 28, 2012).

At the start of the volunteer programme, both volunteers and hosts embark on a process of familiarisation where the volunteers become accustomed to their new environment and the Cook Islanders get acquainted with a new set of volunteers. Throughout this process, the hosts reiterated the existence of a learning process which both the volunteers and the hosts work through. Both the Country Managers and hosts played the role of cultural translators:

Sometimes we might have some volunteers who may not understand some aspects of the culture. We always are willing to explain to them why we do this and why we do that. For example a classic one was that they didn't quite 
understand was why our people can sit on graves. And of course it was explained to them from a cultural perspective just going and spending time sitting on the graves and talking about old times in relation to the one that is buried here is a very important pastime for our culture (Host 9, April 4, 2012).

\section{Outsider policies}

Despite the benefits of local Country Managers being able to make the programme relevant to the Rarotongan context, Global Volunteers is still essentially an outside, international organisation. As a result, the organisation has a standard set of policies which are implemented in all of its programmes around the world. When there is a single policy for every setting it is difficult for it to be culturally appropriate in every situation. This can be demonstrated through Global Volunteers donations policy.

When volunteers sign up for the Global Volunteer programme, they receive a list of items which they can choose to donate to their selected programme. In the Cook Islands, the volunteers donated items are collected by the Country Manager on the first day of the programme. Examples of these donated items have included books, toothbrushes and toothpaste, sports equipment and school stationary. The donations are distributed to the hosts once the volunteer programme is finished and the volunteers have left Rarotonga.

The volunteers are not permitted to make any individual donations directly to the organisations that they are working with, nor are they permitted to donate to outside organisations (Global Volunteers 2012). According to Global Volunteers (2012), this approach is beneficial because it prevents organisations from being unnecessarily saturated with donations:

Direct donations to individuals are specifically prohibited by Global Volunteers to avoid inequalities or appearances of favouritism within the community. Further, donations to host organizations independent of Global Volunteers have been largely disruptive to our programmes. Both actions risk Global Volunteers' ongoing development partnerships (Global Volunteers, 2012). 
Although Global Volunteers reasoning behind this donations policy is reasonable, it depersonalises donations and fails to take into account the culturally appropriate method of gift giving in the local context. The importance of expressing appreciation, particularly in a face to face exchange is important within the Cook Island context. As discussed within the methodology section, 'Kanohi kitea (the seen face, that is present yourself to people face to face)' was regarded as being significant within the Cook Islands context (Smith 1999, p. 120). Since Global Volunteers distributes the donations, the hosts are not given an opportunity to thank the individual volunteers for their donations in person. This was recognised by the following host:

The volunteers bring donations in their bags on the plane when they arrive. When they leave, [the Country Manager] brings some donations to us. ... I think this is unfair. It is hard to show appreciation to the volunteers through an email. It is much more respectful to show our appreciation face to face. It is some kind of policy that [the Country Manager] has to bring in the donations and donations have to go through [the Country Manager] first (Host 5, March 23, 2012).

The donations policy caused discontent from this particular host. While one can recognise Global Volunteers' reasoning behind why donations are not distributed by volunteers, having one policy for every volunteer programme around the world makes it difficult to effectively integrate policies into the local setting. Although it is not the intention of Global Volunteers, this can be perceived as a devaluing of local culture.

\section{Language and translation}

Although English is commonly spoken in Rarotonga, language difficulties and translation errors have been a cultural barrier between the volunteers and locals in Rarotonga. Since culture is deep-rooted within a language, it is difficult for a culture to be understood without its language. As an outcome, language differences restrict the volunteers in Rarotonga from totally engaging with the locals. One of the previous Country Managers exemplified this notion:

One issue that we always had with volunteers was that when they went into schools sometimes the teachers would speak Māori, like for instance during 
lunch periods, the teachers would speak Māori and so the volunteer couldn't understand and didn't feel included so that was one challenge that we always had was to encourage the teachers to speak English and to include the volunteers, because volunteers weren't going to learn enough Māori to interact so that was always a cultural challenge, because sometimes the volunteers felt like they were being talked about, even though they probably weren't (Manager 2, March 29 2012).

Due to the short timeframe of the volunteer programme, it is difficult for volunteers to fully engage with the Cook Island Māori language. Although some volunteers come to Rarotonga with the intention to learn, they are not in the Islands long enough to gain a good grasp of the language (Manager 1, April 15, 2012). Even though English was used by each group, sometimes Cook Island English and American English did not match. As a result, Country Managers had to initially interpret what was being said between the groups (Manager 2, March 29 2012).

\section{Global Volunteers' Country Managers as cultural translators}

The Global Volunteers' Country Managers played an important role in managing and reducing the cultural clash between the volunteers and the locals by acting as cultural translators. Each of the Country Managers have either been Cook Islanders or become Cook Islanders by marriage. They were well-connected to the community and had strong links with the local organisations (Fieldwork Journal, 27 March, 2012). During the field research, I noted the large community network that the current Country Manager was involved in (Fieldwork Journal, 27 March, 2012). The Country Managers had the ability to implement elements of the Cook Island culture (family and community networks, language, customs and values) into the volunteer programme.

The Country Managers had the job of translating and explaining issues between each group. The effectiveness of the Country Manager in this position influenced the extent of the cultural issues that both the volunteers and the hosts faced. The volunteer orientation and subsequent team meetings were useful for managing the cultural clash 
between volunteers and hosts. During these meetings, Country Managers have the opportunity to explain various cultural differences to the volunteers. It was likely that tension was eased when volunteers were aware of certain differences. One of the cultural differences that was discussed during orientation was explained by a former Country Manager:

Even time wise, it was quite hard for Americans to adjust to the fact that there was a thing called 'island time', so we would always have to explain for instance if there was going to a ceremony that we were going to, that although it started at $6[\mathrm{pm}]$, not to be surprised if it started at $6.30 \mathrm{pm}$ or $7 \mathrm{pm}$, because if you didn't warn them, they would get a little bit stressed. So that's usually part of the orientation to tell them different things. But even if you tell them, you would still get issues (Manager 2, March 29 2012).

The Country Managers used a daily journal to encourage volunteers to critically engage with ideas and situations that they faced while volunteering in Rarotonga. Each day, a different volunteer took turns writing the journal entry for the day. Although this journal gave the chance for volunteers to think about their experiences and arising issues, the attitude that I personally perceived was that volunteers viewed the journal as a chore rather than an opportunity. By the end of the programme, most of the volunteers only briefly recorded what they had done during the day rather than critically engaging with the issues that arose (Fieldwork Journal, 31 March, 2012).

Although the orientation, team meetings and daily journal were used by the Country Manager to translate and engage with the various cultural differences, it was important that the Country Manager played a more active role throughout the programme to ensure that every group involved in Global Volunteers reduced the prospect of cultural clash.

This final section of the findings has shown that due to the collaboration and clash of culture within the Global Volunteer programme in Rarotonga, volunteer tourism was revealed as being both useful and detrimental for promoting cultural understanding. It 
was highlighted that the Country Manager played a significant role as the cultural translator. It was important that the Country Manager played more of an active role to ensure that each group engaged with the various issues that arose and gained a deeper insight of culture.

\subsection{Conclusion}

This chapter has presented the research findings. These findings were framed around separate sections on development, culture and power. While there were many positive outcomes which resulted from Global Volunteers, the extent to which they could be considered a contribution towards development were unconvincing. The differences in power were outlined, with each group holding power at various times and to varying degrees. Lastly, the section on culture revealed that Global Volunteers was both useful and detrimental for promoting cultural understanding. The Country Manager was viewed as playing a significant role as the cultural translator. The following chapter will build on these findings by connecting the key themes with the existing volunteer tourism literature. 


\section{Chapter Six: Wider reflections}

The central purpose of this chapter is to make wider reflections on the research findings by linking the themes of development, power and culture into the literature on volunteer tourism. The chapter is framed around each of the key questions that this thesis is centred upon. This reflection has revealed that volunteer tourism is not exclusively good or bad nor 'black' or 'white' for those involved. While there are a range of positive and negative outcomes of volunteer tourism, it is important that the programme is effectively managed. Furthermore, it is important that the people who host the volunteers maintain a sense of ownership over the volunteer programme. Although this chapter has attempted to refrain from repetition, it was necessary to reconsider the key issues that were developed in chapter five so that they could be reflected upon in greater depth.

\subsection{The relationship between Global Volunteers and development in Rarotonga}

The research findings exposed the complexities of correlating the Global Volunteer programme with development in Rarotonga. The findings found that although positive outcomes were made, the relationship between development and volunteer tourism was inconclusive. Building on from these findings, this discussion on the relationship between Global Volunteers and development in Rarotonga will shed light on the absence of development language, the underlying assumptions of volunteer tourism, the limitations of development, the positive outcomes of the practice and the role of local agency. Instead of attempting to shape volunteer tourism into development work, this discussion will conclude that the most important aspect of the practice involves the agency held by the local people. 


\subsubsection{An absence of development language}

An absence of development language within volunteer tourism organisations gave an indication of the disconnection between volunteer tourism and development. Since volunteer tourism organisations controlled the way that their programmes were presented to prospective participants, this lack of development language could be viewed as being self-imposed by the volunteer tourism organisations. This disconnection between development and volunteer tourism was considered by Simpson (2004) who discussed the lack of references to development within the promotional material of volunteer tourism organisations. Instead of explicitly using development language, phrases such as 'making a difference' and 'doing something worthwhile' were regularly used (Simpson, 2004, p. 683). In addition to ignoring development language, these vague expressions suggested that the volunteers were at the centre of the change rather than the host organisations.

While Global Volunteers took advantage of the terms presented by Simpson (2004) the organisation was different to most other volunteer tourism organisations as they openly used development language to describe aspects of their programme (Global Volunteers 2012). Phrases such as, 'You can contribute directly to local development efforts' and 'Our short-term volunteer service opportunities focused on providing 'helping hands' to community development programs' could be found on the Global Volunteers (2012) website. Nonetheless, it is interesting to note that despite Global Volunteers use of development language, the participants were extremely hesitant to describe their assistance as development work. The use of development language did not flow through to the participants' perception of the programme.

By limiting the use of development language, it is implied that volunteer tourism organisations are distinguishing their work from development work. This is not necessarily a negative position to take. However, Simpson (2004, p. 684) suggested that 'By avoiding the language of 'development' many organizations may be trying to avoid 
the questioning of such an agenda'. When development was viewed as running separately from volunteer tourism, it was difficult to find grounds to question the practice. Instead, the practice becomes more aligned with mainstream tourism operations. However, since Global Volunteers uses development language, the organisation provides us with an opportunity to ask questions about their development agenda and the underlying assumptions of development that are made as a result of this agenda.

\subsubsection{Underlying assumptions of development within volunteer tourism}

There were a number of underlying assumptions of development embedded within volunteer tourism which influenced the type of 'development' that the practice has promoted. Simpson (2004, p. 685) suggested that the volunteer tourism industry has created its own 'development discourse'. This discourse has presented development as 'something that can be 'done', and specifically, by non-skilled, but enthusiastic, volunteer-tourists' (Simpson, 2004, p. 685). Volunteer tourism has advocated that outsiders have the ability to engage with the issues that the recipients face and hold the answers and the skills to assist. This frames development as a simple matter which can be easily resolved (Simpson, 2004). In agreement with this perspective, Vodopivec and Jaffe (2011, p. 125) argued that, 'Volunteer tourism is reinforced by the idea that the development will come from outside, and is located in the hands and wallets of enlightened, wealthy volunteer consumers'. This situation can be described as an 'externalization of development' (Simpson, 2004, p. 685).

A critique of this western notion of development which volunteer tourism has promoted can be found within the post-development school of thought. In alignment with the assumptions that volunteer tourism has made, Escobar (1995, p. 13) asserted that, 'Development has relied exclusively on one knowledge system, namely, the modern Western one. The dominance of this knowledge system has dictated the 
marginalization and disqualification of non-Western knowledge systems'. In other words, development has been concerned with western ways of knowing at the expense of indigenous knowledge (Escobar, 1995). Furthermore, Nederveen Pieterse (2000, p. 175) argued that, 'Development is rejected because it is the 'new religion of the West'... it means cultural Westernisation and homogenization'. He also rejected development, 'Not merely on account of its results but because of its intentions, its worldview and mindset' (Nederveen Pieterse, 2000, p. 175). When connecting these thoughts with volunteer tourism, it can be argued that the practice is yet another form of westernisation which has presented the west as having the solution to the issues that recipients are facing. The resulting relationship between the volunteer and the recipient expresses neo-colonial undertones (Conran, 2011).

The fundamental development assumptions surrounding volunteer tourism and the post-development school of thought contained parallels with the Global Volunteer programme in Rarotonga. The majority of the participants in the programme came from the US or the 'west' (Fieldwork Journal, 19 March, 2012). There was an assumption that these people had an innate authority to participate in the volunteer programme in Rarotonga and as a result, had the capacity to contribute towards development. Although many of the volunteers were skilled in the areas where they assisted, there were others that were 'unqualified' but were still accepted to participate anyway. This notion that development was a simple process (Simpson, 2004) which anyone could participate in was echoed through the Global Volunteer programme in Rarotonga.

\subsubsection{The limitations of development}

There were a number of limitations within the Global Volunteer programme in Rarotonga which stopped development from being linked to volunteer tourism. 


\section{Global ideas of development into a local context}

The Cook Islands context was not always adequately considered by Global Volunteers. Despite the different needs between each Global Volunteer programme, the organisation tended to have a standardised approach across all of its programmes. As a result, the contributors to this research expressed the lack of cohesion between Global Volunteers' agenda and the local Cook Island context (Volunteer 5, April 11, 2012). Although Global Volunteers is a US based organisation, the Rarotongan case study showed the importance of engaging with the local Cook Island context. There cannot be an expectation that one policy or programme idea will be relevant in every context. For instance, although the 'Earthbox' or donations policy may be relevant within one context, its promotion or use in Rarotonga does not necessarily intertwine with the locals' needs. This perspective is connected to the need for local agency to be consistently expressed throughout all areas of the programme.

The research findings revealed the resistance and conflict between global ideas of development and local needs. The findings suggest the importance for global ideas to be deconstructed into each localised setting. This was important as it allowed for development to be relevant and become integrated into each localised setting.

\section{The role of time}

Both the hosts and the volunteers highlighted time as a significant catalyst of positive change within Rarotonga. There was an understanding among the volunteers that they could only contribute to development if they were assisting for a time period longer than two or three weeks. This understanding expressed the view that development is not quick. Change does not usually take place at high speed. Although the process of development may be constant, it is not usually a sudden progression. It takes time to build relationships and to develop an understanding of the local context. This perspective raises the question of whether volunteer tourists or short-term volunteers could ever be involved in development work. 
A longer volunteering period allowed volunteers to be more integrated into their host organisation and to become less of a burden on their hosts (Devereux, 2008; Lough et al., 2011). Palacios (2010) discussed the limitation of time by suggesting that, 'Indeed, neither I nor the rest of the volunteers feel that the time allowed was sufficient to create a significant change or assist with the long-term goals in their training program'. Furthermore, Sherraden et al. (2008) found that while short-term volunteers did encourage positive outcomes, these were mainly directed towards the volunteers rather than the host communities. These perspectives were expressed by the volunteers in this study, who found that the short length of the programme infringed on their perception that they worked towards positive change and that the positive outcomes were often found within themselves rather than the hosts.

\section{Lack of strategic planning}

A lack of strategic planning has been identified within volunteer tourism organisations (Ingram, 2010). This lack in strategic planning is regarded as a characteristic of ineffective volunteer tourism organisations (Fee \& Mdee, 2012). Within gap year organisations, Simpson (2004, p. 685) identified the assumptions and reasoning and behind the lack of strategic project planning:

Doing something is better than doing nothing, and therefore, that doing anything, is reasonable. A particular type of 'development' activity is targeted, where the emphasis is on end products, such as 'teach the child', 'conserve the forest', 'build the bridge' (clinic, well, library etc.). Questions around long-term strategy, along with questions on the appropriateness and impact of volunteers, appear to be missing from the majority of gap year programmes.

This was the case within the Global Volunteer programme in Rarotonga. While the volunteers filled in formal evaluation sheets at the end of their programme, Global Volunteers did not initiate any formal evaluations or monitoring of the overall programme in Rarotonga. The long term strategic plan for Global Volunteers in Rarotonga was limited. Ingram (2010, p. 218) suggested that this lack of strategic planning, 'Propagates a public myth of development, one of simplicity'. 


\section{A lack of critical engagement}

While the contributors to this research consistently described the limitations to positive change and highlighted elements within Global Volunteers which weakened the opportunity for good outcomes, they never took a step back to critically engage with volunteer tourism as a practice. The practice of volunteer tourism was never questioned. This finding was supported by Vodopivec and Jaffe (2011, p. 120) who argued that, 'Volunteers tended to blame their limited impact on a lack of language skills, time or on the organizations, rather than interrogating the broader concept of volunteer tourism itself'. This lack of critical engagement with volunteer tourism as a practice can be connected to the body of literature on volunteer tourism, which is overwhelmingly positive of the practice. This has significant implications for the future of volunteer tourism.

Despite these limitations which prevented Global Volunteers from being connected to development within Rarotonga, there were many positive outcomes which resulted from the volunteer programme. It is important that an analysis of volunteer tourism does not stop with the practice's limitations. This is particularly important within the Global Volunteers case study due to the array of positive outcomes which resulted from the programme in Rarotonga. The prospect of using the practice as an opportunity for growth is diminished when discussions do not move beyond a critique of volunteer tourism. Despite this critique, there is still space for positive action to take place. This view was supported by Hutnyk (1996, p. 222, cited in Conran, 2011, p. 1466) who suggested that 'It is not enough just to raise questions ... because something must be done'.

\subsubsection{Positive outcomes of volunteer tourism}

An array of positive outcomes of the Global Volunteer programme in Rarotonga was presented in the research findings. These positive outcomes included both tangible and intangible benefits. The volunteers' assistance was generally well received by the host 
organisations. The hosts were quick to express their appreciation of the volunteers and highly regarded and valued their work (Fieldwork Journal, 27 March, 2012). The positive outcomes of the volunteers assistance was reflected on within the literature on volunteer tourism. Guttentag (2009), Sin (2010) and Lough et al. (2011) gave examples of direct tangible benefits to the host communities.

The positive outcomes in Rarotonga largely involved tasks which contributed to the capacity development of the host organisations and specialised assistance. The volunteers' involvement in capacity development often involved seemingly menial tasks, such as assisting teachers in the classroom, cleaning books and answering telephones. In most cases, the volunteers were viewed as an extra pair of helping hands and assisted with filling gaps within the organisations. The volunteers that held specialised skills were able to complete more specific tasks and pass on their skills to the host organisations. The literature suggested that development volunteering was a much more comprehensive practice than what was carried out by the volunteers in Rarotonga (Devereux, 2008; Georgeou \& Engel, 2011).

Nonetheless, not labelling the volunteers assistance as 'development work' did not make the practice worthless. While this form of volunteering might not be specifically working towards bringing about development outcomes, the volunteers were able to help maintain the day-to-day running of the organisations. Furthermore, Devereux (2008) promoted capacity development because it encouraged local ownership. Moreover, assisting in this way was an indirect contribution towards development as most of the host organisations had overarching development objectives.

\subsubsection{Local agency}

According to Bandura (2001, p. 2), 'To be an agent is to intentionally make things happen by one's actions'. Bandura (2001, p. 2) portrayed that, 'The core features of agency enable people to play a part in their self-development, adaptation, and self- 
renewal with changing times' (Bandura, 2001, p. 2). While the literature presented the host communities as a passive collective (e.g. Vodopivec \& Jaffe, 2011), this research found that the locals held a level of agency which enabled them to define in their own terms what progress and development meant to their organisations and communities. This notion of local agency contradicted the assumptions that volunteer tourism made about development.

In Rarotonga, the local people were significant drivers of the volunteer programme. The local people were in a position to define their level of interaction with the programme. The volunteers worked under the umbrella of local leadership. The agency held by the hosts enabled them to direct and instruct the volunteers towards their own identified areas of need. The hosts actively made decisions and set the specific tasks that the volunteers carried out. They had the capacity to decide the level of effort that they were willing to contribute towards the volunteers. As an outcome, the volunteers usually worked from a starting point which was designed by the local people and were directed towards building upon a local perception of progress.

The hosts' agency can be exemplified through a successful funding grant which the volunteers assisted an NGO with in Rarotonga. The organisation identified a need within the community which required attention and made a choice to focus their efforts on this particular area. The organisation recognised that they needed finances to fund a programme which would address the need but were initially unsuccessful in their own application for funding. The organisation received volunteers through Global Volunteers to assist with a subsequent funding proposal. Together with the volunteers, the organisation was able to complete a funding proposal and develop skills for future funding opportunities. Through the volunteers' assistance, the organisation was successful in receiving significant finances for their programme. This example portrayed the volunteers working under the leadership of the hosts. The volunteers helped to develop momentum towards a need which was specifically identified by the 
organisation. This funding had the prospect of positively contributing to the particular need that the host organisation was addressing.

This section has described the underlying assumptions that volunteer tourism has made about development. It has shown that while the relationship between development and volunteer tourism within Global Volunteers in Rarotonga was inconclusive, the most important element of the programme involved the agency possessed by the local people. As long as the people were defining the volunteers' assistance and retained a sense of ownership over the volunteer programme, it did not matter whether or not the assistance was described as 'development' work.

\subsection{The nature of power within the Global Volunteer programme in Rarotonga}

The Global Volunteer programme in Rarotonga revealed that the nature of power was not simply the 'powerful' versus the 'powerless' but that each of the groups possessed varying degrees of power at different times. Power was revealed throughout the programme in both strong and subtle ways. Through a consideration of the complexity of power, in addition to the power of the hosts, volunteers and Global Volunteers, this section will discuss this nature of power within the Global Volunteer programme in Rarotonga. Within this examination, space will be established as a significant facilitator of power.

\subsubsection{The complexity of power}

On one hand, volunteer tourism has been seen as an enabler of mutual relationships between the volunteers and their hosts (McIntosh \& Zahra, 2007). Guttentag (2012, p. 156) suggested that the practice, 'can create an environment in which power is equally shared between tourists and hosts'. On the other hand, it has been claimed that 
volunteer tourism is responsible for establishing an imbalance of power between those that volunteer and those that receive the volunteers (Sin, 2010). According to McGehee (2012, p. 93), the practice has established 'Power/knowledge relations between the economically and socially powerful volunteer tourists ... who can pay to volunteer and can stay for several days to upwards of several weeks, and the less powerful host communities (who are, by nature, being exploited or dominated by forces that place them in the position of being "voluntoured")'. Moreover, volunteer tourism has been perceived as furthering existing power hierarchies (Sin, 2010, p. 988).

Power has been viewed as being concentrated with the volunteers rather than the hosts. As an outcome of this kind of relationship, it has been argued that the formation of a dichotomy between 'us' and 'them' has been created (Simpson, 2004; Raymond \& Hall, 2008; Conran, 2011). However, to describe the power relations between the volunteers and the hosts as a dichotomy is overly simplistic. The Global Volunteer programme in Rarotonga has revealed that power is complex. The relationship between the volunteers and the hosts within the programme was not simply the 'powerful' verses the 'powerless'. Rather, there were multifaceted intersections of power within and between each of the groups which were consistently changing. This perspective correlates with Foucault's (1977 in McGhee, 2012) view of power. Foucault asserted that, 'Power is fluid and unstable, strategic and inextricably related to knowledge' (Foucault, 1978 in McGhee, 2012, p. 89).

To illustrate this complexity of power within Global Volunteers' activities in Rarotonga, it is necessary to revisit an example which was presented within the findings. This particular scenario involved a volunteer who assisted as a nurse at the local hospital. During her time at the hospital, the volunteer was faced with a situation where they were required to attend to a patient who had active Tuberculosis without an adequate mask. The volunteer was provided with an insufficient mask by the nurse that she was assigned to work with. Although there were other more adequate masks available, the 
higher supervisor had to give permission for the nurses to use them. Since the volunteer did not want to step out of line, she attended to the patient with the inadequate mask.

When reflected upon, this example has expressed many levels of power between each of the people involved in the Global Volunteer programme. As the sending organisation, Global Volunteers had the power to place the volunteer in this particular placement. By being in a position to travel from the other side of the world to Rarotonga, the volunteer undoubtedly held a degree of power. The volunteer had the right of entry into an area which was not typically accessed by regular visitors to the island. The local hosts in this example had the power to determine the type of work that the volunteer carried out and to promote their view of acceptable practice. Additionally, there was an indication of a higher power structure which both the local staff and this particular volunteer were working under. As shown through this example, the nature of power within Global Volunteers in Rarotonga was multilayered. It involved much more than one powerful group asserting control over the majority.

\subsubsection{The power of volunteers}

The volunteers held power in a number of ways through the Global Volunteer programme in Rarotonga. Rather than being considered tourists, those that participated on the Global Volunteer programme were distinguished from regular tourists and were viewed as volunteers. In turn, the volunteers were given access to spaces where they normally would not be permitted to go as mainstream tourists. The hosts' workplaces, schools and in some instances, homes, became common areas for the volunteers. As an outcome, the volunteers held a degree of power which was difficult to attain by regular

tourists. The typical tourist space and local space was blurred and redefined by the volunteers. This blurring and redefining of space within volunteer tourism was described by Sin (2010). Sin (2010, p. 987) used Edensor's (1998) term, 'heterogeneous 
spaces' to describe this phenomenon. The 'heterogeneous space' gave power to the volunteers to interact at a level which was different to the normal interactions between tourists and locals.

By gaining access to local spaces, the volunteers had a closer interaction with the locals. As an outcome, the volunteers were in a position to exert power over their hosts. One way that this assertion of power was displayed within the literature involved the labelling of volunteers as specialists despite having limited relevant experience and knowledge of the local context (Palacios, 2010; Sin, 2010). Although Global Volunteers tended to match the volunteers in Rarotonga to their area of expertise, the contributors discussed instances where volunteers were placed with local schools based on the sometimes erroneous assumption that any volunteer could teach. This action was discussed by Guttentag (2012, p. 153) who suggested that, 'it is incorrect to assume that volunteers possess some innate ability to perform jobs like teaching English'.

Through her case study, Sin (2010) suggested that although the local hosts had control over their volunteer projects, the power was ultimately with the volunteers since they had the power to decide where they were placed. This was also true within Global Volunteers in Rarotonga. Although the host organisations could choose how their projects ran, the volunteers ultimately had the power to decide whether they wished to assist in the projects. This power was shown by a volunteer in Rarotonga that was placed with one organisation but pushed to change their work project to another organisation despite still being required at the initial organisation (Fieldwork Journal, 28 March, 2012).

Although the assertion of the volunteers' power has generally been perceived negatively, the Global Volunteers case study alternatively promoted the positive use of power. Volunteers were often aware of how the power of their home countries had been to the detriment of other countries. This attentiveness enabled them to be mindful 
of their actions. One particular volunteer described the shame that she felt about the way that her home country promoted itself as being all powerful and possessing a domineering "we know best" philosophy (Fieldwork Journal, 19 March, 2012). This positive use of power within volunteer tourism was supported by Pearce and Coghlan (2008, p. 132) who argued that, 'Volunteer tourism can be seen as a sociocultural group or movement representing an ethical body of people correcting or at least ameliorating the historical exploitation'. By being aware of the differences in power, some volunteers were able to work towards correcting the historical misuse of power.

\subsubsection{The power of host organisations}

Although the literature was quick to describe the lack of power held by host organisations (Guttentag, 2009; Sin, 2010; Vodopivec \& Jaffe, 2011), the Global Volunteer programme in Rarotonga revealed that the hosts did have opportunities to assert power over the volunteer programme. The hosts were very much actively involved with the volunteers. They were not merely the recipients of help. Since the volunteers were located within the locals' space, the locals had the capacity to promote their own 'identities' to the volunteers. This notion has been supported by Edensor (1998, p. 2000 in Sin, 2010). Since the volunteers in Rarotonga worked under the leadership of their host organisations, the hosts had the power to define the rules and determine acceptable practice for the volunteers. Furthermore, the hosts helped to dictate the type of experience that the volunteers received. They had the power to promote the level of attention that they were willing to give to the volunteers and could implement an 'initiation process' where they waited for volunteers to prove themselves before they were properly welcomed.

For the most part, the interactions between the hosts and the volunteers were not simply 'give and take'. Rather, they involved more of a reciprocal relationship where the host organisations receive assistance, while the volunteers gain a unique experience. This view was reinforced by Berno's (1999) discussion of the relationship between 
locals and guests in the Cook Islands. Within the schools, for instance, the hosts enabled the volunteers to experience Cook Island culture and gain a glimpse into island life while the volunteers gave the teachers extra support.

\subsubsection{The power of Global Volunteers}

As the volunteer sending organisation, Global Volunteers played an important part in the construction of power between the volunteers and the hosts in Rarotonga. They held the largest portion of power over the programme. This was reinforced within the literature by Vodopivec and Jaffe (2011, p. 125) who found that the volunteer sending organisation constructed the encounter between the locals and the volunteers before it took place. Accordingly, both the locals and volunteers were viewed as working under the authority of the volunteer sending organisation. Within the case study, Global Volunteers had been instrumental in defining volunteer-host power relations. Global Volunteers had the power to decide who could participate and the type of environment that volunteers worked in. This gave power to Global Volunteers over both the hosts and volunteers in Rarotonga.

Global Volunteers was in the position to select both the volunteers and the hosts of the volunteer programme. They had the power to determine the level of care that they were willing to take towards making this selection. The choice in volunteers had significant implications for how beneficial they were to their respective hosts. Based on the study's findings, Global Volunteers did not take adequate care in choosing their participants in Rarotonga. This lack of care could be portrayed by a volunteer who had insufficient English language competencies but was selected to teach in a school and an older volunteer who was selected despite not being mobile enough to hop on and off the local bus without assistance (Volunteer 5, April 11, 2012). Although the selection of these volunteers did not severely harm their hosts, the potential for inadequate volunteers to bring harm to hosts in the future was possible if ample attention was not given to the selection process. Raymond and Hall (2008, p. 538) suggested that it is essential that 
volunteer tourists had the proper skills to make a positive contribution. This lack of care within the selection process reflected the power that Global Volunteers had over the volunteer programme.

The administration of the Global Volunteer programme in Rarotonga further revealed the power of Global Volunteers. The volunteers highlighted gaps within Global Volunteers' administration by suggesting that their application forms were either not read or not adequately considered. The volunteers found that details and preferences which they had put on their application forms did not match with their activities in Rarotonga (Volunteer 1, April 3, 2012; Volunteer 2, April 5, 2012; Volunteer 3, March 28, 2012). Furthermore, the volunteers in this research found that the information which was provided to them by Global Volunteers often differed from reality in Rarotonga. The volunteers found a lack of communication between what occurred at the local level and the information that was provided to them by Global Volunteers before they arrived on the island (Volunteer 2, April 5, 2012; Volunteer 4, April 5, 2012; Volunteer 5, April 11, 2012). The need to match the information that participants received with the current situation in Rarotonga was highly regarded by the volunteers. This lack of care corresponded with Vodopivec and Jaffe's (2011, p. 123) study who found that application forms often appeared to be 'empty bureaucratic measures'. This lack of care could also be linked to the commodification of volunteer tourism where monetary gain becomes an important driver of the practice at the expense of the host communities (Lyons \& Wearing, 2008; Cousins et al., 2009).

The absence of regulation within Global Volunteers demonstrated the power of volunteer sending organisations. Although Global Volunteers has consultative status with the United Nations, it was not affiliated with any other volunteering associations or outside organisations which would help to ensure accountability and transparency. Since Global Volunteers is ultimately accountable to themselves, they are in a position to determine their own standards of ethical practice within their organisation (Global 
Volunteers, 2012). As a practice, volunteer tourism is generally unregulated (Fee \& Mdee, 2010; Tomazos \& Cooper, 2012). There are no overarching rules or procedures which govern the practice across the board. Fee and Mdee (2010, p. 234) identified the need for the establishment of volunteer tourism standards. Furthermore, Tomazos and Cooper (2012, p. 410) found that the International Volunteer Program Association (IVPA) was the only organisation available which helped to control the quality of volunteer tourism. According to their website, the IVPA (2012) provided principles and practices which they required their members to adhere to.

This section has revealed that the nature of power within the Global Volunteer programme in Rarotonga was complex. This power was not just one group asserting control over everyone else. The hosts, volunteers and Global Volunteers have each played a part in asserting power at different levels of the programme. Ultimately, power is always going to be present within volunteer tourism. Nonetheless, it is important that each person that is involved in the practice recognises the existence of power and subsequently works towards managing it without disempowering people in the process.

\subsection{The role of culture within the Global Volunteer programme in Rarotonga}

Volunteer tourism can be viewed as a practice which has created opportunities for participants to experience and engage with a culture and way of life that is distinctly different to their own. Culture is naturally expressed throughout each interaction that the volunteers and hosts have. However, this expression of culture is used for the purpose of having a good time and creating good memories for the volunteers rather than to develop and engage with the underlying cultural epistemologies. A discussion of the distinction between volunteer tourism and mainstream tourism, the extent of cross-cultural understanding, relationship building and critical engagement can reveal 
the role that culture has played within the Global Volunteer programme in Rarotonga. This dialogue exposes culture as a significant aspect of volunteer tourism.

\subsection{1}

\section{Distinction between volunteer tourism and mainstream tourism}

The point of difference between volunteer tourism and mainstream tourism involves the close level of interaction between volunteers and locals. The cultural experience that is gained through this interaction has distinguished volunteer tourists from both cultural tourists and mainstream tourists (McIntosh \& Zahra, 2007). The practice has brought about a cultural experience where each group can gain a greater understanding of each other. Since the volunteers are spending time with the locals on a daily basis, they do not have to seek opportunities to find culture. Culture is naturally experienced as an everyday practice rather than a performed or constructed artefact. The volunteer tourists within Raymond and Hall's (2008) study echoed this thought. They suggested that they had 'gained a far greater and more 'real' understanding of the host country than they could have through conventional forms of tourism' (Raymond \& Hall, 2008, p. 537). This aspect of volunteer tourism promotes a sense of cultural authenticity which other more conventional forms of tourism lack.

Within the case study, the cultural experience that volunteers gained through participating on a Global Volunteer programme in Rarotonga was much more substantial than what a regular tourist to the island would experience. It extended beyond a casual interaction. For instance, many of the larger hotels in Rarotonga hold an 'Island Night', where tourists pay to eat a Cook Island meal and watch a cultural performance. Often, this is one of the few displays of 'culture' that tourists encounter during their visit to Rarotonga. These island nights would be described by MacCannell (1976) as 'staged authenticity'. Although it is not the intention of this discussion to dispute the authenticity of these island nights, it is unlikely that the tourists who attend them would receive a substantial understanding of Cook Island culture or would gain 
the same degree of authenticity than what they would acquire through participating on a Global Volunteer programme.

Culture was integrated into the Global Volunteer programme in Rarotonga. It was naturally expressed and revealed throughout everyday interactions. The opportunity for the volunteers to learn and engage with Cook Island culture motivated them to participate on the programme (Fieldwork Journal, 19 March, 2012). This finding aligns with other research (Brown, 2005; Bailey \& Russell, 2010; Coren \& Gray, 2012) which found that the people who participated on volunteer tourism programmes were motivated by the opportunity to be immersed within a culture and actively chose to interact and work closely with people who come from a different background.

\subsubsection{Extent of cross-cultural understanding: Culture for experience}

It is important to consider the extent to which volunteer tourism has brought about cross-cultural understanding for both the volunteers and the locals in Rarotonga. Raymond and Hall (2008, p. 538) proposed the view that while volunteer tourism had the potential to promote cross-cultural understanding, it was not a given outcome of participation on a volunteer programme. Likewise, Simpson (2004) and Sin (2010) also suggested that volunteer tourism does not always result in increased cross-cultural understanding. In reality, volunteer tourism may 'undermine' the 'cultural well-being' of local communities (Coren \& Grey, 2012, p. 222). While there were many opportunities for the volunteers and the locals to gain a greater cultural understanding of each other, this was not an automatic result of the Global Volunteer programme in Rarotonga.

Within Global Volunteers, the Cook Island culture was often used as an instrument to make good memories and experiences for the volunteers rather than to develop deep cultural understanding or long-lasting structural change. In other words, culture was 
superficially used as a vehicle for the volunteers to have a good time. This perspective within volunteer tourism was reiterated by Conran (2011). In this sense, culture was used as a commodified good to create a good experience for the volunteers. This perspective was built on from Raymond and Hall's (2008, p. 537) assertion that, 'While the majority of such volunteers [two-week group volunteer tourism programme] enjoyed the chance to meet local people, these 'interactions' were usually perceived as providing memories, rather than lasting friendships'. This type of volunteer experience limited the expression of cross-cultural understanding. While it enabled the volunteers to naturally interact with culture and to see culture from a different perspective to mainstream tourists, they were still only seeing a surface expression rather than the underlying epistemologies of the culture.

Furthermore, the Global Volunteers case study revealed that there were certainly instances where cross-cultural understanding did not eventuate within volunteer tourism. To illustrate this point, it is useful to consider the views of a volunteer who was initially placed within one organisation but had to change their work project because, in addition to other issues, they could not deal with the male host who asserted 'shoveyness' and 'superiority' over the particular volunteer (Fieldwork Journal, 7 April, 2012). When asked about their experience of cultural issues in Rarotonga, the volunteer noted:

I think this is a more sexist culture, which I was sort of aware of. You know I think being from the US you forget, because we aren't as sexist in the US. We are really equal. This really has roles that men and women play - so that was really interesting. There are people who are not playing those roles though because they are part of the world. Yeah, that was interesting. (Volunteer 2, April 5, 2012).

Rather than reflecting on their preconceived views and increasing their understanding of diverse cultural perceptions, the volunteer retained an ethnocentric point of view. They had the inability to consider the unique roles and responsibilities of males and females beyond their own western lens. Furthermore, by asserting that, 'We are really 
equal', the volunteer made an unwarranted generalisation about their own country. This view of having little regard for the host's culture was examined by Sin (2010). If the volunteer had taken a deeper consideration of the gender differences between cultures, they would have had the opportunity to respect a different view.

The need to create purposeful opportunities for interaction between the volunteers and locals was highlighted by the contributors to this study (Volunteer 2, April 5, 2012; Volunteer 3, March 28, 2012). This view paralleled Raymond and Hall's (2008, p. 540) understanding that while interaction naturally occurred during work placements, it was important that there were additional opportunities during the programme for volunteers to meet and engage with the local people. The duty or responsibility to organise these interactions was up to the Global Volunteer' Country Manager. Interactions with the local people that were additional to the volunteers' work assignments enabled increased opportunities for the volunteers and the locals to gain cross-cultural understanding.

The short timeframe of each Global Volunteer programme in Rarotonga infringed on the extent to which the programme had contributed to cross-cultural understanding. When discussing culture with a non-Cook Islander, who had lived in Rarotonga for many years, they were adamant that the volunteers were not in Rarotonga long enough to understand the culture (Fieldwork Journal, March 30, 2012). Even after spending many years in the Cook Islands, she acknowledged that she did not completely understand (Fieldwork Journal, March 30, 2012). Although the volunteers were immersed within a different culture during their work placements, this did not mean that they would be able to fully understand the culture or recognise and comprehend differences. This viewpoint articulates cross-cultural understanding as an extended process which would be more attainable through long-term volunteering. 
Furthermore, the extent of cross-cultural understanding between the hosts and volunteers was individualised. Due to their diverse backgrounds, each of the individual volunteers had varied cultural experiences and subsequently had different ways of approaching their experiences. This corresponds to Raymond and Hall's (2008) view that the degree of learning about the hosts culture varied between each individual. This perception was furthered by Bailey and Russell (2010, p. 363) who suggested that, 'Openness may not occur naturally among diverse groups'. It was important to consider these differences between individual volunteers.

\subsubsection{Relationship building and friendship}

The formation of strong relationships between volunteers and hosts was central to the development of cross-cultural understanding. The relationships that were forged between the hosts and the volunteers within the Global Volunteer programme in Rarotonga enabled each group to be accepting of each other. This included acceptance of cultural issues which arose during the programme. The locals were not as easily offended by cultural misunderstanding because they had built relationships with the volunteers (Host 9, April 4, 2012). This view aligned with a contributor in Sin's (2010, p. 987) case study who suggested that the hosts tended not to judge volunteer tourists because they were aware of the volunteers' good intentions. Since the volunteers were assisting the hosts, the hosts were more likely to accept cultural differences and be more open to sharing their way of life with the volunteers. However, this type of relationship had the potential to have negative outcomes for the hosts. Hosts could use the volunteers' assistance as a reason to turn a blind eye to any prejudiced attitudes that the volunteers held.

While McGhee and Andereck (2008) asserted that volunteer tourism had the prospect of creating life long bonds, the case study revealed that this was not always the case. Although there were exceptions, the Global Volunteer programme in Rarotonga generally did not facilitate the growth of lasting relationships between volunteers and 
hosts. The forging of relationships were more for the purpose of working with each other in the present context rather than for an extended period of time. Although many of the hosts received cards and letters from volunteers once they returned home, the host-volunteer relationship did not usually go beyond these formalities (Host 8, March 26, 2012). Nonetheless, this type of relationship should not be discounted. The relationships formed between the hosts and the volunteers in Rarotonga were meaningful for those involved.

\subsubsection{Critical engagement}

Enabling the volunteers and the hosts to critically engage and reflect on their experiences was viewed as a significant element of reducing cultural misunderstanding (Raymond \& Hall 2008). Critical engagement of the volunteers' experiences gives an opportunity for any misconceptions to be ironed out. Raymond (2008, p. 54) highlighted the need for volunteer sending organisations to incorporate an 'experiential learning approach' into their programmes which would facilitate this type of critical reflection. The volunteer sending organisations could encourage this approach through their applications, journal writing, evaluations and role plays and through the implementation of a training course which the local people would run (Raymond \& Hall, 2008; Coren \& Gray, 2011). By involving the locals in these critical engagement methods, Coren and Gray (2011, p. 232) emphasised that the locals would 'serve as mediators between their community and the VTs and so increase cultural understanding'.

Within Rarotonga, a number of these approaches were taken to encourage critical engagement. It was up to the Country Manager to implement most of these approaches. While they were beneficial, they were not always effectively carried out. For instance, the volunteer journal in which the participants recorded their Rarotongan experiences was viewed as a chore rather than a method of critical reflection by the participants (Volunteer 5, April 11, 2012). The use of 'mediators' which Coren and Gray (2011) 
proposed were implemented in the form of the Global Volunteer' Country Managers. The Country Managers acted as cultural translators for the volunteers and assisted with guiding the volunteers in Rarotonga. The type of experience that each of the volunteers had through the programme and the ability for the volunteers to grasp some understanding of Cook Island culture relied largely on these Country Managers. While the Country Manager was an effective guide in some instances, there were other situations where they needed to work more closely with the volunteers (Volunteer 2, April 5, 2012). Volunteers needed to be effectively supported through the programme and steered in a way which would eliminate any unwarranted opinions.

This section has revealed that the Global Volunteer tourism programme in Rarotonga enabled volunteers and hosts to interact and engage with a culture that was different to their own. The programme facilitated a natural portrayal of culture rather than an expression of culture which was performed as an artefact. This distinguished the practice from mainstream tourism. However, culture was exposed as a means to create experiences and good memories for the volunteers rather than to bring deep cultural insight. Furthermore, while there was increased cross-cultural understanding in some instances, this was not a predetermined part of the programme. The role of the Country Manager was viewed as an enabler of critical engagement and cross-cultural understanding.

\subsection{Conclusion}

This chapter has made some wider reflections by linking the key research findings relating to development, culture and power with the literature on volunteer tourism. While the relationship between volunteer tourism and development was found to be inconclusive, the most important element of the practice involved the agency possessed by the local people. The nature of power was viewed as being a complex process with every group possessing power at varying times. Although a more natural and authentic 
portrayal of culture was promoted through volunteer tourism, this did not automatically flow to deeper cultural insight by the volunteers. While there was increased cross-cultural understanding in some instances, this was not a predetermined part of volunteer tourism. These wider reflections have revealed that volunteer tourism produces a range of positive and negative outcomes. Each of these outcomes need to be carefully managed by all of the groups involved in the practice. Furthermore, it is important that the hosts maintain a sense of ownership over volunteer tourism programmes. 


\section{Chapter Seven: Conclusion}

This final chapter draws conclusions from the research. Specifically focusing on Global Volunteers in Rarotonga, the study set out to establish a deeper insight into the development implications of volunteer tourism. This was carried out through an analysis of three central themes: development, power and culture. In addition to the existing literature on volunteer tourism, the research was supported by observations made during fieldwork and the perspectives, experiences and stories of the hosts, volunteers and Country Managers involved in the Global Volunteer programme in Rarotonga. Through the Global Volunteers' case study in Rarotonga, volunteer tourism was revealed as a useful practice which has the potential to bring positive outcomes for the host organisations.

\subsection{Summary}

This section readdresses the three key questions that the study has investigated throughout the thesis. It summarises the central themes of the study. By revisiting each of the key questions, the fundamental development implications of the Global Volunteer programme in Rarotonga are revealed.

\subsection{1}

What is the relationship between Global Volunteers and development in Rarotonga?

The relationship between Global Volunteers and development in Rarotonga was not strongly correlated. There was a blurry line between the work that was carried out by the volunteers and development in Rarotonga. There were a range of good outcomes which resulted from the volunteer programme, particularly involving capacity development and the implementation of specialised skills within the host organisations. The volunteers helped to fill gaps and passed on specialised skills. The hosts were 
appreciative of the volunteers' work and the benefits that they had gained through their involvement with Global Volunteers. For the most part, they suggested that the volunteers' work had made a valuable contribution to their organisations.

However, the programme was not without its flaws. The volunteers contributed negatively to their respective organisations by draining their hosts' time and resources. This caused some hosts to describe the volunteers as being burdensome in some instances. This potential for volunteers to be a burden on their hosts was also considered within the literature by Raymond (2008) and Sin (2011). Some volunteers found that there was a lack of substance within the programme which led them to suggest that they were not involved in 'real' work but had undertaken 'work experience'. Both the hosts and the volunteers found that the short timeframe infringed on the value of the programme. There was also evidence of a lack of strategic planning and lack of critical engagement during the programme. Furthermore, the Cook Island context was not always adequately considered by Global Volunteers when the organisation attempted to implement standardised policies and practices across all of its programmes.

In light of these outcomes, the extent to which the volunteers' assistance could be considered a contribution towards development in Rarotonga was inconclusive. Although Global Volunteers made use of development language to describe the programme, the extent to which the outcomes resembled development was not concrete. If the volunteers' assistance was to be labelled as development work, the underlying assumptions of this type of 'development' could be questioned. This was supported by Simpson (2004, p. 685) who argued that volunteer tourism presented a development discourse as, 'something that can be 'done', and specifically, by nonskilled, but enthusiastic, volunteer-tourists'. It also corresponded to Vodopivec and Jaffe's (2011, p. 125) perspective that, 'Volunteer tourism is reinforced by the idea that the development will come from outside, and is located in the hands and wallets of 
enlightened, wealthy volunteer consumers'. In other words, if the Global Volunteer programme in Rarotonga was to be viewed as development, it would be based on a very simplistic and external form of development (Simpson, 2004). This critique reflected notions of post-development where development was viewed as being reliant on western ways of knowing (Escobar, 1995).

However, a key component of the Global Volunteer programme in Rarotonga involved the agency which was possessed by the host organisations. Despite the literature's portrayal of host communities as a passive collective (e.g. Guttentag, 2009; Vodopivec \& Jaffe, 2011), the hosts in Rarotonga possessed the agency to define in their own terms what their needs were and could use the volunteers to fill those needs. Furthermore, the hosts could determine the level of attention that they gave to the volunteers. This was a unique aspect of the volunteer programme and conflicted with Vodopivec and Jaffe's (2011) view that volunteer tourism projected western dominance. As a result, rather than assessing whether the programme had contributed to development outcomes, the most significant element of the programme was that the hosts could be drivers of the programme and were in a position to lead the volunteers towards their own identified needs. For the most part, the hosts' agency enabled the local organisations to utilise the volunteers in a way which would best suit them.

\subsubsection{How has power been revealed through the Global Volunteer programme in Rarotonga?}

Power was a significant component of the Global Volunteer programme in Rarotonga. The relationship between the volunteers and the hosts was not simply the powerful verses the powerless. Rather, the programme involved complex intersections of power within and between each of the groups which were consistently changing. Power was revealed in both strong and subtle ways. Space was a key determiner of this power. 
The volunteers, Global Volunteers and the hosts held power at different times. Due to having the means to participate on the programme, the volunteers inherently held power over the hosts. This finding exposed the unequal power relationship that existed between volunteers and hosts within volunteer tourism. This form of relationship was discussed within the literature by Sin (2010) who argued that volunteer tourism reinforced existing power structures and hierarchies between 'developed' and the 'developing'. McGhee (2011, p. 93) supported this view by proposing that volunteer tourism, 'Establishes power/knowledge relations between the economically and socially powerful volunteer tourists ... and the less powerful host communities (who are, by nature, being exploited or dominated by forces that place them in the position of being 'voluntoured')'. In addition to the inherent power held by the volunteers, the findings showed that within the volunteers, there were some individuals that expressed their power more openly than others.

As the volunteer sending organisation, Global Volunteers was hugely influential over the programme and held the greatest potential to bring about positive outcomes or detrimental consequences to the hosts in Rarotonga. When considered more broadly, volunteer tourism organisations could be perceived as determiners of positive or negative outcomes. This was supported by McGehee (2011, p. 86) who viewed these organisations as, 'Catalysts for positive sociocultural change or facilitators of neocolonialism and dependency'. Global Volunteers had the power to decide who could participate, to define the focus and to control the programmes standards. Raymond and Hall (2008) also highlighted the important position that sending organisations were in to effectively plan and manage the volunteer programmes.

The host organisations within the Global Volunteer programme in Rarotonga revealed that the hosts were not entirely powerless. The hosts in Rarotonga had the power to initiate the volunteers into their respective organisations, to control the level of engagement that they were willing to contribute towards the volunteers and to 
determine acceptable practice within their respective organisations. This finding contradicted Guttentag (2009) and Sin's (2010) view that the host communities within volunteer tourism lacked power with regard to their decision-making capabilities.

\subsubsection{What role has culture played within the Global Volunteer programme in Rarotonga?}

Within the Global Volunteer programme in Rarotonga, culture was naturally expressed throughout the interactions between the hosts and the volunteers. Culture was presented to the volunteers as an everyday practice rather than a performed artefact. This ability to gain a deeper insight into another culture was a key factor which distinguished those that participated on the Global Volunteer programme from mainstream tourists who visited Rarotonga. This perspective echoed the participants in Raymond and Hall's (2008, p. 537) study who suggested that they had, 'Gained a far greater and more 'real' understanding of the host country than they could have through conventional forms of tourism'. The natural expression of culture between the hosts and the volunteers in the Global Volunteer programme enabled forms of cultural collaboration. In this regard, the hosts and the volunteers worked together towards a shared outcome. This interaction brought about notions of cooperation and the growth of relationships. Through every day interactions between the hosts and volunteers, there were instances where both groups developed a more positive outlook and altered their attitudes, perspectives and knowledge of one another. This view was supported within the literature by Raymond and Hall (2008), Lough et al. (2011) and Conran (2011) who found that within volunteer tourism, the collaboration between volunteers and host communities provided opportunities for increased cross-cultural understanding.

However, rather than developing a deep understanding of culture, the volunteers only saw surface expressions of culture. The underlying epistemological elements of Cook Island culture were not easily obtained by the volunteers. This view was supported by 
Simpson (2004); Raymond and Hall (2008) and Sin (2010) who suggested that volunteer tourism did not always result in increased cross-cultural understanding. Within the case study, this was partially the consequence of the limited timeframe of the volunteer programme. In order for deeper cultural understanding, the volunteers needed to participate on the island for an extended period. As an outcome, the extent of crosscultural understanding could be viewed as an opportunity for the volunteers to gain good memories and experiences rather than to promote deep cultural understanding or to make a contribution towards lasting structural change. This impression of volunteer tourism was put forward by Conran (2011). Despite evidence of a cultural collaboration between the hosts and the volunteers, there was an indication of a cultural clash. This was due to the volunteer expectations not matching reality, volunteers making comparisons between the Cook Islands and their homes, outsider policies and language barriers.

The Global Volunteer programme in Rarotonga revealed that critical engagement and reflection of volunteers' experiences was essential for the volunteers to gain a genuine understanding of their surroundings. As the volunteer sending organisation, Global Volunteers was central to ensuring that the volunteers took a step back and reflected on the Cook Island context. Raymond and Hall (2008, p. 538) also highlighted the role that the sending organisation played in developing cross-cultural understanding through 'careful planning and management'. The Global Volunteer case study showed that it was imperative that the local Country Managers acted as cultural translators for the hosts and the volunteers. Furthermore, it was important that volunteers had the opportunity to critically engage with their thoughts and experiences.

\subsection{The verdict: Is volunteer tourism good?}

The aim of this thesis was to develop a greater understanding of the development implications of volunteer tourism in the Cook Islands. Through an analysis of 
development, power and culture, the study revealed that volunteer tourism is neither good nor bad. However, since there are many good outcomes which result from the practice, it would be naïve to dismiss the practice entirely.

Although the volunteers' assistance could not necessarily be regarded as a contribution towards development, the host organisations retained a sense of agency and ownership over the programme and valued the work that the volunteers carried out. Even though there were aspects of the programme which led to clashes in culture, the volunteer programme also gave opportunities for cultural collaboration where each group could gain a greater insight into a different way of life and where preconceived attitudes could be challenged. In terms of power, the Global Volunteer programme in Rarotonga revealed that although power was complex, it was held, to varying extents at various times by each of the groups involved.

By highlighting that volunteer tourism is neither good nor bad, this research has presented a balanced analysis of the practice. The research has shown that it is fundamentally important that every group involved in volunteer tourism takes responsibility to ensure that positive outcomes result from the practice. It is essential that the host organisations hold ownership over the programmes and actively work with volunteer tourism organisations to define the volunteers' assistance.

\subsection{The Cook Island context}

The Cook Island context of this research played an important role in formulating this argument that volunteer tourism is neither good nor bad. Chapter Three identified Rarotonga as a relatively prosperous island, with a well-established tourism industry. The Cook Islands were viewed as having a long history of engagement with the outside world. Each of these elements has encouraged a 'safe' environment for a volunteer tourism programme. Therefore, it would be worthwhile to question how Global 
Volunteers or other volunteer tourism organisations would function in a destination with higher levels of poverty, a less agreeable setting and less experience of the outside world.

\subsection{Suggestions for future research}

There are many areas within volunteer tourism which would benefit greatly from more research. This research has focused on one specific case study at one point in time. It would be useful to expand on this research by comparing multiple case studies at different points in time. Keeping in mind the focus of this study, it would be valuable to gain a deeper understanding into the development implications of volunteer tourism by comparing different agencies. For instance, it would be beneficial to compare commercialised volunteer tourism agencies with explicitly development-based agencies. Furthermore, it would be useful to expand the knowledge surrounding the impact of volunteer tourism on host communities.

\subsection{Final thoughts}

An analogy that arose among two of the contributors to this research involved a bucket of water. While a country manager observed that volunteers were helping to put a drop in the bucket, a volunteer suggested that their assistance was less than a drop in the bucket:

I always tell them [volunteers] that you might not see the difference but you are helping to put a little drop in a bucket and eventually the bucket is going to overflow and change is going to happen and people's lives will be improved (Manager 3, March 29 2012).

You're a volunteer, you're here, it's less than a drop in the bucket on the island so how can you affect a lot of change. That's not what you are here for (Volunteer 2, April 5, 2012). 
Despite these differing perspectives, it is important that what goes into the bucket is shaped and fostered by the local people that hold the bucket. Although each of the volunteers may only contribute one small drop of water into the bucket, it is essential that these drops of water are consistently falling inside the bucket and that those who place the drops in the bucket are reflective of their surroundings. In other words, the local people need to be actively involved in shaping the volunteer tourists' work in their communities. It is imperative that volunteer tourism seeks to bring about good outcomes for the local people and that all those involved continually engage and reflect upon the local context. 


\section{References}

Allen, J. (1997). Economies of power and space. In R. Lee and J. Wills (Eds.), Geographies of economies (pp. 59-70). London: Arnold.

Andereck, K., McGehee, N., Lee, S., \& Clemmons, D. (2011). Experience expectations of prospective volunteer tourists. Journal of Travel Research, 51(2), 130-141.

Archer, B., Cooper, C., \& Ruhanen, L. (2004). The positive and negative impact of tourism. In W.F. Theobald (Ed.) Global tourism (3 ${ }^{\text {rd }}$ ed.) (pp. 79-102) Amsterdam: Elsevier.

Asian Development Bank (2011). Asian Development Bank and Cook Islands. Retrieved from http://www.adb.org/sites/default/files/pub/2012/COO.pdf Retrieved 18 June 2012.

Bailey, A., \& Russell, K. (2010). Predictors of interpersonal growth in volunteer tourism: A latent curve approach. Leisure Sciences, 32(4), 352-368.

Bandura, A. (2001). Social cognitive theory: An agentic perspective. Annual Review of Psychology, 52(1), 1-26.

Barnes, T. (2000). Social construction. In R.J. Johnston, D. Gregory, G. Pratt, M. Watts (Eds.), The dictionary of human geography (4th ed.) (pp. 747-748). Oxford: Blackwell Publishers.

Benson, A., \& Henderson, S. (2011). A strategic analysis of volunteer tourism organisation. The Service Industries Journal, 31(3), 405-424.

Berno, T. (1999). When a guest is a guest: Cook Islander's view tourism. Annals of Tourism Research, 26(3), 656-675.

Bertram, G., \& Watters, R. (1985). The MIRAB economy in South Pacific microstates. Pacific Viewpoint, 26(3), 497-579.

Blackman, D., \& Benson, A. (2010). The role of the psychological contract in managing research volunteer tourism. Journal of Travel $\mathcal{E}$ Tourism Marketing, 27(3), 221-235. 
Britton, S. G. (1982). The political economy of tourism in the third world. Annals of Tourism Research, 9(3), 331-358.

Brockington, D., \& Sullivan, S., (2003). Qualitative research. In R. Scheyvens, and D. Story (Eds.), Development fieldwork: A practical guide (pp. 57-75). London: Sage Publications.

Brohman, J. (1996). New directions in tourism for the third world. Annals of Tourism Research, 23(1), 48-70.

Brown, S., \& Lehto, X. (2005). Travelling with a purpose: Understanding the motives and benefits of volunteer vacationers. Current Issues in Tourism, 8(6), 479-496.

Brown, S., \& Morrison, A. (2003). Expanding volunteer vacation participation: An exploratory study on the mini-mission concept. Tourism Recreation Research, 28(3), 73-82.

Callanan, M., \& Thomas S. (2005). Volunteer tourism: Deconstructing volunteer activities within a dynamic environment. In M. Novelli (Ed.), Niche tourism: Contemporary issues and trends (pp. 183-200). New York: Elsevier.

Campbell, L., \& Smith, C. (2006). What makes them pay? Values of volunteer tourists working for sea turtle conservation. Environmental Management, 38(1), 84-98.

Central Policy and Planning Office (2010). National millennium development goals report, 2009 [Office of the Prime Minister, Rarotonga]. Retrieved from http://www.stats.gov.ck/Statistics/MDG/MDG RPRT June 2010.pdf Retrieved 18 June 2012.

Central Policy and Planning Office (2011). The Cook Island Te Keveinga Nui national sustainable development plan 2011- 2015 [Office of the Prime Minister, Rarotonga]. Retrieved from http://www.pmoffice.gov.ck/images/opm/Files/NSDP201115.pdf Retrieved 18 June 2012.

Central Intelligence Agency (CIA) (2012). Cook Islands. Retrieved from https://www.cia.gov/library/publications/the-world-factbook/geos/cw.html Retrieved 28 November 2012. 
Chacko, E. (2004). Positionality and praxis: Fieldwork experiences in rural India. Singapore Journal of Tropical Geography, 25(1), 51-63.

Chambers, R. (1997). Whose reality counts? Putting the first last. London: Intermediate Technology Publications.

Clifton, J., \& Benson A. (2006). Planning for sustainable ecotourism: The case for research ecotourism in developing country destinations. Journal of Sustainable Tourism, 14(3), 238-54.

Cnaan, R. A., Handy, F., \& Wadsworth, M. (1996). Defining who is a volunteer: Conceptual and empirical considerations. Nonprofit and Voluntary Sector Quarterly, 25(3), 364-383.

Coghlan, A. (2007). Towards an integrated image-based typology of volunteer tourism organisations. Journal of Sustainable Tourism, 15(3), 267-287.

Coghlan, A., \& Fennell, D. (2009). Myth or substance: An examination of altruism as the basis of volunteer tourism. Annals of Leisure Research, 12(3-4), 377-402.

Coghlan, A., \& Gooch, M. (2011). Applying a transformative learning framework to volunteer tourism. Journal of Sustainable Tourism, 19(6), 713-728.

Connell, J. (2010). Pacific Islands in the global economy: Paradoxes of migration and culture. Singapore Journal of Tropical Geography, 31, 115-129.

Conran, M. (2011). They really love me! Intimacy in volunteer tourism. Annals of Tourism Research, 38(4), 1454-1473.

Cook Islands Statistics Office (2012a). Economic statistics. Retrieved from http://www.stats.gov.ck/Statistics/Economic/National\%20Account/gdp summar y.htm Retrieved 7 June 2012.

Cook Islands Statistics Office (2012b). Key statistics. Retrieved from http://www.stats.gov.ck/Statistics/CensusSurveys/censurvnav.htm Retrieved 7 June 2012.

Cook Islands Government (2012a). The Cook Islands. Retrieved from http://www.cookislands.gov.ck/cook-islands.php Retrieved 7 June 2012. 
Cook Islands Government (2012b). Voyage to statehood. Retrieved from http://www.cook-islands.gov.ck/history.php Retrieved 1 December 2012.

Coren, N., \& Gray, T. (2012). Commodification of volunteer tourism: A comparative study of volunteer tourists in Vietnam and in Thailand. International Journal of Tourism Research, 14, 222-234.

Cousins J., Evans J., \& Sadler J. (2009). Selling conservation? Scientific legitimacy and the commodification of conservation tourism. Ecology and Society, 14(1), 32-49.

Croall, J. (1995). Preserve or destroy: Tourism and the environment. London: Calouste Gulbenkian Foundation.

Crocombe, R. (1990). Voluntary service and development in the Cook Islands, Auckland: University of the South Pacific.

Crossley, E. (2012). Poor but happy: Volunteer tourists' encounters with poverty. Tourism Geographies: An International Journal of Tourism Space, Place and Environment, 14(2), 235-253.

Curry, G. (2003) Moving beyond postdevelopment: Facilitating indigenous alternatives for "development". Economic Geography, 79(4), 405-423.

Devereux, P. (2008). International volunteering for development and sustainability: Outdated paternalism or a radical response to globalisation? Development in Practice, 18(3), 357-370.

Department of Foreign Affairs and Trade (DFAT) (2012). Cook Islands country brief. Retrieved from http://www.dfat.gov.au/geo/cook islands/cook islands brief.html Retrieved 20 June 2012.

Edensor, T. (1998). Tourists at the Taj: Performance and meaning at a symbolic site. London: Routledge.

Escobar, A. (1995). Encountering development. New Jersey: Princeton University Press. Esteva, G. (1992). Development. In W. Sachs (Ed.), The development dictionary: A guide to knowledge as power (pp. 6-25). London: Zed Books. 
European Commission (2007). Cook Islands-European Commission EDF10 country strategy paper and national indicative programme for the period 2008-2013. Retrieved from http://ec.europa.eu/development/icenter/repository/scanned ck csp10 en.pdf Retrieved 30 November 2012.

Fee, L., \& Mdee, A. (2010). How does it make a difference? Towards 'accreditation' of the development impact of volunteer tourism. In A. Benson (Ed.), Volunteer tourism: Theoretical frameworks and practical applications (pp. 223-239). London: Routledge.

Foucault, M. (1978). The history of sexuality: Volume 1: An introduction. New York: Vintage Books.

Geering, J. (2007). Case study research: Principles and practices. Cambridge: Cambridge University Press.

Georgeou, N., \& Engel, S. (2011). The impact of neoliberalism and new managerialism on development volunteering: An Australian case study. Australian Journal of Political Science, 46(2), 297-311.

Global Volunteers (2012). Global Volunteers. Retrieved from http://www.globalvolunteers.org/ Retrieved 17 July 2012.

Gray, D. (2004). Doing research in the real world. London: Sage Publications.

Gray, N., \& Campbell, L. (2007). A decommodified experience? Exploring aesthetic, economic and ethical values for volunteer ecotourism in Costa Rica. Journal of Sustainable Tourism, 15(5), 463-482.

Grimm, K., \& Needham, M. (2012). Moving the "I" in motivation: Attributes and perceptions of conservation volunteer tourists. Journal of Travel Research, 51(4), 488-501.

Gursoy, D., Chi, C., \& Dyer, P. (2010). Locals' attitudes toward mass and alternative tourism: The case of Sunshine Coast, Australia. Journal of Travel Research, 49(3), 381-394.

Guttentag, D. (2009). The possible negative impacts of volunteer tourism. International Journal of Tourism Research, 11, 537-551. 
Guttentag, D. (2012). Volunteer tourism: As good as it seems? In T. Singh (Ed.), Critical Debates in Tourism (pp. 152-159). Bristol: Channel View Publications.

Halapua, S. (2000). Talanoa process: The case of Fiji. Honolulu, Hawai'i: East West Centre. Hau' ofa, E. (1993). Our sea of islands. In V. Naidu, E. Waddell, E. Hau'ofa (Eds.) A new Oceania: Rediscovering our sea of islands (pp. 2-19). Suva, Fiji: University of the South Pacific.

Higgins-Desboilles, F. (2003). Reconciliation tourism: Tourism healing divided societies! Tourism Recreation Research, 28(3), 35-44.

Holmes, K., Smith, K., Lockstone-Binney, L., \& Baum, T. (2010). Developing the dimensions of tourism volunteering. Leisure Sciences, 32, 255-269.

Hutnyk, J. (1996). The rumour of Calcutta: Tourism, charity and the poverty of representation. London: Zed Books.

Illich, I. (1968, April). To hell with good intentions. Address to the Conference on InterAmerican Student Projects (CIASP) in Cuernavaca, Mexico. Retrieved from http://www.volunteerbolivia.org/illich reading.pdf

Ingram, J. (2010). Volunteer tourism: How do we know it is 'making a difference'? In A. Benson (Ed.), Volunteer Tourism: Theoretical frameworks and practical applications (pp. 211-222). New York: Routledge.

IVPA (2012). Our principles and practices. Retrieved from http://www.volunteerinternational.org/principles.html Retrieved 10 October 2012.

Johnston, R.J. (2000) Power. In R.J. Johnston, D. Gregory, G. Pratt and M. Watts (Eds.), The dictionary of human geography (4 ${ }^{\text {th }}$ ed.) (pp. 629-631). Oxford: Blackwell Publishers.

Jonassen, J. (2003) Tu tangata: Personality and culture. In R. Crocombe, M. Tua'inekore Crocombe (Eds.), Akono'anga Maori: Cook Islands culture (pp. 127-143). Suva, Fiji: Institute of Pacific Studies and Cook Islands.

Kiely, R. (1999). The last refuge of the noble savage? A critical assessment of postdevelopment theory. The European Journal of Development Research, 11(1), 30-55. 
Koloto, A. (2003). The needs of pacific peoples when they are victims of crime. Wellington, New Zealand: Ministry of Justice.

Lepp, A. (2007). Residents' attitudes towards tourism in Bigodi Village, Uganda. Tourism Management, 28, 876-885.

Levinson, J., \& Milne, S. (2004). From brochures to the internet: Tourism, marketing and development in the Cook Islands. The Journal of Pacific Studies, 26(1-2), 175-198.

Lewis, D. (2006). Globalization and international service: A development perspective. Voluntary Action, 7(2), 13-26.

Liu, Z. (2003). Sustainable tourism development: A critique. Journal of Sustainable Tourism, 11(6), 459-475.

Lo, A., \& Lee, C (2011). Motivations and perceived value of volunteer tourists from Hong Kong. Tourism Management, 32, 326-334.

Lough, B., McBride, A., Sherraden, M., \& O'Hara, K. (2011). Capacity building contributions of short-term international volunteers. Journal of Community Practice, 19(2), 120-137.

Lyons, K. (2003). Ambiguities in volunteer tourism: A case study of Australians participating in a J-1 visitor exchange programme. Tourism Recreation Research, $28(3), 5-13$.

Lyons, K., \& Wearing, S. (2008). Volunteer tourism as alternative tourism: Journeys beyond otherness. In K. Lyons, S. Wearing (Eds.), Journeys of discovery in volunteer tourism (pp. 3-11). Wallingford, UK: CABI International.

Lyons, K., Hanley, J., \& Wearing, S. (2012). Gap year volunteer tourism: Myths of global citizenship? Annals of Tourism Research, 39(1), 361-378.

MacCannell, D. (1976). The tourist: A new theory of the leisure class. London: Macmillan.

Macnaught, T. (1982). Mass tourism and the dilemmas of modernization in Pacific Island communities. Annals of Tourism Research, 9, 359-381.

Marsters, E., Lewis, N., \& Friesen, W. (2006). Pacific flows: The fluidity of remittances in the Cook Islands. Asia Pacific Viewpoint, 47(1), 31-44. 
Mayoux, L. (2006). Quantitative, qualitative or participatory? Which method, for what and when? In V. Desai and R. Potter (Eds.), Doing development research (pp. 115130). London: Sage Publications.

McGehee, N.G., \& Santos, C. (2005). Social change, discourse and volunteer tourism. Annals of Tourism Research, 32(3), 760-779.

McGehee N., \& Andereck K. (2008). 'Pettin' the critters': Exploring the complex relationship between volunteers and the voluntoured in McDowell County, West Virginia, USA, and Tijuana, Mexico. In K. Lyon, S. Wearing (Eds.), Journeys of discovery in volunteer tourism (pp. 12-24). Cambridge, MA: CABI Publishing.

McGehee, N. \& Andereck, K. (2009). Volunteer tourism and the "voluntoured": The case of Tijuana, Mexico. Journal of Sustainable Tourism, 17(1), 39-51.

McGehee, N. (2012). Oppression emancipation and volunteer tourism. Annals of Tourism Research, 39(1), 84-107.

McIntosh, A., \& Zahra, A. (2007). A cultural encounter through volunteer tourism: Towards the ideals of sustainable tourism? Journal of Sustainable Tourism, 15(5), 541-556.

McGregor, J. (2006). Diaries and case studies. In V. Desai and R. Potter (Eds.), Doing development research (pp. 144-153). London: Sage Publications.

McMillon, B., Cutchins, D., \& Geissinger, A. (2006). Volunteer vacations: Short-term adventures that will benefit you and others (9th ed.). Chicago: Chicago Review Press, Inc.

Merriam, S.B., Johnson-Bailey, J., Lee, M., Ntseane, G. \& Muhamad, M. (2001). Power and positionality: negotiating insider/outsider status within and across cultures. International Journal of Lifelong Education, 20(5), 405-16.

Ministry of Foreign Affairs and Trade (MFAT) (2012a). Cook Islands. Retrieved from http://www.aid.govt.nz/where-we-work/pacific/cook-islands Retrieved 13 June 2012. 
Ministry of Foreign Affairs and Trade (MFAT) (2012b). Cook Islands. Retrieved from http://www.mfat.govt.nz/Countries/Pacific/Cook-Islands.php Retrieved 1 December 2012.

Mila Schaaf, K. (2009). What do we mean by Pacific knowledge and Pacific research methodologies? Negotiated spaces between Western and Pacific knowledge traditions. In R. Gounder (Ed.), Pacific development perspectives: Meeting our diverse goals (pp. 19-40). Palmerston North, New Zealand: Massey University.

Mustonen, P. (2005). Volunteer tourism: Postmodern pilgrimage. Journal of Tourism and Cultural Change, 3(3), 160-177.

Nederveen Pieterse, J. (2000). My paradigm or yours? Alternative development, postdevelopment, reflexive development. Development and Change, 29(2), 343-373.

Novelli, M. (2005). Niche tourism: Contemporary issues, trends and cases. Oxford: Elsevier Butterworth-Heinemann.

OECD (2008). Joint Evaluation of the Paris Declaration Phase 2 Cook Islands Country Evaluation. Retrieved from http://www.oecd.org/dataoecd/61/32/47083075.pdf Retrieved 4 October 2011.

Palacios, C. (2010). Volunteer tourism, development and education in a postcolonial world: Conceiving global connections beyond aid. Journal of Sustainable Tourism, 18(7), 861-878.

Pearce, P., \& Coghlan, A. (2008). The dynamics behind volunteer tourism. In K. Lyons \& S. Wearing (Eds.), Journeys of discovery in volunteer tourism (pp. 130-146). Wallingford, UK: CABI International.

Rattan, J., Eagles, P., \& Mair, H. (2012). Volunteer tourism: Its role in creating conservation awareness. Journal of Ecotourism, 11(1), 1-15.

Raymond, E. (2008). 'Make a difference!': The role of sending organizations in volunteer tourism. In K. Lyon, S. Wearing S (Eds.), Journeys of discovery in volunteer tourism (pp. 49-60). Cambridge, MA: CABI Publishing.

Raymond, E., \& Hall, C. (2008). The development of cross-cultural (mis)understanding through volunteer tourism. Journal of Sustainable Tourism, 16(5), 530-543. 
Reid, J. (1987). The learning style preferences of ESL students. TESOL Quarterly, 21(1), $87-111$.

Robson, C (2011). Real world research (3 $3^{\text {rd }}$ ed.). Chichester: John Wiley \& Sons.

Said, E. (1978). Orientalism. New York: Vintage Books.

Scheyvens R. (2002a). Tourism for development: Empowering communities. Harlow: Pearson Education.

Scheyvens, R. (2002b). Backpacker tourism and third world development. Annals of Tourism Research, 29(1), 144-164.

Scheyvens, R., Nowak, B., \& Scheyvens, H. (2003). Ethical issues. In R. Scheyvens, and D. Story (Eds.), Development fieldwork: A practical guide (pp. 139-166). London: Sage Publications.

Scheyvens, R., \& Momsen, J. (2008). Tourism and poverty reduction: Issues for small island states. Tourism Geographies: An International Journal of Tourism Space, Place and Environment, 10(1), 22-41.

Sharpley, R., \& Telfer, D. (2002). Introduction. In R. Sharpley, D. Telfer (Eds.), Tourism and development: Concepts and issues (pp. 1-7) Clevedon: Channel View Publications.

Sharpley, R. (2002). Tourism: A vehicle for development? In R. Sharpley, D. Telfer (Eds.), Tourism and development: Concepts and issues (pp. 11-35) Clevedon: Channel View Publications.

Sherraden, M., Lough, B., \& Moore McBride, A. (2008). Effects of international volunteering and service: Individual and institutional predictors. Voluntas, 19, 395-421.

Sidaway, J. (2008). Post-development. In V. Desai and R. Potter (Eds.), The Companion to Development Studies (2nd ed.) (pp. 16-19). London: Hodder Education.

Simpson, K. (2004). 'Doing development': The gap year volunteer-tourists and a popular practice of development. Journal of International Development, 16, 681-692.

Sin, H. (2009). Volunteer tourism: "Involve me and I will learn?" Annals of Tourism Research, 36(3), 480-501. 
Sin, H. (2010). Who are we responsible to? Locals' tales of volunteer tourism. Geoforum, 41, 983-992.

Singh, S., \& Singh, T. V. (2001). Pilgrimages to the Himalayas new horizons in tourism: Strange experiences and stranger practices. London: CABI International.

Singh, T. (2012). Introduction. In. T. Singh (Ed.) Critical debates in tourism (pp. 1-25). Bristol: Channel View Publications.

Smith, L.T. (1999). Decolonizing methodologies: Research and indigenous peoples. Dunedin: University of Otago Press.

Smith, M., \& Laurie, N. (2011). International volunteering and development: Global citizenship and neoliberal professionalisation today. Transactions of the Institute of British Geographers, 36, 545-559.

Stoddart, H., \& Rogerson, C. (2004). Volunteer tourism: The case of Habitat for Humanity South Africa. GeoJournal, 60(3), 311-318.

Tamasese, K., Parsons, L., Sullivan, G., \& Waldegrave, C. (2010). A qualitative study into Pacific perspectives of cultural obligations and volunteering. Family Centre Social Policy Research Unit: Wellington, New Zealand. Retrieved from http://www.familycentre.org.nz/Publications/PDF's/Cultural\%20Obligations $\% 20$ and\%20Volunteering\%20Main.pdf Retrieved 19 June 2012.

Tourism Research and Marketing (2008). Volunteer tourism: A global analysis. Barcelona: Atlas.

Tomazos, K., \& Butler, R. (2012). Volunteer tourists in the field: A question of balance? Tourism Management, 33, 177-187.

Tomazos, K., \& Butler, R. W. (2009). Volunteer tourism: the new ecotourism? An International Journal of Tourism and Hospitality Research, 1(20), 196-212.

Tomazos, K., \& Butler, R. (2010). The volunteer tourist as 'hero'. Current Issues in Tourism, 13(4), 363-380.

Tomazos, K., \& Cooper, W. (2012). Volunteer tourism: At the crossroads of commercialisation and service? Current Issues in Tourism, 15(5), 405-423. 
Turner, L., \& Ash, J. (1975). The golden hordes: International tourism and pleasure periphery. London: Constable.

United Nations Development Programme (UNDP) (2008). Country programme action plan (CPAP), 2008-2012. Retrieved from http://www.undp.org.ws/Portals/12/About\%20Us/Who\%20We\%20Are/CPAPs/C PAP CKL signed.pdf Retrieved 28 November 2012.

Uriely, N., A. Reichel, A., \& Ron, A. (2003). Volunteering in tourism: Additional thinking. Tourism Recreation Research, 28(3) 57-62.

Valentine, J. (1997). Tell me about...: Using interviews as a research methodology. In R. Flowerdew and D. Martin (Eds.) Methods in human geography (pp. 110-26). Harlow: Longman.

Vodopivec, B., \& Jaffe, R. (2011). Save the world in a week: Volunteer tourism, development and difference. European Journal of Development Research, 23, 111128.

Wearing, S. (2001). Volunteer tourism: Experiences that make a difference. Wallingford, UK: CABI International.

Wearing, S. (2003). Special issue on volunteer tourism. Tourism Recreation Research, 28(3), 3-4.

Wearing, S., \& Neil, J. (1999). Ecotourism: Impacts, potentials and possibilities. Oxford, UK: Butterworth Heinemann.

Wichman, V. (2003) Puapinga: The economics of culture. In R. Crocombe, M. Tua'inekore Crocombe (Eds.), Akono'anga Maori: Cook Islands culture (pp. 143151). Suva, Fiji: Institute of Pacific Studies and Cook Islands.

Willis, K. (2006). Interviewing. In V. Desai and R. Potter (Eds.), Doing development research (pp. 144-153). London: Sage Publications.

Wilson, S. (2008). Research is ceremony. Halifax: Fernwood Publishing.

Woosnam, K., \& Lee, Y. (2011). Applying social distance to voluntourism research. Annals of Tourism Research, 38(1), 309-313. 
Yin, R. (1994). Case study research: Design and methods (2 ${ }^{\text {nd }}$ ed.) California: Sage Publications.

Young, T. (2008). Mediating volunteer tourism alternatives: Guidebook representations of travel experiences in Aboriginal Australia. In K. Lyon, S. Wearing (Eds.), Journeys of discovery in volunteer tourism (pp. 195-209) Cambridge, MA: CABI Publishing.

Zahra, A. (2006). The unexpected road to spirituality via volunteer tourism. Tourism: An International Interdisciplinary Journal, 54(2), 173-185. 


\section{Appendix One: List of research contributors}

Table 4. List of research contributors

\begin{tabular}{|c|c|c|}
\hline Type of contributor & Code name & Date interviewed \\
\hline \multirow{5}{*}{ Volunteer } & Volunteer 1 & 3 April 2012 \\
\hline & Volunteer 2 & 5 April 2012 \\
\hline & Volunteer 3 & 28 March 2012 \\
\hline & Volunteer 4 & 5 April 2012 \\
\hline & Volunteer 5 & 11 April 2012 \\
\hline \multirow{14}{*}{ Host } & Host 1 & 3 April 2012 \\
\hline & Host 2 & 2 April 2012 \\
\hline & Host 3 & 1 May 2012 \\
\hline & Host 4 & 22 March 2012 \\
\hline & Host 5 & 23 March 2012 \\
\hline & Host 6 & 26 March 2012 \\
\hline & Host 7 & 26 March 2012 \\
\hline & Host 8 & 26 March 2012 \\
\hline & Host 9 & 4 April 2012 \\
\hline & Host 10 & 29 March 2012 \\
\hline & Host 11 & 26 April 2012 \\
\hline & Host 12 & 30 March 2012 \\
\hline & Host 13 & 2 April 2012 \\
\hline & Host 14 & 24 April 2012 \\
\hline \multirow{3}{*}{ Cook Islands Country Manager } & Manager 1 & 15 April 2012 \\
\hline & Manager 2 & 29 March 2012 \\
\hline & Manager 3 & 29 March 2012 \\
\hline
\end{tabular}




\title{
Appendix Two: Participant information sheet
}

\author{
VICTORIA UNIVERSITY OF WELLINGTON \\ PARTICIPANT INFORMATION SHEET
}

\begin{abstract}
Researcher: Kylie Enoka: School of Geography, Environment and Earth Science, Victoria University of Wellington
\end{abstract}

I am a Masters student in Development Studies at Victoria University of Wellington. As part of this degree I am undertaking a research project leading to a thesis. The project I am undertaking examines Volunteer tourism in Rarotonga, specifically focusing on the impact that Global Volunteers has on the communities that they are working with in Rarotonga, Cook Islands. Ethics approval for this study has been given by the Victoria University of Wellington Human Ethics Committee.

I am inviting adults (aged 18+) who are both directly and indirectly involved with Global Volunteers to be involved in this study. If you are able to be involved, you will be asked about your experiences and perspectives of Global Volunteers in Rarotonga and how these experiences and perspectives have both positively and negatively impacted you and the community. I would like to observe and participate in the Global Volunteers programme which takes place between [dates removed to retain confidentiality].

In some instances, interviews will be requested. It is envisaged that interviews will take up to an hour of your time and will be undertaken at a time which is convenient for both you and me. If you would like to add or alter any information which you have provided, you are welcome to arrange a time to do so.

Should you feel the need to withdraw from the project, you may do so without question at any time before the data is analysed. If you would like to withdraw, please let me know by email or phone (see below) by [date removed to retain confidentiality].

Responses collected from interviews and observation of the Global Volunteers programme form the basis of my research project and will be put into a written report. In most cases, this will be on an anonymous basis and it will not be possible for you to be identified personally. When information is non- anonymous and it could be possible for you to be personally identified in the research, I will discuss this and seek permission from you during the interview.

All material collected will be kept confidential. No other person besides me and my supervisor, Professor John Overton, will see the interview transcripts or participant observation journal. Interview transcripts and the participant observation journal will be destroyed one year after the end of the project. The thesis will be submitted for marking to the School of Geography, Environment and Earth Science and will be deposited in the University Library. It is intended that one or more articles will be submitted for publication in scholarly journals.

If you have any questions or would like to receive further information about the project, please contact me at kylie_enoka@hotmail.com, or my supervisor, Professor John Overton, at the School of Geography, Environment and Earth Science at Victoria University, john.overton@ vuw.ac.nz.

Kylie Enoka

Signed: 


\title{
Appendix Three: Anonymous consent form to participate in research
}

\author{
VICTORIA UNIVERSITY OF WELLINGTON \\ Consent to Participate in Research \\ [For Anonymous Participants]
}

Title of Project: The Social Impact of Global Volunteers on the Targeted Communities in Rarotonga, Cook Islands.

I have been given and have understood an explanation of this research project. I have had an opportunity to ask questions and have them answered to my satisfaction. I understand that I may withdraw myself (or any information I have provided) from this project (before data collection and analysis is complete) without having to give reasons or without penalty of any sort. If I choose to withdraw from this project, I understand that it needs to be before [date removed to retain confidentiality] by email, kylie_enoka@hotmail.com.

I understand that any information I provide will be kept confidential to the researcher and the supervisor. The published results will not use my name, and no opinions will be attributed to me in any way that will identify me. I understand that the tape recording of interviews, interview notes and the observation journal will be destroyed one year from the completion of the project.

$\square$ I consent to information or opinions which I have given being attributed to me in any reports on this research

$\square$ I would like to receive a summary of this research when it is completed.

$\square$ I agree to take part in this research

Signed:

Name of participant (please print clearly):

Date: 


\title{
Appendix Four: Non-anonymous consent form to participate in research
}

\author{
VICTORIA UNIVERSITY OF WELLINGTON \\ Consent to Participate in Research \\ [For Non- Anonymous Participants]
}

Title of Project: The Social Impact of Global Volunteers on the Targeted Communities in Rarotonga, Cook Islands.

I have been given and have understood an explanation of this research project. I have had an opportunity to ask questions and have them answered to my satisfaction. I understand that I may withdraw myself (or any information I have provided) from this project (before data collection and analysis is complete) without having to give reasons or without penalty of any sort. If I choose to withdraw from this project, I understand that it needs to be before [date removed to retain confidentiality] by email, kylie_enoka@hotmail.com.

I understand that it will be possible for me to be personally identified in the research. I understand that the tape recording of interviews, interview notes and the observation journal will be destroyed one year from the completion of the project.

$\square$ I consent to information or opinions which I have given being attributed to me in any reports on this research

$\square$ I would like to receive a summary of this research when it is completed.

$\square$ I agree to take part in this research

Signed:

Name of Participant (please print clearly):

Date: 


\section{Appendix Five: Potential questions for semi- structured interviews}

\section{Questions for Volunteers}

1. Tell me about yourself (e.g. background, hometown, employment, family, travel, interest in social justice issues)

2. What did you hope to achieve on your trip? Holiday, volunteering?

3. What did you think of Rarotonga before you arrived? What did you think you would see?

4. What do you think are some good development outcomes for Rarotonga?

5. What do you want to see in Rarotonga/ Cook Islands?

6. What do you think are the main development issues/ problems in Rarotonga?

7. Have you had any other experiences of volunteering or visiting a developing country?

8. What did you learn overall? What did you learn from the locals?

1. What surprised you?

2. What are some positive experiences that you have had through working with the locals?

3. What are some negative experiences that you have had with the locals?

4. Do you think the training that you received was adequate for the work that you were participating in?

5. Do you think your skills and experience was utilised during your time in Rarotonga?

6. Did you feel like a volunteer or a tourist during your time in Rarotonga? How important was 'tourist time' to your trip?

7. What kind of cultural issues have you experienced through your involvement with Global Volunteers?

8. How important has the exchange of ideas and knowledge been between you and the people that you have been working with?

9. Do you think that the organisations could work efficiently without regular help from volunteers?

10. Do you feel like Global Volunteers are working on the most needed projects?

11. Would you recommend Global Volunteers to other people? Why/ why not?

12. How would you improve/ change the operation of Global Volunteers to make their work more positive for Rarotonga?

13. How satisfied were you with your Global Volunteers experience in Rarotonga?

\section{Questions for Country Managers}

1. Personal background (e.g. length of time working with GV, work experience, Cook Island aspirations, development aims)

2. Background of GV (e.g. focus, length of projects, community participation)

3. What do you think are the main development issues/ problems in Rarotonga?

4. What do you think are some good development outcomes for Rarotonga?

5. How mutual is your relationship with community partners? Who makes the final decisions about where volunteers should be placed?

6. Do you think Global Volunteers are working on the most needed projects? Why/why not?

7. Do you think the Global Volunteers training is adequate for the work that they participant in? 
8. Long term goals: Do you see a need for the volunteers in the long term? Do you have the goal of making the volunteers jobs obsolete?

9. What kind of vetting process is undertaken to ensure the safety of the host community?

10. What are the communities' feelings or reactions to volunteers?

11. How would you improve/ change the operation of Global Volunteers to make their work more positive for Rarotonga?

12. How has this group of volunteers compared to previous groups?

13. How have you tried to involve the volunteers in the community?

\section{Questions for Hosts}

1. Who makes the final decisions about where volunteers should be placed?

2. Do you feel like Global Volunteers are working on the most needed projects?

3. What do the volunteers bring to your organisation? Good and bad

4. How important are Global Volunteers to your organisation? Could you function without Global Volunteers?

5. Do you see Global Volunteers as tourists or volunteers?

6. How have this group of volunteers compared to previous groups?

7. What do you think about reciprocity between volunteers and the people that they are working with?

8. Have you had any experiences where Global Volunteers have negatively impacted the people that they have been working with?

9. Would you recommend Global Volunteers to other organisations? Why/ why not?

10. Are you happy with the type of volunteers that Global Volunteers provides? e.g. level of skill and experience of working in a particular area

11. Do you think the Global Volunteers training is adequate for the work that they participant in?

12. How effective do you think Global Volunteers has been in you organisation?

13. How would you improve/ change the operation of Global Volunteers to make their work more positive for Rarotonga? 